\title{
Modeling of Turbulent Separated Flows for Aerodynamic Applications
}

Joseph G. Marvin

August 1983

\section{LBRARY GOPY}




\section{Modeling of Turbulent Separated Flows for Aerodynamic Applications}

Joseph G. Marvin, Ames Research Center, Moffett Field, California



National Aeronautics and

Space Administration

Ames Research Center

Moffett Field. California 94035 
MODELING OF TURBULENT SEPARATED FLOWS FOR AERODYNAMIC APPLICATIONS

Joseph G. Marvin

Chief, Experimental Fluid Dynamics Branch

NASA Ames Research Center

Moffett Field, California 


\begin{abstract}
A review is given of the advances made over the past decade in modeling steady, high speed, compressible separated flows through numerical simulations resulting from solutions of the mass-averaged Navier-Stokes equations. Emphasis is placed on bench-mark flows that represent simplified (but realistic) aerodynamic phenomena. These include impinging shock waves, compression corners, glancing shock waves, trailing edge regions, and supersonic high angle-of-attack flows. A critical assessment of modeling capabilities is provided by comparing the numerical simulations with experiment. The importance of combining experiment, numerical algorithm, grid, and turbulence model to effectively develop this potentially powerful simulation technique is stressed.
\end{abstract}




\section{INTRODUCTION}

Although the separation that occurs in many aerodynamic flows can have a profound influence on vehicle performance, it remains one of the least understood and most difficult problems in fluid dynamics. Over the past decade, two primary factors have operated to intensify interest in understanding turbulent separation: the imposition on the vehicle designer of higher performance standards, and an increased possibility of predicting separation by applying recent advances in computational fluid dynamics.

A potentially powerful approach to predicting turbulent separated flows is to solve directly the Reynolds-averaged Navier-Stokes equations (Chapman 1979). For practical reasons, such an approach is favored over direct simulation of the time-dependent, unaveraged Navier-Stokes equations because the three-dimensional, widely varying scales of turbulence present impossible requirements for even the largest and fastest computers (Chapman 1981). A significant amount of research has been under way at Ames Research Center to develop the technology required to solve separated flows of practical interest within the framework of the Reynolds-averaged Navier-Stokes equations. An obvious advantage of such an approach is that the entire viscous and inviscid portions of the flow are captured simultaneously, and the potential exits for focusing directly on turbulence modeling, which is an important pacing item for the successful development of computational fluid dynamics. A disadvantage is the long computing time and large storage limitations of current computers, which has hampered attempts to focus directly on 
turbulence modeling without considering numerical resolution and accuracy. As it now stands, the competing elements of turbulence modeling, numerical resolution, and accuracy must all be considered in any evaluation of our ability to compute flows with separation (Marvin 1982). This will be particularly true for three-dimensional flows, which are the interesting ones from the viewpoint of applications.

The purpose of this paper is to review the advances made over the past decade in modeling separation in practical aerodynamic flows. As the paper develops, the problems remaining will become obvious, as will the need for future study. Nevertheless, it will also become apparent that great strides have been made and that the potential of numerical modeling has not diminished. In order to keep the scope of the paper within reasonable proportions, attention will be directed to steady, high-speed, compressible flows of particular interest to the author and his colleagues. Some of the practical situations of current interest are shown in the photographs of figure 1. Figure la shows a shadowgraph of the ascent configuration of the Space Shuttle and the multiple impinging shock waves that exist. Figure $1 \mathrm{~b}$ shows an oil-flow pattern of the region on a lifting surface where separation occurs when a control surface is deflected. Figure 1c shows the transonic flow over an airfoil where a strong shock wave develops. And figure 1d shows the Space Shuttle orbiter at high angle of attack and at a supersonic speed where separation dominates the leeside flow. Such problems obviously involve many complications and the approach to their solution has been attempted in simplified stages, which this author has referred to as a building-block approach (Marvin 1980). 
The paper begins with a section that develops the governing equations, presents a short discussion of the technique developed to solve these equations, and introduces the various turbulence models under development. Subsequently, examples of solutions for some buildingblock flows are presented and critically assessed by comparing the results of computations and experiments.

FLOW MODELING

Modeling of turbulent separated flows is a combination of numerical modeling of the discretized form of the governing equations and the requirement for providing an adequate model of the turbulent correlations in the governing equations.

\section{Governing Equations}

The time-dependent Navier-Stokes equations, supplemented by mass conservation and suitable gas-law relationships, describe the turbulent motion of a continuum fluid. Solutions to the equations for turbulent flows of practical interest are virtually impossible using today's computers because turbulence is three-dimensional and has an enormous range of length and time scales. The difficulty can be circumvented by rewriting the equations for another set of variables, obtained by suitable averaging. For compressible flows, this has been accomplished by introducing mass-weighted variables, decomposing them into their mean and fluctuating components, and averaging over a time that is long relative to the largest turbulent time-scale (see Rubesin 1973). 
In the process, however, physical information on the turbulent motion itself is 1ost. Furthermore, the formalism results in a new set of equations that has more unknowns, and an equation-closure problem arises. Usually, this is referred to as the turbulence-modeling problem. Even introducing supplemental equations, derived by obtaining moments of the original equations, does not alleviate the problem, but does help to provide a means to introduce more information on the turbulence itself. Necessarily then, turbulence modeling becomes an integral, important part of our overall modeling process. A general description of various turbulence-modeling approaches used for applications in aerodynamic flows was presented by Marvin (1982).

Solutions to most of the complex aerodynamic flows discussed herein use eddy-viscosity turbulence models. The governing equations in massaverage variables and supplemental equations used in some of the eddyviscosity models are written for plane flow in vector form as follows:

$$
\frac{\partial U}{\partial t}+\frac{\partial F}{\partial x}+\frac{\partial G}{\partial y}=H
$$

$$
\mathrm{U}=\left[\begin{array}{c}
\rho \\
\rho \mathrm{u} \\
\rho \mathrm{v} \\
\rho \mathrm{e} \\
\rho \mathrm{k} \\
\rho \mathrm{s}
\end{array}\right] \mathrm{F}=\left[\begin{array}{c}
\rho \mathrm{u} \\
\rho \mathrm{u}^{2}+\sigma_{\mathrm{xx}} \\
\rho \mathrm{uv}-\tau_{\mathrm{xy}} \\
\mathrm{u}\left(\rho \mathrm{e}+\sigma_{\mathrm{xx}}\right)-\mathrm{v} \tau_{\mathrm{xy}}+\mathrm{q}_{\mathrm{Tx}} \\
\rho \mathrm{uk}+\mathrm{q}_{\mathrm{ky}} \\
\rho \mathrm{us}+\mathrm{q}_{\mathrm{sx}}
\end{array}\right]
$$




$$
G=\left[\begin{array}{c}
\rho v \\
\rho u v-\tau_{x y} \\
\left.\rho v^{2}+\sigma_{y x}+\sigma_{y y}\right)-u_{x y}-q_{T y} \\
\rho v k+q_{k y} \\
\rho v s+q_{s y}
\end{array}\right] \quad H=\left[\begin{array}{c}
0 \\
0 \\
0 \\
0 \\
H_{k} \\
H_{s}
\end{array}\right]
$$

Contd.

The last two equations are the supplemental equations providing the velocity $(k)^{1 / 2}$ and length scale $s$ required in higher-order eddyviscosity models. In the column vectors, $\mathrm{q}_{\mathrm{Tx}}$ and $\mathrm{q}_{\mathrm{Ty}}$ are the laminarplus-turbulent heat-flux vectors; $\sigma_{x x}, \sigma_{y y}$ are the laminar-plusturbulent normal stresses; $\tau_{x y}$ is the laminar-plus-turbulent shear stress; and $\mathrm{q}_{\mathrm{ky}}, \mathrm{q}_{\mathrm{sx}}$, and $\mathrm{q}_{\mathrm{sy}}$ are flux vectors associated with the turbulence field variables.

The stress terms and flux vectors are

$$
\begin{aligned}
& \sigma_{\mathrm{xx}}=\mathrm{p}+\frac{2}{3} \rho \mathrm{k}-\tau_{\mathrm{xx}}, \quad \tau_{\mathrm{xy}}=\mu_{\mathrm{T}}\left(\frac{\partial \mathrm{u}}{\partial \mathrm{y}}+\frac{\partial \mathrm{v}}{\partial \mathrm{x}}\right), \\
& \tau_{\mathrm{xx}}=\frac{2}{3} \mu_{\mathrm{T}}\left(2 \frac{\partial \mathrm{u}}{\partial \mathrm{x}}-\frac{\partial \mathrm{v}}{\partial \mathrm{y}}\right), \quad \mu_{\mathrm{T}}=(\mu+\rho \varepsilon), \\
& \mathrm{q}_{\mathrm{Tx}}=\mathrm{k}_{\mathrm{T}} \frac{\partial \mathrm{T}}{\partial \mathrm{x}}, \quad \mathrm{q}_{\mathrm{kx}}=-\mu_{\mathrm{k}} \frac{\partial \mathrm{k}}{\partial \mathrm{x}}, \quad \mathrm{q}_{\mathrm{sx}}=-\mu_{\mathrm{x}} \frac{\partial \mathrm{s}}{\partial \mathrm{x}}
\end{aligned}
$$

where $\mathrm{p}$ is the hydrostatic pressure; $2 / 3 \mathrm{\rho k}$ is the pressure associated with the turbulence; $\mathrm{k}_{\mathrm{T}}$ is the thermal conductivity, including the turbulent diffusivity; and $\rho \varepsilon$ is the turbulent eddy viscosity. The functional forms of the source functions $H$ depend on the choice of the turbulence model. 
Solution Methods and Turbulence Models

The methods available for solving equation (1), along with the various turbulence models, are introduced in historical order so that the unfamiliar reader will be able to see what the technological deve1opments have been and how they arrived at their present state.

Development of methods for solving the mass-weighted form of the Navier-Stokes equations began after MacCormack (1971) used an explicit time-marching scheme to solve the laminar form of the equations. In this second-order-accurate method the equations are discretized and advanced in time such that

$$
\mathrm{U}^{\mathrm{n}+1}=\mathrm{L}(\Delta \mathrm{t}) \mathrm{U}^{\mathrm{n}} \mathrm{i}, \mathrm{j}
$$

The $L(\Delta t)$ term is replaced by a sequence of time-split, one-dimensional operators, for example,

$$
\mathrm{L}(\Delta \mathrm{t})=\mathrm{L}_{\mathrm{x}}\left(\frac{\Delta \mathrm{t}}{2}\right) \mathrm{L}_{\mathrm{y}}(\Delta \mathrm{t}) \mathrm{L}_{\mathrm{x}}\left(\frac{\Delta \mathrm{t}}{2}\right)
$$

where $L_{x}$ solves the parts of equation (1) given by

$$
\frac{\partial U}{\partial t}+\frac{\partial G}{\partial x}=0
$$

and $\mathrm{L}_{\mathrm{y}}$ solves the part given by

$$
\frac{\partial U}{\partial t}+\frac{\partial F}{\partial y}=0
$$

The operators are advanced in time to a steady state, if one exists, according to a predictor-corrector sequence of steps. A numerical stability criterion exists that limits the time-step used to advance the solution. Typically, in high-Reynolds-number turbulent flows the limiting time-step occurs in computational sweeps normal to the surface. It is given by 


$$
\Delta t_{y} \leq \frac{\Delta y}{|v|+c+\left\{\frac{v_{1}}{\Delta x}+\frac{v_{2}}{\Delta y}\right\}}
$$

where $c$ is the sound speed and $V_{1}$ and $V_{2}$ represent viscous terms. The $\Delta y$ step interval has to be very small to resolve the wall region of a turbulent boundary layer, and this time-step limit presents severe limitations which result in long computing times. Nevertheless, many solutions of shock-separated flows were reported using this method in the mid-1970s.

Given the severe time-step restriction of the method and computer storage limitations, most investigators chose simple zero-equation eddy-viscosity models that use mean-flow information to close the governing equation. These two-layer eddy-viscosity models employed Prandtl's mixing-layer hypothesis in the inner layer,

$$
\varepsilon_{\text {inner }}=\ell^{2}\left|\frac{\partial u}{\partial y}+\frac{\partial v}{\partial x}\right|
$$

where

$$
\left.\begin{array}{rl}
\ell & =0.4 \mathrm{y}\left(1-\exp ^{\mathrm{y} / \mathrm{A}}\right) \\
\mathrm{A} & =\mathrm{A}^{+} \mu_{\mathrm{w}} /\left(\tau_{\mathrm{w}} / \rho\right)^{1 / 2} \\
\mathrm{~A}^{+} & =26
\end{array}\right\}
$$

In the outer region, either a mixing-length value was chosen, based on some length scale such as boundary-layer thickness, for example,

$$
\ell=\ell_{\max }
$$

or Clauser's eddy-viscosity formulation was chosen with an intermittency factor, for example,

$$
\varepsilon_{\text {outer }}=0.0168 \mathrm{u}_{\max } \delta_{i}^{*} /\left[1+5.5(\mathrm{y} / \delta)^{6}\right]
$$


where $u_{\max }$ is the maximum velocity achieved in the boundary layer and $\delta_{i}^{*}$ is the kinematic displacement thickness. The turbulent heat flux is modeled through a turbulent Prandt1 number. To date, this latter aspect of modeling has not been altered. As will be shown later, solutions with these formulations fail to give satisfactory predictions, although they qualitatively reproduce many experimentally observed features. Most of the shortcomings were earlier blamed on turbulence modeling, but not many of the studies reported effects of grid dependence or numerical smoothing which in retrospect may have been as important as the turbulence model.

Even though computing times were excessive (several hours on a CDC 7600 computer) attempts were made to modify the turbulence model and some improvement in the solutions to complex separated-flow problems was demonstrated. Two approaches are worth noting. One used experimental data to guide modifications to the mixing-1ength constants in the turbulence model (Marvin et al. 1975), and the other attempted to relax the outer eddy viscosity to account for the fact that turbulence does not adjust immediately to rapid changes in the mean flow (Shang et al. 1976; Baldwin and Rose 1975); for example,

$$
\rho \varepsilon=\rho \varepsilon_{0}+\left[\rho \varepsilon_{e q}-\rho \varepsilon_{0}\right] 1-\exp ^{\alpha\left(x-x_{0} / \delta_{0}\right)}
$$

where $(\rho \varepsilon)_{0}$ and $\delta_{0}$ are undisturbed values ahead of the interaction region, $(\rho \varepsilon)_{\text {eq }}$ is the usual unmodified value given by equation (10), and $\alpha$ is a relaxation length obtained by a best-fit comparison of final computed results with experiment. It is obvious that both attempts rely heavily on experimental data over a wide range of conditions which limits 
their generality. However, these studies illustrated the potential of the numerical simulations and encouraged development of faster computing methods and better turbulence models.

At this point, the numerical algorithm development research branched. MacCormack (1976) developed his more efficient explicit hybrid method and Beam and Warming (1978) developed their factored implicit scheme. Also, turbulence-modeling improvements using higher-order eddy-viscosity models followed in the wake of the hybrid-method development, and improvements to algebraic eddy-viscosity models, mostly from a computational compatibility standpoint, followed in the wake of the factoredimplicit scheme.

The time-step efficiency of the MacCormack explicit method was improved by combining the advantages of implicit numerical stability with physical insight of the wave-propagating property of the fluid. Conceptually, this was accomplished by further splitting of the y-operator, $\mathrm{L}_{\mathrm{y}}$, into hyperbolic and parabolic parts,

$$
\mathrm{L}_{\mathrm{y}}(\Delta \mathrm{t})=\mathrm{L}_{\mathrm{yh}}(\Delta t) \mathrm{L}_{\text {yp }}(\Delta t)
$$

The hyperbolic operator contains the convective and pressure terms in the column vector $G$ such that

$$
\frac{\partial U}{\partial t}+\frac{\partial G_{h}}{\partial y}=0
$$

In the prediction solution to $G_{h}$, pressures and velocities are obtained by the method of characteristics in a manner that eliminated the speed of sound from the time-step limit such that

$$
\Delta t_{y}=\frac{\Delta t}{|v|}
$$


Since the finest portion of the mesh is usually confined to the wallbounded region where $\mathrm{v}$ is sma11, the stability bound of the allowable time-step is much less restrictive than that given by equation (7). The corrector step is applied as before. The parabolic operator $\mathrm{L}_{\mathrm{yp}}$ is treated implicitly and, therefore, unconditionally stable with regard to time advances. The programming for the hybrid method is complicated by the necessity of using characteristic relations in the prediction step for the hyperbolic operator. However, decreases in computing times by an order of magnitude or more relative to the purely explicit method were achieved. Such decreases encouraged some investigators to apply higher-order eddy-viscosity models (e.g., see Viegas and Horstman 1979), and others to move forward in the computations of three-dimensional flows (e.g., see Hung and MacCormack 1978).

Higher-order eddy-viscosity turbulence models were introduced into the hybrid method by expanding the column vectors to include the turbulent kinetic-energy and length-scale equations in equation (2). The one-equation model from Rubesin (1976), two-equation model from Jones and Launder (1971), and the two-equation mode1 from Wilcox and Rubesin (1980) have been examined for a range of different problems. The ful1 equations describing the implementation of these models in the hybrid algorithm are given in Viegas and Horstman (1979). Modeling constants developed for incompressible flows are usually used without modifications. Authors have reported mixed results, but conclude overall that the higher-order models produce improvements.

Concurrently, development of implicit methods was undertaken. For our purposes, the factored-implicit scheme of Beam and Warming (1978) will 
be briefly described. The method is an extension of their earlier development of an inviscid-flow solver, and, for convenience, the essential elements of the method will be discussed in that context. Timedifferencing of equation (1), where $F$ and $G$ contain only inviscid terms, is accomplished by the unconditionally stable scheme given by

$$
U^{n+1}=U^{n}+\frac{\Delta t}{2}\left[\left(\frac{\partial U}{\partial t}\right)^{n}+\left(\frac{\partial U}{\partial t}\right)^{n+1}\right]+0(\Delta t)^{3}
$$

where

$$
\frac{\partial U}{\partial t}=\left(\frac{\partial F}{\partial x}+\frac{\partial G}{\partial y}\right)
$$

In this form, however, the system of equations is nonlinear and contains a large system of algebraic equations; as a result, the advantage of unconditional stability might not result in solution times significantly smaller than the times for explicit schemes. However, they linearized the equations while maintaining temporal accuracy by a Taylor-series expansion of the nonlinear terms. For example, they let

$$
F^{n+1}=F^{n}+\left(\frac{\partial F}{\partial U}\right)^{n}\left(U^{n+1}-U^{n}\right)+0(\Delta t)^{2}
$$

Substituting this expression and a similar one for G, writing the resulting in a delta form $\Delta \mathrm{U}^{\mathrm{n}}=\mathrm{U}^{\mathrm{n}+1}-\mathrm{U}^{\mathrm{n}}$, and employing spatial factorization, the final form of the equation was written as

$$
\left(I+\frac{\Delta t}{2} \frac{\partial A^{n}}{\partial x}\right)\left(I+\frac{\Delta t}{2} \frac{\partial B^{n}}{\partial y}\right) \Delta U^{n}=-\Delta t\left(\frac{\partial F}{\partial x}+\frac{\partial G}{\partial y}\right)^{n}
$$

The solution is marched in time to a steady state, if one exists, through a three-step sequence, as follows: 


$$
\begin{aligned}
\left(I+\frac{\Delta t}{2} \frac{\partial A^{n}}{\partial x}\right) \Delta U^{*} & =\Delta t\left(\frac{\partial F}{\partial x}+\frac{\partial G}{\partial y}\right)^{n} \\
\left(I+\frac{\Delta t}{2} \frac{\partial B^{n}}{\partial y}\right) \Delta U^{n} & =\Delta U^{*} \\
U^{n+1} & =U^{n}+\Delta U^{n}
\end{aligned}
$$

Results from this procedure compare favorably with those of the hybrid method for the same test problems. Refinements to this method and other implicit solvers have been developed on a continuing basis; see for example, Briley and McDonald (1977) and Coakley (1983). MacCormack (1982) has recently reported a new mixed, explicit-implicit scheme which reduces the computation times and the complex programming problems associated with his hybrid method.

Solutions to separated-flow problems using the implicit scheme developed by Beam and Warming (1978) have usually employed zero-equation turbulence models and the thin-layer approximation to the full equation; for example, see Baldwin and Lomax (1978). The thin-layer approximation neglects derivatives of the viscous stresses in the flow direction. Baldwin and Lomax (1978) argue that this is computationally acceptable for even large separated flow regions because the accuracy of these derivatives in the discretized form of the full equations is questionable since the aspect ratio of computational cells in the near-wall viscous regions is usually very much less than unity for grids used to resolve turbulent layers. Briley and McDonald (1977) and Coakley (1983), however, have employed higher-order, two-equation models and the full equations . 
One aspect of zero-equation turbulence-mode1 improvement, still presently employed in the thin-layer implicit Navier-Stokes codes under development at Ames, is that carried out by Baldwin and Lomax (1978). The development of the model was initiated to circumvent a shortcoming of the Clauser outer-eddy-viscosity formulation (eq. (10)), arising because in many instances the inviscid regions in complex flows have a nonuniform velocity field, and determination of the viscous-layer edge needed to evaluate $\delta_{i}^{*}$ in the model becomes difficult. The outer eddy viscosity is redefined as

$$
\varepsilon_{\text {outer }}=0.0168 C_{1} F_{\text {wake }}\left[1+5.5\left(\frac{0.3 y}{y_{\max }}\right)^{6}\right]^{-1}
$$

where

$$
F_{\text {wake }}=\left\{\begin{array}{c}
y_{\max }{ }^{F_{\max }} \\
\text { or } \\
\mathrm{C}_{\text {wk }} \mathrm{y}_{\max } \mathrm{U}_{\mathrm{diff}} / \mathrm{F}_{\max }
\end{array}\right\} \text { the smaller }
$$

The values of $\mathrm{F}_{\max }$ and $\mathrm{y}_{\max }$ are determined from

$$
F(y)=y\left[\left(\frac{\partial u}{\partial x}-\frac{\partial v}{\partial y}\right)^{2}\right]^{1 / 2}\left[1-\exp ^{-y^{+} / A^{+}}\right]
$$

In wakes, the exponential part of $F(y)$ is set to zero. The $F_{\max }$ term is the maximum value of the function and $y_{\max }$ is the corresponding value of $\mathrm{Y}$ at $\mathrm{F}_{\max }$; $\mathrm{U}_{\mathrm{diff}}$ is the difference between the maximum and minimum total velocity at a fixed $x$-station. The constant $C_{1}$ was determined to have a value of 1.6 by ensuring that the resulting skin friction computed for a flat plate was equivalent to the value obtained from the original Cebeci-Smith model formulation. In order to have a correct value of eddy viscosity for a far-wake, $C_{w k}$ was taken to be 
0.25. For two test problems involving shock-wave interaction, the model gave results that were improved relative to those of the simple twolayer zero-equation model and more or less comparable to those achieved with the relaxation formulation given by equation (11). However, recent studies suggest that a certain degree of caution be exercised in applying this mode1. It requires modification of constants for Mach-number changes, the function $F(y)$ is not always a smoothly varying one, and the choice of $\mathrm{F}_{\max }$ is problem-dependent. See for example Deganni and Schiff (1983) and Visbal and Knight (1983).

\section{EXPERIMENTAL REQUIREMENTS}

The emergence of methods for computing complex, turbulent separated flows places stringent requirements on experiments used to assess the development of the methods. In addition to the traditional role of providing basic understanding of the controlling mechanisms, they must also provide guidance for modeling approximations and provide sufficient detail so that accurate checks on computational output can be made. A synergistic framework for advancing computational aerodynamics consisting of closely coordinated experiments and computations was described by Marvin (1982). The continued necessity for data required to support the development of research-, pilot-, and production-type computer codes was emphasized in that work and will not be repeated here.

At the present stage of their development, computer codes used to solve separated-flow problems that employ the mass-averaged NavierStokes equations are probably best classified as research codes. Furthermore, the experimental data used to assess their development vary in 
completeness and accuracy because the flows are complicated by the presence of shock waves or separation or both, and because many investigators used instrumentation techniques that were themselves in developmental stages.

Nevertheless, a series of building-block or bench-mark flows has been developed that can assist in the development of computational methods (e.g., see Marvin 1982). Those used for the problems discussed in this paper are given in tables 1-6. They represent a cross section of simple, but practical, aerodynamic flows. The tables provide the unfamiliar reader with ample bibliographic sources for further study. In addition to bibliographic citations, information is given on test conditions, grid size, and type of turbulence model employed. Grid size alone is not the only criterion for assessing computational resolution, however, because grid stretching and special refinement in regions of rapid flow changes are important techniques commonly used by most investigators. But the sizes provide some measure for comparison between various computations. Likewise, the turbulence models used are only broadly categorized because they usually differ in detail as a result of programming decisions made by the various investigators. Experiments conducted before 1981 are noted in the tables; they were recently reviewed by an independent evaluation committee and ascertained to contain the most comprehensive data sets for code validation (see Kline et a1. 1981). 


\section{RESULTS AND DISCUSSION}

The modeling of the complex separated flows introduced earlier will now be critically reviewed. The physical characteristics of the flows, as determined by experiment, will be introduced and then comparisons of the results of computations and experiments will be presented to illustrate how well these physical characteristics can be simulated computationa11y.

\section{Impinging Oblique Shock Waves}

Sketches showing the important features of two-dimensional oblique shock-wave interactions are shown in figure 2. For a purely inviscid flow the uniform upstream flow processed by the incoming shock wave is uniformly turned toward the surface and then straightened again by the reflected shock. The corresponding surface-pressure signature is shown. Analytic expressions are available to predict this rather simple situation. The presence of a boundary layer confounds the problem, and the resulting flow-field characteristics depend on the strength of the incoming shock wave.

In the weak interaction, the shock wave penetrates the turbulent boundary layer and turns more steeply toward the surface as it encounters the lower speeds within the viscous layer. It reflects from the viscous layer through a series of compression waves that coalesce into a reflected shock wave. A uniformly increasing surface-pressure signature is found, whose overall rise is nearly equivalent to the inviscid jump.

In the strong interaction, the shock wave also penetrates the viscous layer, but that layer cannot overcome the pressure rise, and 
separation takes place. The viscous layer is turned above the separation through a series of compression waves that coalesce into what is called a separation shock which is later weakened by expansion waves emanating from the viscous flow accelerating over the separation bubble. Downstream, where the bubble terminates, a series of compression waves coalesce into a reflected shock where the flow aligns itself with the surface. The corresponding surface pressure is characterized by a smooth pressure rise and an inflection region characteristic of separation. Because of the multiple shock losses the overall pressure rise is lower than the inviscid jump, by an amount that depends on the flow Mach number and incident shock angle. Also, it is assumed that the separation is closed by a dividing streamline that separates the mass entrained in the region from the outer flow and that a recirculating region is present. In actuality, the turbulent-flow probably leads to unsteadiness within this separated region, but how much influence this has on the mean characteristics is not understood at this time and further study is warranted. Above the separated region an island of very high peak pressure exists near the bifurcation associated with the intersection of the incoming and separation shocks. The extent (scale) of the interaction depends on the boundary-layer thickness, flow Reynolds number, and Mach number.

One of the first considerations in computing such flows is the ability of the computation to resolve shock waves. As reported by Metha and Lomax (1982), the solution methods discussed previously are a11 capable of capturing shock waves. However, the degree of shock sharpness depends on the numerical method and computational mesh. An 
example, taken from Coakley (1983), which illustrates what can be achieved with a reasonably good numerical method and a uniform mesh, is shown in figure 3. Pressures along the solid surface and at a location about midway up in the mesh above the surface are shown for the case of an oblique wave inclined at $29^{\circ}$ at a free-stream Mach number of 2.9 . Similar results would be displayed in pressure distributions normal to the surface as the shock wave was traversed. The mesh used in this example is typical of the mesh dimensions used in the Navier-Stokes codes out in the inviscid regions of the flow. The point to note is that the numerical method requires at least several mesh points to capture the pressure jump associated with the waves. From results such as these, it is easy to deduce that for solutions to the strong-interaction problems, in which separation and reflected-shocks occur, mesh choice will have an influence on how well the flow is modeled and further that a certain amount of shock "smearing" will always occur in practice. What seems to be missing in studies reported in the literature on shock-separated flow problems is an assessment of this effect on the results.

Many of the first computations of separated turbulent flows were directed toward solving the two-dimensional, strong impinging-shock interaction problem (see table 1). Turbulence modeling was reported to have a strong influence on the results. An illustrative example is shown next. The bench mark experimental flow of Kussoy and Hortsman (1975) was computed with an explicit numerical method. The experimental apparatus was axisymmetric and thus eliminated three-dimensional effects now known to be present in other "two-dimensional" experiments. 
Pressure contours from the experiment and two computations are shown in figure 4. The experimental contours show the presence of the incident-, separation-, and reflected-shock waves as evidenced by the closely spaced contour levels. An island of very high pressure exists above the separation near the intersection of the incident and separation shocks. The computations were made with zero-equation eddy-viscosity models and the equations were solved down to the wa11; the baseline computation used the mixing-length formulation given by equations (8) and (9), and the modified mixing-length model was determined from data analysis (Marvin et al. 1975). The grid was chosen to allow good shock capture in the outer regions, and in the viscous region a fine mesh was placed near the wall to resolve the turbulent boundary layer. The eddy viscosity from the baseline model is too high in the interaction region and as a consequence the computation only predicts the existence of a reflected shock wave.

Consistent with this single-shock reflection, the surface pressures are overpredicted somewhat. On the other hand, the modified model, which results in lower eddy viscosities, gave a better simulation of the experimental flow. In addition to the reflected shock wave, the presence of a separation shock is evident, but it appears to be weaker and smeared compared with the experiment. This deficiency in the calculations is probably a result of two things: the grid, which is still probably not fine enough to resolve the flow in the region of the island of high pressure, and the modified turbulence model, which still gives a small separation-bubble height relative to the experimental one. Surface skin friction and heat transfer were not accurately predicted within the 
separated zone, although the model modification did improve the results. In this instance, the mode1 modification was experiment-dependent and, therefore, not extendable to the other conditions of Mach number and Reynolds number.

Although advances in numerical methods that improved computational efficiency provided the opportunity for investigating improvements in turbulence modeling, there has not yet been a significant advance in our ability to predict the flow detail within the separated region. What is known is that zero-equation eddy-viscosity models developed for attached flows must be modified or abandoned in favor of other approaches to provide a physically plausible representation of the flow and that the model must provide some mechanism for altering the effective viscosity in the interaction zone. Two approaches have provided some improvement: modifying the zero-equation model eddy viscosity (Baldwin and Lomax 1978) and using two-equation eddy-viscosity models (Viegas and Horstman 1979).

The former approach, which is advantageous from the viewpoint of computational efficiency, has been used extensively in three-dimensional computations in which computer storage and speed make application of higher-order models less attractive.

Results of a recent study by Brosh et al. (1983) of a threedimensional shock interaction are worth examining because they illustrate current limitations. The flow field is sketched in figure 5. A plane shock impinges on a cylinder aligned with free-stream flow. Separation occurs on the windward surface because of shock interaction, and on the leeward surface because, in part, of the cross flow imposed 
by the windward portion of the free stream being processed by the oblique shock. On the windward plane of symmetry the shock interaction is similar to that depicted in figure 2, but the separation is not closed, and the flow within it is not a result of recirculation fed by downstream flow reattachment. (There has been some speculation that such open separations may be modeled appropriately with zero-equation eddyviscosity models.)

A cursory examination of the computed results indicates that many of the features observed experimentally are simulated, for example, surface-pressures distributions (fig. 5) and the initial separation line. More detailed examination, however, shows deficiencies that result from both turbulence modeling and grid resolution. In figure 6 , the windward plane flow field, determined by flow-field surveys, is sketched, and comparisons with static-pressure profiles are shown. Grid resolution in the region outside the viscous zone leads to significant shock smearing, and no separation shock is predicted. One reason that the overall pressure rise of the interaction is predicted is that at this Mach number the additional losses caused by the presence of the separation shock are small compared with those caused by the recompression of the turning.

In figure 7 , the surface skin-friction directions from the computations are compared with a photograph of oil-flow patterns on a Mylar sheet that had been placed around the cylinder and then "unwrapped" and photographed after the test. On the windward plane $(\phi=0)$, a single separated line is predicted, whereas a double separation line is evident in the experiment. It is likely that the deficiencies of the computation are caused by the combination of a poor turbulence model, which 
gives an effective viscosity that is too high, and poor numerical resolution of the shock system, which causes a local weakening of the shock strength. As the flow proceeds around to the leeward, a single line of separation is predicted, whereas a double line of separation is measured. As we will see in a later section, the turbulence model of Baldwin and Lomax (1978) is unlikely to predict secondary separations without modification and, in addition, the azimuthal grid spacing was probably too coarse. Hence grid resolution and turbulence modeling must both be improved before definitive conclusions can be reached on the modeling of three-dimensional, impinging-shock, separated flows. These particular calculations took $2 \mathrm{hr}$ on a Cray $1-\mathrm{S}$ computer, so finer grid resolution that could help resolve this issue is costly and has not been carried out.

\section{Supersonic Compression Corner}

The physical characteristics and corresponding wall pressures for a two-dimensional compression corner are sketched in figure 8 . For the inviscid flow situation a single shock forms, and the pressure rises abruptly to the level predicted by wedge-flow relations. The presence of a boundary layer complicates the flow, as depicted for two situations, the weak and strong interactions. In the weak interaction, a series of compression waves forms within the boundary layer as it encounters the pressure rise and they coalesce with the shock formed in the inviscid flow, which is required to turn the flow in the direction of the ramp. The corresponding pressure rise shows a smoothing of the pressure at the beginning and end of the interaction. For the strong 
interaction, the boundary layer cannot withstand the pressure rise and it separates. Compression waves that coalesce into a shock wave form near the forward portion of the separation bubble as the outer viscous flow negotiates the pressure rise.

Experimentally, the separation shock-angle is found to be independent of the corner angle. If the separation is large enough and the free-shear Mach number high enough, a second shock will form downstream when the flow over the separated region reattaches and turns in the direction of the ramp. The separation and recompression shocks coalesce with the outer shock wave. The corresponding pressure rise shows inflection over the separated region and the upstream influence is more pronounced than in the weak case. The overall pressure rise through the interaction is somewhat lower than the inviscid rise because of the additional shock losses. Conceptually, the flow in the closed separated region is divided from the outer flow, and mass is entrained and recirculated through the reattachment process. However, as we shall see, there is experimental evidence of unsteadiness in this process. The characteristic scale of the interaction depends on the boundary-layer thickness and free-stream Mach number.

Computations of this complex flow have been reported, as indicated in table 2. Different numerical methods and turbulence models have been employed. A comparison of two of the more recent computations with experiment is shown in figure 9. Two cases are shown, one near incipient separation (weak interaction) and one with separation (strong interaction). In one computation, an implicit algorithm and the thinlayer form of the equations were used with the modified zero-equation 
model of Baldwin and Lomax (1978) which was described earlier. In the other, the MacCormack hybrid algorithm and the full equations were used with the two-equation turbulence model of Wilcox and Rubesin (1980). Metha and Lomax (1982) stated that these different numerical schemes should yield similar results, since comparable grids are used and care in carrying out the computation is exercised. Accepting that premise, the differences between these calculations mainly reflect differences owing to turbulence modeling.

In both the weak and strong cases, the pressures predicted using either model agree reasonably well with the data, and this reflects the common observation that the pressure rise can be estimated, for engineering purposes, using any of the eddy-viscosity models. However, differences occur in the viscous regions. The modified zero-equation model predicts skin-friction values that are much too low downstream of the weak interaction, and this manifests itself more critically in the strong-interaction case by predicting reattachment too far downstream and velocity profiles that do not compare well with experiment. On the other hand, velocity profiles and shape factors in the downstream region are predicted better by the two-equation model, even for the stronginteraction case in which skin friction is somewhat overpredicted (see Marvin 1982). It is thought that the failure of the two-equation model to predict the skin friction resides in the low-Reynolds-number modeling terms developed to allow integration to the wall, but this must be investigated further and in light of the experimental observations on unsteadiness, which is discussed next. 
Unsteady pressures have been measured on compression corners by Dolling and Or (1983). Results from a $20^{\circ}$ compression corner test are shown in figure 10. Normalized mean pressures, $\overline{\mathrm{p}}_{\mathrm{W}} / \overline{\mathrm{p}}_{\mathrm{w}_{\mathrm{O}}}$, their rms fluctuations, $\sigma_{w}$, and an intermittency factor, $\gamma$, are shown for positions upstream of the corner. The intermittency factor represents the fraction of time that $\overline{\mathrm{p}}_{\mathrm{w}}>\overline{\mathrm{P}}_{\mathrm{w}_{\mathrm{O}}}+3 \sigma \overline{\mathrm{P}}_{\mathrm{w}_{\mathrm{O}}}$ (i.e., the time that the instantaneous pressure is greater than that of the undisturbed turbulent boundary layer). The peak rms fluctuations occur ahead of separation in the region of the initial pressure rise. The intermittency reaches a value of 1 near the point of maximum fluctuations and just ahead of the mean separation point. It was deduced that these measurements most probably indicate a separation shock movement of about one boundarylayer thickness.

Such unsteadiness could be caused by unsteady mass entrainment in the recirculating zone as a result of scale changes within the turbulent structure. None of the computations reported have indicated unsteady motion of this sort, and if it is caused by time-varying turbulent structure changes, turbulence models based on mass-averaged variables will not be appropriate for modeling the unsteady details. Much, therefore, remains to be learned about modeling for these shock interacting flows. At this time, only mean pressures can be predicted with reasonable confidence, as can the trends of separation and the reattachment location movement with changing Reyno1ds number based on the incoming boundarylayer thickness (see fig. 11).

Three-dimensional compression corner flows are also now under study; see for example Teng and Settles (1982). Interesting classifications 
of these flows on the basis of conical and cylindrical upstream influence have been postulated. Although no calculations have been reported, one of the author's colleagues, C. C. Horstman, has had recent success in predicting the flows with conical upstream influence. These results should be available shortly.

\section{Glancing Shock Wave}

Control surfaces on vehicles or missiles can produce shock waves that sweep across adjacent boundary layers. Some bench mark experiments depicting the essential features of these flows are available for verifying computations (see table 3). Geometries for two of these are sketched in figure 12 along with surface skin-friction lines and shock-wave structrues which help to describe the general physical characteristics of the flows.

The sharp leading-edge shock generator can result in both weak and strong interactions. In the weak case, the shock interacts with the incoming boundary layer and causes simple flow-turning, with the lower momentum fluid near the wall undergoing larger turning than the higher momentum fluid at the boundary-layer edge. Far from the generator leading edge, the shock pattern formed by the component of the Mach nuniber normal to the shock wave might appear as a weak shock, as sketched in figure 12. In the strong interaction, the boundary layer cannot overcome the pressure gradient, and a separation line forms ahead of the shock wave and a reattachment line forms downstream. Skin-friction lines accompanying such characteristics are sketched in the figure (see Peake and Tobak 1980). In this case, the component of the Mach number normal 
to the shock wave is larger, and the interaction is stronger and a shock wave with the characteristic lambda foot emanating from the compression waves formed near the separation line. In contrast to the twodimensional, normal-shock-wave case, the flow in the separation region is not closed and continued recirculation of the shock-processed fluid does not occur. In this sense, the swept shock flows are probably more steady than the two-dimensional flows. Furthermore, the flow relief owing to the third dimension causes the boundary layers to separate sooner and to have correspondingly larger upstream influence than the two-dimensional flows. The scale of these interactions is determined mainly by the incoming boundary-layer thickness and Mach number.

In the case of the blunt leading edge, a bow shock wave is formed and a strong interaction takes place. Separation and reattachment lines form ahead and downstream of the bow shock wave. A horseshoe vortex forms as a result of the presence of the blunt generating surface, and it streams around it. The shock wave in the plane of symmetry can form a lambda foot near the separation line for the strongest interactions and an inviscid shear layer emanates from the bifurcation point. The scale of the interaction is determined by the bluntness of the generator, because the shock standoff position and the horseshoe vortex scale are proportional to it.

Surprisingly, numerical simulations of these glancing shock-wave flows using rather coarse grids and a simple turbulence model provide adequate predictions of experimental data in contrast to the impingingshock-wave and corner-flow results discussed in previous sections. To illustrate this point for the sharp-generator case, typical comparisons 
of computation and experiment are shown in figures 13-15. The computations by Horstman and Hung (1979) were made with the MacCormack hybrid method along with a two-layer, zero-equation, mixing-1ength eddyviscosity model (eqs. (8) and (10)), modified by Hung and MacCormack (1978) to account approximately for the flow in the corner formed at the intersection of the generator and the plate.

The axial variations of pressure and skin friction (fig. 13) and the spanwise variation of pressure and heat transfer (fig. 14) agree with the measurements except in the corner where modeling is undoubtedly incorrect. Differences in the axial variations at the farthest downstream location are caused by locating the computational boundary there. Although not shown here, agreement with mean-velocity profiles is also good. Similarly good comparisons of surface and flow-field quantities have been reported for wedge angles to $12^{\circ}$ and Mach numbers to 6 . Surface skin-friction lines from the computations are shown in figure 15. Locations of the main features of this strong-interaction case are noted. The separation and reattachment lines were determined by examining cross-flow velocity vector plots oriented in a plane normal to the center of the vortex formed by the interaction. They correspond closely to the converging and diverging lines usually associated with the separation and reattachment locations (Peake and Tobak 1980). Several factors are believed responsible for the good agreement between computations, in which course grids and a simple mixing-length turbulent model are used, and experiment. First of all, the normal component of the Mach number is not large and therefore the shock-wave structure is not so difficult for capture. (In the example shown 
$\left.\mathrm{M}_{\mathrm{N}}=1.3.\right)$ Secondly, the separated-flow region is not closed and highly turbulent fluid is not recirculating. And, as a consequence of the latter, the flow within the separated region is probably more steady than that within a two-dimensional separated region.

The strong interactions resulting from a blunt generator have been recently computed by Hung and Kordulla (1983). The computations were made using a finite-volume version of the newest implicit-explicit method of MacCormack (1982) with the zero-equation turbulence model of Baldwin and Lomax (1978) modified in the same manner as the sharp-generator case to account for the presence of the generator wall. Some example comparisons of these computations with the experimental data of Dolling and Bogdonoff (1982) are shown in figures 16 and 17. Surface pressures along the flat plate and along the generator surface are shown. It can be inferred from these comparisons that the scale of the interaction, including its upstream influence on the oncoming flow and its height relative to the oncoming boundary-layer thickness are probably being predicted quite well, although no flow-field data are available to verify such a conclusion.

The predicted particle paths which represent streamlines in the plane of symmetry are shown in figure 18 to illustrate the resolution of the flow-detail within the horseshoe vortex. Although not readily apparent in this plot (because of the scale of the figure), there is a secondary vortex formed at the junction between the blunt generator and the plate (see Hung and Kordulla 1983). The separation region formed by the horseshoe vortex is open and the vortex streams around the blunt generator and eventually merges with the secondary vortex. 
Most of the features observed in oil-flow photographs taken during the experiment also compare favorably, at least qualitatively, with these computations. Again, it may appear surprising that the computations are doing so we11, considering the grid resolution and simplicity of the turbulence mode1. However, the scale of the interaction is set mainly by the blunt leading edge of the generator, in contrast to the three-dimensiona1, impinging-shock case (figs. 5 and 6) in which no physical scale other than boundary-layer thickness is present.

Further study of this blunt generator case is needed to determine whether important quantities, such as heat transfer or skin friction, can be predicted. It should also be mentioned that an unsteady shockwave structure was found experimentally and that no such unsteadiness was found in the computation.

\section{Norma1-Shock-Wave Interaction}

Understanding the normal-shock-wave problem is important for the development of supercritical-wing technology. In this paper we will focus our attention on studies that have attempted to isolate the flow in the vicinity of the shock wave and in which the elliptic nature of transonic flow does not have to be considered (see table 4). Some of the physical characteristics are depicted in figure 19. The Schlieren photographs and Mach contours from the two-dimensional experiment of East (1976) are shown. At the lowest Mach number, a weak interaction develops and very little change in the normal-shock-wave structure occurs. A thickening of the subsonic layer takes place during the movement of the viscous-layer from the supersonic to the subsonic 
regions. A small foot to the normal shock wave appears through a series of weak compression waves. The resulting wall-pressure distribution appears as a smoothing of the inviscid pressure jump, as we have seen previously for the weak-interacting, impinging oblique-shock flows. Increasing the Mach number strengthens the pressure rise, and eventua11y the boundary layer can no longer pass through without separating. The thickening of the viscous layer occurs sooner (farther upstream) and the series of compression waves can eventually coalesce into a distinct oblique, separation shock forming the so-called lambda foot. This oblique shock will intersect the normal shock wave at a bifurcation point. The losses through the normal shock wave are larger than those through the oblique shock wave and, therefore, the static pressure downstream of the normal shock wave is higher than that of the flow downstream of the oblique shock wave and a second rearward-running shock will form at the bifurcation to equalize the disparity.

At the higher Mach numbers, existence of a supersonic "tongue" has been observed (see for example, Kooi 1978). At the bifurcation point there is a difference in total pressure between the flow processed by the normal and compound shock systems and a shear layer (a discontinuity surface sometimes referred to as a vortex layer) forms. Corresponding surface-pressure distribution will show a steep rise in pressures ahead of separation, a decrease in the pressure gradient over the region of separation, and gradual increase to a level somewhat below the inviscid jump pressure for a normal shock.

A certain degree of success has been achieved in modeling the moderately strong normal-shock interaction where separation is rather 
sma11. An example is illustrated in figures 20 and 21. Computations were made using the MacCormack hybrid method and the two-equation eddy-viscosity model of Wilcox and Rubesin (1980). The grid (table 4) was chosen in order to provide adequate capture of the shock structure and to resolve the near-wall region of the turbulent boundary layer. In figure 20, pressure-distributions and velocity-profile shape parameters are compared with the experiment reported by Om et a1. (1982) for a range of Mach number and Reynolds number. The experiment was performed in an axisymmetric test section so that three-dimensional effects could be eliminated; therefore, a high degree of confidence can be placed in the experimental trends that are observed.

The effects of Mach number and Reynolds number are predicted by the computations, except possibly in the immediate vicinity of the shock at the highest Mach numbers. Mach contours are compared in figure 21 for the highest Mach number case. For the most part the shock structure is also predicted by the computations. The shock is weakened because of viscous-layer thickening near the separation, and a series of compression waves coalesces into the normal shock. A smaller region of supersonic flow is predicted. One would not expect to capture any discontinuity surface in total pressure that would lead to a so-called vortex layer because the grid is obviously too coarse. The extent of separation in the prediction is somewhat smaller than that of the experiment.

Studies have shown that the choice of turbulence model has an influence on the predictions (Viegas and Horstman 1979). An illustrative example is shown in figure 22. Although the turbulence model has little influence on the prediction of the overall pressure rise, models that 
use information on the turbulent kinetic energy changes through the shock wave to form the velocity scale of the eddy viscosity provide much better estimates of the skin friction. We can also note that trends with Reynolds number over a wide, practical range are predicted with those higher-order eddy-viscosity models. However, even these higher-order models have to be applied with caution when wall skin friction or heat transfer is being predicted, because the low-Reynoldsnumber functions, required when integrating the equation system from a wall boundary out into the flow field have not always been developed adequately.

The reader is referred to a very recent paper by Viegas and Rubesin (1983) in which that aspect of higher-order eddy-viscosity modeling for the moderately strong, normal-shock problem is studied. Figure 23 summarizes the main points from that study. When integrating from the wall boundary, only the Wilcox-Rubesin mode1 gives adequate skin-friction predictions. In developing this mode1's low-Reynoldsnumber functions, particular attention was given to ensure that modeling was adequate for attached, large adverse-pressure-gradient flows, and evidently the model can also perform adequately in moderately strong normal-shock interactions in which small separation occurs.

On the other hand, the model of Jones and Launder (1971), with its original formulation of the low-Reynolds-number terms, and one developed by Chien (1982) to minimize computational stiffness encountered when applying the model of Jones and Launder, do not have the same degree of success. However, they did provide adequate predictions of surfacepressure and velocity-profile shapes. Wall functions were developed by 
Viegas and Rubesin (1983) for all the models to eliminate the need for integration to the wall. Successful prediciton of the skin friction was achieved with all models, as shown in the second part of figure 23 . In addition to developing the wall functions for the two-equation models, the study of Viegas and Rubesin (1983) also showed that the computer code became more robust and converged faster. Together with the savings in grid points near the wall and the advantage of robustness, computational times using wall functions were decreased by nearly one order of magnitude over those using integration to the wall boundary. Although the axisymmetric bench mark experimental flows have the advantage of minimizing three-dimensional effects, they are limited to moderately strong interactions because the flow is confined and separation extent is limited. Therefore, one must exercise caution in generalizing these results for two-dimensional situations, in which for the same free-stream Mach number, separation may be considerably larger. In those cases, predictions from computations are not as good. To illustrate this aspect, unpublished computations by C. C. Horstman of Ames Research Center for the experiment reported by Delery (1983) are presented in the next figures.

In the experiment by Delery, a region of supersonic flow was achieved in an asymmetric channel formed by having a bump on one wall of a rectangular test section. In addition to forming a lambda shock foot, a separated region developed which closed downstream of the junction formed by the bump and the channel wall. Although the flow was choked across the channel, the significant viscous interaction effects only occurred in the bump-wall side. The computations were made using 
the new implicit-explicit method of MacCormack (1982) along with the two-equation turbulence model of Jones and Launder (1971). Both walls were treated viscously, but the grid resolution was rather coarse on the far wall where interaction effects were small. The equations were inte-grated to the wall.

An interferogram taken of the flow above the bump-wall is shown in figure 24. Mach contours determined from the interferogram are also shown. They can be compared with the computed contours using two different turbulence models. The unmodified model of Jones and Launder (1971), with the low-Reynolds-number formulation of Chien (1982), predicts a region of separation smaller than that found experimentally. As a result, the shock structure also differs in that the computed lambda foot of the shock is weaker and the zone of supersonic flow smaller. As mentioned previously, the low-Reynolds-number functions of the turbulence model may be affecting these calculations, but at the time they were made, that weakness of this model had not been reported. Therefore, Horstman made another computation using an ad hoc modification to the model that had provided some improvements in other separatedflow computations (see Horstman 1983) to see if the correct flow field could be predicted. The results, shown in figure 25, provide a better comparison for the Mach contours and extent of separation. It is worth noting that these transonic flows also have unsteady aspects that may influence our ability to model the separated region.

The shear layer that develops during this strong norma1-shock-wave interaction behaves like the one that develops downstream of a rearwardfacing step (Seegmiller et al. 1978; Delery 1983). Other studies 
(Driver and Seegmiller 1982; and Driver et a1. 1983) of such a flow, which eliminates uncertainties in separation location and the complicating presence of unsteady shocks, indicate that eddy-viscosity models do not work as well as Reynolds-stress models in predicting the flow within the separated region. Such models remove the assumption that the stresses respond immediately to changes in the strain rate and therefore constitute a more plausible physical description in the case of strong interactions.

Some results which exemplify the main thrust of these studies are shown in figure 26. In the experiment, the size of the separated zone was altered by varying the upper angle of the channel walls, which changed the reattachment location. The separated flow was also unsteady, but the characteristic frequency was below any expected turbulence frequencies by a factor of 3 . The prediction of the reattachment location is a measure of how well the separated zone is being calculated, and one can note that significantly better results are achieved with an algebraic Reynolds-stress model.

In these computations by Sindir (1982), the steady form of the equations was solved and the wall functions were developed and implemented to eliminate the low-Reynolds-number terms needed for integration to the wall. It was recognized early in Sindir's study that the scale equation used in the original algebraic stress model was the weakest aspect of the model formulation. Therefore, when the original stressmodel formulation failed to predict the experiment, the production term was modified. The change causes the dissipation to increase and shear stresses to decrease with the net effect yielding an increase on 
reattachment length or larger separated zones. Within the separated zone, improved velocity and shear-stress profiles are also achieved. Such a model has not yet been implemented in shock-separated flows because of computational efficiency considerations. However, with the compressible-flow wall functions developed by Viegas and Rubesin (1983) future attempts can be anticipated.

\section{Trailing-Edge Flow Interactions}

Supercritical-wing technology development also depends on an understanding of the flow at the trailing edge because of its global influence on wing lift and drag. A series of two-dimensional bench mark flows, as shown in table 5 , has been under investigation to provide modeling guidance. The experimental flows range from attached incompressible flows with no pressure gradient to high subsonic speed compressible flows with adverse pressure gradients leading to small separation. For incompressible flows, viscous-inviscid interactions have not been important, and modeling studies have shown that twoequation eddy-viscosity models are adequate to resolve the flow in the near-wake region (Marvin 1982). For the higher speed flows, viscousinviscid interactions are important and some additional discussion is warranted herein.

Some of the important physical characteristics of these higher speed flows are depicted in figure 27. A spark shadowgraph and meanflow characteristics, determined from laser velocimeter measurements of Viswanath and Brown (1982), are shown. There is a rapid thickening of the upper surface displacement thickness as the trailing edge is 
approached. This displacement effect causes changes in streamline curvature and significant influence on the outer inviscid flow. Such effects must be accounted for if correct drag and lift characteristics are to be predicted. Two viscous layers of different thickness merge in the near-wake, and the locus of $U_{\min }$ does not occur along the imaginary geometric line separating the upper and lower surfaces. Turbulence modeling that reflects the mixing of two viscous regions of different characteristic scales must be addressed. In this regard, the incompressible experiments have been extremely useful. They have verified that two-equation models accomplish this mixing of two different length scales quite adequately and they have a definite advantage over zero-equation models which must heuristically blend these two lengths as a function of Reynolds number and angle of attack. When pressure gradients are large enough, small separation can occur as in this example.

The flow direction in this separated region has been found to be intermittent (Viswanath and Brown 1982). Another feature of the flows, observed in the short-duration shadowgraph exposure, is the existence of district counterclockwise vortical structures that originate at the trailing edge, grow, and merge with one another downstream. Such structures have also been observed in high-speed, unseparated, asymmetric trailing-edge flows. Their occurrence is due to the singular nature of the trailing edge where the interaction between the high-momentum lowersurface flow and the low-momentum upper-surface flow occurs. It is not known if these structures are the primary causes of the unsteadiness in the small separated zone. 
Some success has been achieved in modeling the mean flow within complex trailing-edge regions (see Horstman 1983). An example of comparisons between experiment and computations using the two-equation turbulence model of Wilcox and Rubesin (1980) are shown in figures 28 and 29 for the case with small separation. Grid resolution was fine enough to resolve the expected interaction between the viscous and inviscid regions, to provide proper integration of the near-wa11, lowReynolds-number terms in the modeling equations, and to provide adequate numerical transition between the no-slip wall-boundary condition and the near-wake flow without resorting to grid alignment with the experimentally determined $u_{\text {min }}$ streamline.

In figure 28, the predicted pressure distribution is shown to agree adequately with the experimental one. Although the location of separation was different in the computation and experiment, values of the viscous displacement and momentum thickness also showed excellent agreement. Corresponding mean-velocity and turbulence profiles are shown in figure 29. These comparisons also indicate good agreement. The intermittent nature of the separated flow and the vortical structures were not predicted.

Whether these aspects could ever by predicted within the framework of the mass-averaged Navier-Stokes equations depends on whether the characteristic shedding times are much longer than the characteristic times associated with the turbulent structure. Although no estimates of the vortical shedding frequencies were made, a characteristic frequency of pressure fluctuations beneath the separated zone was measured 
and found to be about $9 \mathrm{kHz}$. This frequency is of the order of the characteristic frequencies within the attached turbulent layer and hence it is unlikely that computations would resolve these structures. The importance of resolving these unsteady features has not been fully explored and further study of this aspect may be warranted.

\section{Cross-Flow Separation at Supersonic Speeds}

Aircraft maneuverability requirements and space transportation vehicle reentry attitudes require an understanding of flows over bodies at high angle of attack where separation can occur on their leesides. For our discussion, we will limit consideration to steady separations on simple shapes for which some modeling successes for fully turbulent flows have been demonstrated. Bench mark flows are shown in table 6.

Some typical physical characteristics of these flows can be explained with the aid of figure 30 , where cross-flow streamline patterns and surface skin-friction directions are illustrated. The ratio of angle of attack to cone half-angle, $\bar{\alpha}$, is often used to categorize these simple flows. When $\bar{\alpha}$ is less than 1 , inviscid theory, coupled with boundary-layer techniques, is adequate for predicting these flows. As $\bar{\alpha}$ nears or exceeds 1 , separation occurs near the leeside generator. As $\bar{\alpha}$ increases, separation moves farther from the leeside generator. Secondary, and even tertiary, separation can manifest itself. The converging and diverging skin-friction direction represents separation and attachment lines, respectively. Depending on the flow Mach number 
and angle of attack, cross-flow shock waves can also occur; they too can cause separation (such a circumstance is not illustrated).

The separations that occur are open in the sense that there is no recirculation of downstream fluid to forward locations. And, for supersonic flows, the downstream influence on the upstream flow is felt only through the subsonic region of the boundary layers, which can be quite small for turbulent flows. In such situations, the mass-averaged Navier-Stokes equations can be put in parabolic form by neglecting derivatives of the shear stresses in the marching direction, and providing some special procedures in the subsonic region of the flow (see for example Schiff and Steger 1980; Rakich et a1. 1982). Such approximations provide considerable improvement in computational efficiency because the solutions are marched in space coordinates only, time being superfluous. Considerable success has been shown for this approach, using implicit procedures when $\bar{\alpha}$ is less than 1 , and when the flows are attached. In these cases, adequate turbulence modeling is provided by zero-equation eddy-viscosity models.

When separation occurs, viscous effects determine the leeside flow structure. Numerical resolution and turbulence modeling both become important. To illustrate the effect of the choice of turbulence model, the data from the bench mark flow published by Rainbird (1968) at a given axial location are compared with several computations in figure 31 . The surface shear-stress angle directions $\omega_{\mathrm{s}}$ are defined relative to the conical generator. Therefore, when the angle is positive, the flow is toward the leeward plane of symmetry and away from it when the angels are negative. Thus, this flow shows primary separation at the first 
location of a sign change in $w$ (i.e., 123 ), and secondary separation at the next sign change location $\left(154^{\circ}\right)$.

The computations shown in figure 31 were performed using two different algorithms that solve the parabolized form of the Navier-Stokes equations. They differ mainly in the manner in which the subsonic region of the flow is treated. Rakich et al. (1982) solve for a portion of the pressure term in that region, to enable the solution to march more efficiently in regions where departure solutions may occur, and they actually march the solution from the cone apex. Deganni used the approach of Schiff and Steger (1980) in which the pressure within the subsonic region is assumed to be constant and equivalent to that in the supersonic region and the flow is treated as if it were conical. Both methods used implicit procedures to advance the solutions. Although no thorough comparisons of these two methods have been reported, example computations using comparable grids on similar shapes at lower angles of attack where the flow is attached would suggest the two methods yield essentially the same solutions. The comparison in figure 31 tends to substantiate this for separated flows as well.

The differences in results between the computations in figure 31 probably show the effects of different turbulence modeling. First, we observe that the computations of Rakich who used the unmodified zeroequation model (eqs. (8) and (10)) does a reasonably good job of predicting both pressure distribution and shear-stress direction. On the other hand, Deganni's solution using the model of Baldwin and Lomax (1978) fails to predict the leeside flow, giving a simple primary separation with reattachment near the leeside generator. Deganni 
found that the maximum of the vorticity function equation (21), used to establish the length scale, did not have a single maximum. Choosing the $y$ associated with maximum farthest from the body introduced artificially high values of viscosity and erroneous prediction of the flow. Modifying the computational logic to ensure that the length scale was determined at the location of the first maximum resulted in much better prediction. In most respects, the results of the modified model compare with the zero-equation computations of Rakich.

A further illustration of the influence of modeling on the computations is shown in the top portion of figure 32(a) where velocity vectors in the cross-flow plane (taken from Deganni and Schiff 1983) are shown. Proper modeling results in the correct flow field with the primary, secondary, and tertiary vortices. However, another facet of flow modeling - numerical resolution - must also be considered. This facet is shown in figure 32(b). The computations are for another cone and another set of conditions. Using the modified turbulence model, Deganni showed that when the cross-flow grid is too coarse $\Delta \phi=5^{\circ}$, a single vortex associated with primary separation is found. For the finer grid $\left(\Delta \phi=2^{\circ}\right)$ the primary, secondary, and tertiary vortices are found. The latter corresponds better with the measured results from the experiment, and it is concluded that the fine-resolution computations fairly represent the real flow field. The obvious conclusion from such studies is that grid resolution and turbulence modeling in the initial stages of cross-flow development are both very important.

Further work remains to refine our ability to model these flows with large separations. Removing the ambiguity in defining the proper 
length scale in the eddy-viscosity model would be a fruitful area for study, as well as establishing some criteria for proper grid resolution.

\section{CONCLUDING REMARKS}

The status of flow modeling in which numerical simulations of the mass-averaged Navier-Stokes equations are used to compute high-speed, compressible, turbulent separated flows was reviewed. Emphasis was placed on bench mark flows that represent simplified, but realistic aerodynamic phenomena. These included impinging shock waves, compression corners, glancing shock waves, trailing-edge regions, and supersonic, high-angle-of-attack flows. In each case, comparison with experiment provided an assessment of modeling capabilities and shortcomings. Consideration was given to showing the importance of combining experiments, numerical algorithm, grid, and turbulence model to develop effectively this potentially powerful technique for solving separatedflow problems.

The mass-averaged Navier-Stokes computer codes in use today are still in their developmental stages. They represent a compromise between the choice of numerical algorithm, grid, and turbulence model. The compromise is dictated by constraints of numerical efficiency and the lack of an adequate turbulence mode1. Provided that adequate safeguards are used to ensure numerical resolution, it is apparent that the computations employing eddy-viscosity turbulence models can give a qualitatively good representation of many two- and three-dimensional, complex aerodynamic flows involving shock waves and separation. Although flow details within separated regions cannot be predicted with complete 
confidence, the solutions can now provide a bridge for connecting computations on either side of embedded separated regions.

of the work remaining in developing these codes into predictive tools, proper physical modeling remains paramount. The challenges of better numerical accuracy and resolution along with better turbulence modeling are areas for further exploration. With regard to the latter, it is clear that some distinct advantages are gained by employing higher-order turbulence models. Without inordinate increases in computational times (25\% increases are typical), two-equation models provide unambiguous, albeit approximate, determinations of the length and velocity scales needed to define an effective viscosity, and they provide inherent means to allow turbulence to adjust itself appropriately to rapid changes in the mean flow.

Whether they can be improved to provide completely adequate modeling or whether they must give way to Reynolds stress modeling is a debatable issue, the resolution of which requires additional study. More has to be done to determine the causes and effects of flow unsteadiness and its importance in modeling both two- and three-dimensional flows. And, more has to be done experimentally to define flow-field structures and critical parameters, to gain further understanding of modeling, and to provide we11-documented bench mark tests against which progress can be gauged. 


\section{REFERENCES}

Baldwin, B. S.; and MacCormack, R. W. (1974): Numerical Solution of a Strong Shock Wave With a Hypersonic Turbulent Boundary-Layer. AIAA Paper 74-558, Palo Alto, Calif.

Baldwin, B. S.; and Rose, W. C. (1975): Calculations of Shock-Separated Turbulent Boundary Layers. NASA SP-347.

Baldwin, B. S.; and Lomax, H. (1978): Thin Layer Approximation and Algebraic Model for Separated Turbulent F1ows. AIAA Paper 78-257, Huntsville, Ala.

Bannink, W. J.; and Nebbeling, C. (1978): Measurement of the Supersonic Flow Field Past a Slender Cone at High Angles of Attack. High Angle of Attack Aerodynamics, AGARD CP-247, Paper 22.

Beam, R. M.; and Warming, R. F. (1978): An Implicit Factored Scheme for the Compressible Navier-Stokes Equations. AIAA J., vo1. 16, no. 4, pp. 393-402.

Briley, W. R.; and McDonald, H. (1977): Solution of the Multidimensional Compressible Navier-Stokes Equations by a Generalized Implicit Method. J. Comput. Phys., vo1. 24, no. 4, p. 372 .

Brosh, A.; Kussoy, M. K.; and Hung, C. M. (1983): An Experimental and Numerical Investigation of the Impingement of an Oblique Shock Wave on a Body of Revolution. AIAA Paper 83-1757, Danvers, Mass.

Cambier, L.; Ghazzi, W.; Veuillot, J. D.; and Viviand, H. (1981): Une Approche por Domaines Pour Le Calcul D'ecoulements Compressibles. 5 'eme Co11. Int. Sur Les M'ethodes de Calcul Scientifique et Technique, INRIA TP ONERA $\mathrm{N}^{\circ}$ 1981-143. 
Chapman, D. R. (1979): Dryden Lectureship in Research, Computational Aerodynamics Development and Outlook. AIAA J., vol. 17, no. 12, pp. 1293-1313.

Chapman, D. R. (1981): Trends and Pacing Items in Computational Aerodynamics. Seventh International Conference on Numerical Methods in Fluid Dynamics, Lecture Notes in Physics, Springer-Verlag.

Chein, K.-Y. (1982): Predictions of Channel Boundary-Layer Flows with a Low-Reynolds-Number Turbulence Mode1. AIAA J., vo1. 20, pp. 33-38. Coakley, T. J. (1983): Implicit Upwind Methods for the Compressible Navier-Stokes Equations. AIAA Paper 83-1953, Danvers, Mass. Coakley, T. J.; Viegas, J. R.; and Horstman, C. C. (1977): Evaluation of Turbulence Models for Three Primary Types of Shock Separated Boundary Layers. AIAA Paper 77-692, Albuquerque, N. Mex.

Degani, D.; and Schiff, L. B. (1983): Computation of Supersonic Viscous Flows Around Pointed Bodies at Large Incidence. AIAA Paper 83-0034, Reno, Nev.

Delery, J. M. (1983): Experimental Investigation of Turbulent Properties in Transonic Shock/Boundary Layer Interaction. AIAA J., vo1. 21 , no. 2, pp. 180-185.

Dolling, D. J.; and Or, C. T. (1983): Unsteadiness of Shock Wave Structure in Attached and Separated Compression Ramp Flow Fields. AIAA Paper 83-1715, Danvers, Mass. Dolling, D. S.; and Bogdonoff, S. M. (1982): Blunt Fin-Induced Shock Wave/Turbulent Boundary Layer Interaction. AIAA J., vo1. 20, no. 12, pp. $1674-1680$. 
Driver, D. M.; and Seegmiller, H. L. (1982): Features of a Reattaching Turbulent Shear Layer Subject to an Adverse Pressure Gradient. AIAA Paper 82-1029.

Driver, D. M.; Seegmiller, H. L.; and Marvin, J. G. (1983): Unsteady Behavior of a Reattaching Shear Layer. AIAA Paper 83-1712, Danvers, Mass.

East, L. F. (1976): The Application of a Laser Anemometer to the Investigation of Shock-Wave Boundary Layer Interactions. AGARD Conference Proceedings No. 193 on Applications of Non-Intrusive Instrumentation in Fluid Flow Research, Paper 5. Holden, M. S. (1972): Shock Wave-Turbulent Boundary Layer Interaction in Hypersonic Flow. AIAA Paper 72-74, San Diego, Calif. Horstman, C. C.; Settles, G. S.; Vas, I. E.; Bogdonoff, S. M.; and Hung, C. M. (1977): Reynolds Number Effects on Shock Wave Turbulent Boundary-Layer Interaction. AIAA J., vol. 15, no. 8, pp. 1152-1158. Horstman, C. C.; and Hung, C. M. (1979): Computation of Three Dimensional Turbulent Separated Flows at Supersonic Speeds. AIAA Paper 79-002, New Orleans, La. Horstman, C. C. (1983): Numerical Simulation of Turbulent Trailing Edge Flows. Second Symposium on Numerical and Physlcal Aspects of Aerodynamic Flows, Long Beach, Calif.

Hung, C. M. (1982): The 1980-81 AFSOR/HTTM-Stanford Conference on Complex Turbulent Flows: Comparison of Computation and Experiment. Vo1. III. Comparison of Computation with Experiment and Computers Summary Reports. S. J. Kline, B. J. Cantwe11, and G. M. Lilley, eds., pp. $1372-1374$. 
Hung, C. M.; and MacCormack, R. W. (1977): Numerical Simulation of Supersonic and Hypersonic Turbulent Compression Corner Flows. AIAA J., vol. 15, no. 3, pp. 410-416.

Hung, C. M.; and MacCormack, R. W. (1978): A Numerical Solution of Three-Dimensional Shock Wave and Turbulent Boundary Layer Interaction. AIAA J., vo1. 16, pp. 1090-1096.

Hung, C. M.; and Kordulla, W. (1983): A Time Split Finite Volume Algorithm for Three-Dimensional Flow Field Simulations. AIAA Paper 83-1957, Danvers, Mass. Jones, W. P.; and Launder, B. E. (1971): The Prediction of Laminarization with a Two-Equation Model of Turbulence. International Journal of Heat and Mass Transfer, Vo1. 15, Pergamon Press.

Kayser, L. D.; and Sturek, W. B. (1978): Experimental Measurements in the Turbulent Boundary Layer of a Yawed, Spinning Ogive-Cylinder Body of Revolution at $\mathrm{M}=3$. Part II. Data Tabulation. ARBRL-MR-02813, U.S. Army Ballistic Research Laboratory, ARRADCOM, Aberdeen Proving Ground, Md.

Kline, S. J.; Cantwe11, B. J.; and Lilley, G. M., eds. (1981): The 1980-81 AFSOR/HTTM-Stanford Conference on Complex Turbulent Flows: Comparison of Computation and Experiment. Vo1. I. Objectives, Evaluation of Data, Specifications of Test Cases, Discussion, and Position Papers. Published and Distributed by Thermosciences Div., Mechanical Engineering Department, Stanford U., Stanford, Calif. Kooi, J. W. (1978): Influence of Free-Stream Mach Number on Transonic Normal Shock Wave/Turbulent Boundary Layer Interaction. NLR MD 78013 U. 
Kussoy, M. I.; and Horstman, C. C. (1975): An Experimenta1 Documentation of a Hypersonic Shock-Wave Turbulent Boundary Layer Interaction Flow With and Without Separation. NASA TM X-62,412.

Kussoy, M. I.; Horstman, C. C.; and Viegas, J. R. (1980): An Experimental and Numerical Investigation of a 3-D Shock Separated Turbulent Boundary Layer. AIAA J., vo1. 18, no. 12, pp. 1477-1484.

Law, C. H. (1974): Supersonic Turbulent Boundary-Layer Separation. AIAA J., vo1. 12, no. 6, pp. 794-797.

Liou, M. S.; Coakley, T. J.; and Bergman, M. Y. (1981): Numerica1 Simulation of Transonic Flow in Diffusers. AIAA Paper 81-1632, Palo Alto, Calif.

MacCormack, R. W. (1971): Numerical Solution of the Interaction of a Shock Wave with a Laminar Boundary Layer. Lecture Notes in Physics, Vo1. 8, Springer-Verlag, pp. 151-163.

MacCormack, R. W. (1976): An Efficient Numerical Method for Solving the Time-Dependent Compressible Navier-Stokes Equations at High Reynolds Number. NASA TM X-73,129.

MacCormack, R. W. (1982): A Numerical Method for Solving the Equations of Compressible Viscous Flow. AIAA J., vol. 20, no. 9, pp. 1275-1281. McDona1d, H. (1982): The 1980-81 AFSOR/HTTM-Stanford Conference on Complex Turbulent Flows: Comparison of Computation and Experiment. Vo1. III. Comparison of Computation with Experiment and Computors Summary Reports. S. J. Kline, B. J. Cantwell, and G. M. Lilley, eds., pp. $1424-1427$. 
McRae, D. S.; Peake, D. J.; and Fisher, D. F. (1980): A Computational and Experimenta1 Study of High Reynolds Number Viscous/Inviscid Interaction about a Cone at High Angle of Attack. AIAA Paper 80-1422, Snowmass, Colo.

Marvin, J. G. (1980): Advancing Computationa1 Aerodynamics through Wind-Tunnel Experimentation. AGARD Fluid Dynamics Panel Meeting on Integration of Computers and Wind Tunnel Testing, Chattanooga, Tenn., Sept. $24-25$.

Marvin, J. G. (1982): Turbulence Modeling for Computational Aerodynamics. AIAA Paper 82-0164, Orlando, Fla.

Marvin, J. G.; Horstman, C. C.; Rubesin, M. W.; Coakley, T. J.; and Kussoy, M. I. (1975): An Experimental and Numerical Investigation of Shock-Wave-Induced Turbulent Boundary Layer Separation at Hypersonic Speeds. AGARD-CCP 168.

Mateer, G. G.; Brosh, A.; and Viegas, J. R. (1976): A Normal ShockWave Turbulent Boundary Layer Interaction at Transonic Speeds. AIAA Paper 76-161, Washington, D.C. Mateer, G. G., and Viegas, J. R. (1979): Effect of Mach and Reynolds Numbers on a Normal Shock/Turbulence Boundary Layer Interaction. AIAA Paper 79-1502, Williamsburg, Va. Metha, V.; and Lomax, H. (1982): Reynolds-Averaged Navier-Stokes Computations of Transonic Aerodynamics. Progress in Astronautics and Aerodynamics, Vo1. 82, D. Nixon, ed., published by AIAA, New York, N.Y., pp. 297-375. 
Om, D.; Childs, M. E.; and Viegas, J. R. (1982): An Experimental Investigation and a Numerical Prediction of a Transonic Normal Shock Wave/Turbulent Boundary Layer Interaction. AIAA Paper 82-0990, St. Louis, Mo.

Oskam, B.; Bogdonoff, S. M.; and Vas, I. E. (1975): Study of Threedimensional Flow Fields Generated by the Interaction of a Skewed Shock Wave with a Turbulent Boundary Layer. AFFDL-TR 75-21, Air Force Flight Dynamics Laboratory.

Peake, D. J. (1976): Three Dimensiona1 Swept Shock/Turbulent Boundary Layer Separation with Control of Air Injection. Aeronautical Report L. R., 592, National Research Council, Canada. Peake, D. J.; and Tobak, M. (1980): Three Dimensional Interaction and Vortical Flows with Emphasis on High Speeds. NASA TM-81169. Rainbird, W. J. (1968): Turbulent Boundary Layer Growth and Separation on a Yawed Cone. AIAA J., vo1. 6, p. 2410. (See also AGARD CP 30, 1968.)

Rakich, J. V.; Davis, R. T.; and Barnett, M. (1982): Simulation of Large Turbulent Structures with the Parabolic Navier-Stokes Equations. Eighth International Conference on Numerical Methods in Fluid Dynamics, Aachen, W. Germany.

Ramaprian, B. R.; Pate1, V. C.; and Sastry, M. S. (1981): Turbulence Wake Development Behind Streamlined Bodies. IIHR Report 231, Iowa Institute of Hydraulic Research, U. of Iowa, Iowa City, Iowa. 
Redda, D. C.; and Murphy, J. D. (1973): Shock Wave Turbulent BoundaryLayer Interaction in Rectangular Channe1s. Part II. The Influence of Sidewall Boundary-Layers on Incipient Separation and Scale of Interaction. AIAA J., vol. 11, no. 10, pp. 1367-1368.

Rubesin, M. W. (1976): A One-Equation Model of Turbulence for Use with the Compressible Navier-Stokes Equations. NASA TM X-73128.

Rubesin, M. W.; and Rose, W. C. (1973): The Turbulent Mean Flow

Reynolds-Stress and Heat Flux Equations in Mass-Averaged Dependent Variables. NASA TM X-62,248.

Salmon, J. T.; Bogar, T. J.; and Sejben, M. (1981): Laser Velocimeter Measurements in Unsteady, Separated, Transonic Diffuser Flows. AIAA Paper 81-1197, Palo Alto, Calif.

Schiff, L. B.; and Steger, J. L. (1980): Numerical Simulation of Steady Supersonic Viscous Flows. AIAA J., vo1. 18, no. 12, Dec., pp. 1421-1430.

Schiff, L. B.; and Sturek, W. B. (1980): Numerical Simulation of Steady Supersonic Flow over an Ogive-Cylinder/Boattail Body. AIAA Paper 80-0066, Pasadena, Calif. Seddon, J. (1960): The Flow Produced by Interaction of a Turbulent Boundary Layer with a Normal Shock Wave of Strength Sufficient to Cause Separation. Aeronautical Research Council Reports and Memoranda No. 3502, Mar. 1960.

Seegmiller, H. L., Marvin, J. G.; and Levy, L. L., Jr. (1978): Steady and Unsteady Transonic Flows. AIAA J., vol. 16, no. 12, pp. $1262-1270$. 
Settles, G. S.; Vas, I. E.; and Bogdonoff, S. M. (1976): Details of a Shock-Separated Turbulent Boundary Layer at a Compression Corner. AIAA J., vol. 14, pp. 1709-1715.

Settles, G. S.; Fitzpatrick, T. J.; and Bogdonoff, S. M. (1979):

Detailed Study of Attached and Separated Compression Corner Flow Fields in High Reynolds Number Supersonic Flow. AIAA J., vol. 15, no. 4, pp. 1152-1158.

Shang, J. S.; and Hankey, W. L., Jr. (1975): Numerical Solution of the Navier-Stokes Equations for a Compression Ramp. AIAA J., vol. 13, no. 10 , pp. $1368-1374$.

Shang, J. S.; Hankey, W. L., Jr.; and Law, H. C. (1976): Numerica1 Simulation of Shock-Wave-Turbulent Boundary Layer Interaction. AIAA J., vo1. 14, no. 10, p. 1451.

Shang, J. S.; Hankey, W. L.; and Petty, J. S. (1979): Three-Dimensional Supersonic Interacting Turbulent Flow along a Corner. AIAA J., vo1. 10, no. 5, pp. 652-656.

Sindir, M. (1982): Numerical Study of Separating and Reattaching Flows in a Backward-Facing Step Geometry. Ph.D. dissertation, Mechanica1 Engineering Department, U. of California at Davis, Davis, Calif. Teng, H. Y.; and Settles, G. S. (1982): Cylindrical and Conical Upstream Influence Regimes of 3-D Shock/Turbulent Boundary Layer Interactions. AIAA Paper 82-0987, St. Louis, Mo.

Viegas, J. R.; and Horstman, C. C. (1979): Comparison of Multiequation Turbulence Models for Several Shock Boundary Layer Interaction Flows. AIAA J., vo1. 17, no. 8, pp. 811-820. 
Viegas, J. R.; and Horstman, C. C. (1982): The 1980-81 AFSOR/HTTMStanford Conference on Complex Turbulent Flows: Comparison of Computation and Experiment. Vo1. III. Comparison of Computation with Experiment and Computors Summary Reports. S. J. Kline, B. J. Cantwe11, and G. M. Lilley, eds., pp. 1535-1539.

Viegas, J. R.; and Rubesin, M. W. (1983): Wa11 Function Boundary Conditions in the Solution of the Navier-Stokes Equations for Complex Turbulent Flow's. AIAA Paper 83-1694, Danvers, Mass. Visba1, M.; and Knight, D. (1983): Evaluation of the Baldwin-Lomax Turbulence Model for Two-Dimensional Shock-Wave Boundary Layer Interactions. AIAA Paper 83-1697, Danvers, Mass. Viswanath, P. R.; Cleary, J. W.; Seegmiller, H. L.; and Horstman, C. C. (1980): Trailing Edge Flows at High Reynolds Number. AIAA J., vo1. 18, no. 9, pp. 1959-1965.

Viswanath, P. R.; and Brown, J. L. (1982): Separated Trailing-Edge Flow at a Transonic Mach Number. AIAA Paper 82-0348, Orlando, F1a. West, J. E.; and Korkegi, R. H. (1972): Supersonic Interaction in the Corner of Intersecting Wedges and High Reynolds Number. AIAA J., vo1. 10, no. 5, pp. 652-656.

Wilcox, D. C.; and Rubesin, M. W. (1980): Progress in Turbulence Modeling for Complex Flow Fields Including the Effects of Compressibility. NASA TP-1517. 


\section{(a) SHOCK IMPINGEMENT}



(c) TRANSONIC SHOCK INTERACTIONS



(b) CONTROL SURFACES

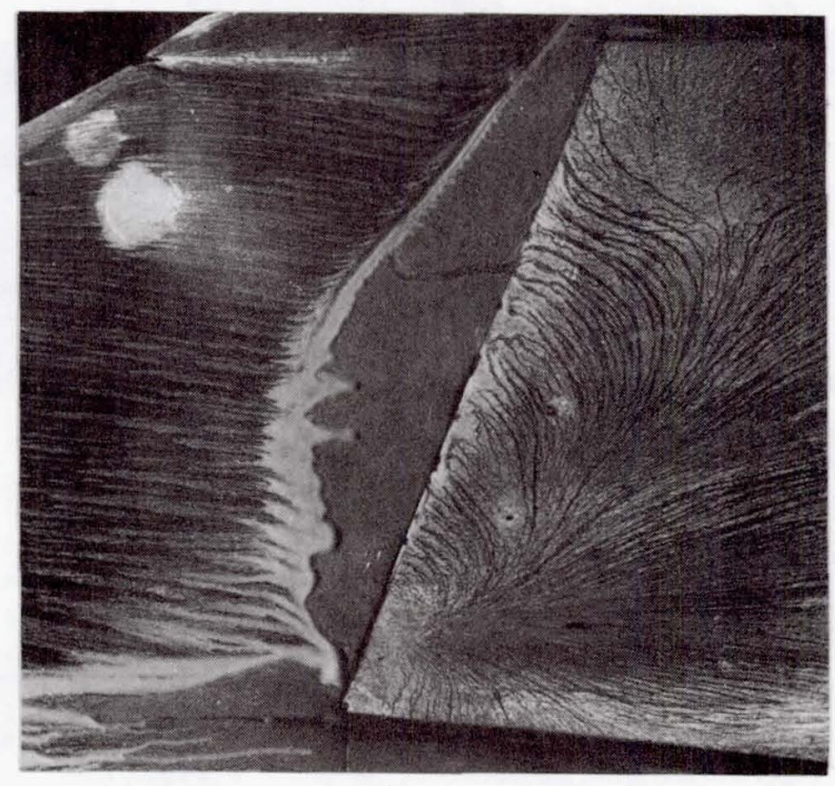

(d) LEESIDE FLOWS

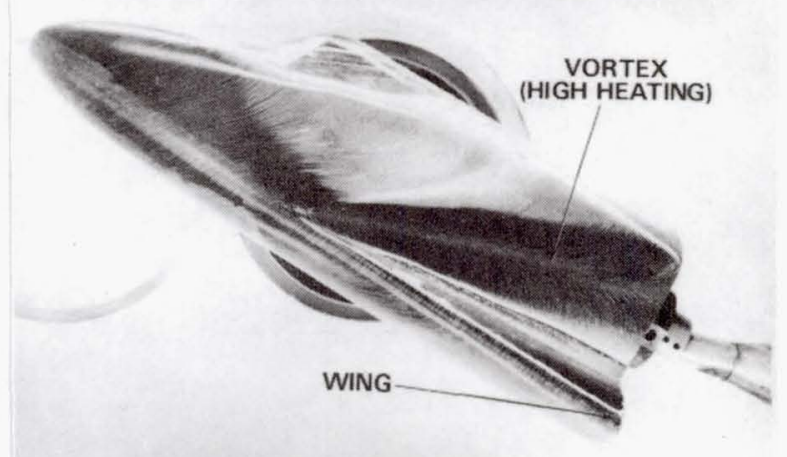

Figure 1.- Photographs showing aerodynamic flows with separation:

(a) Shock impingements; (b) Deflected control surfaces; (c) Transonic airfoils; (d) Leeside flows. 


\section{INVISCID INTERACTION}

I.S.

R.S.
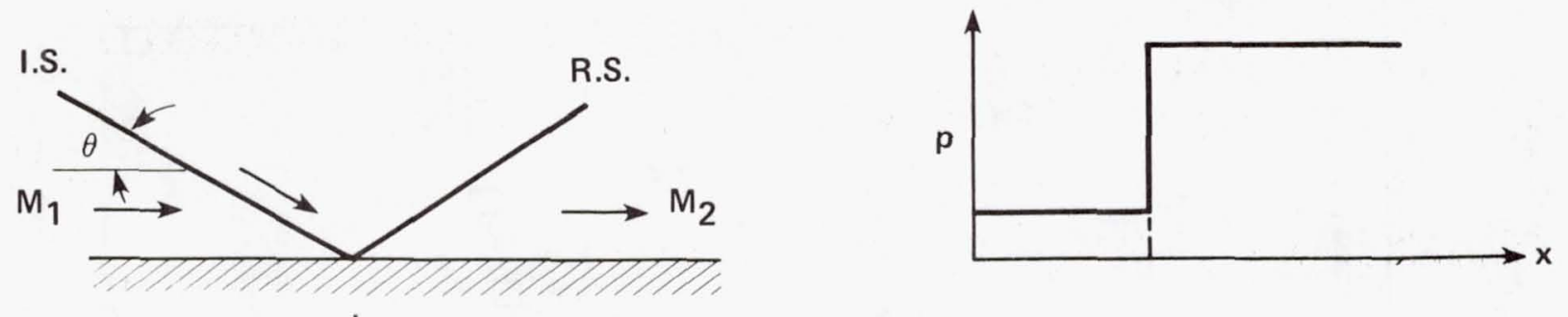

WEAK INTERACTION
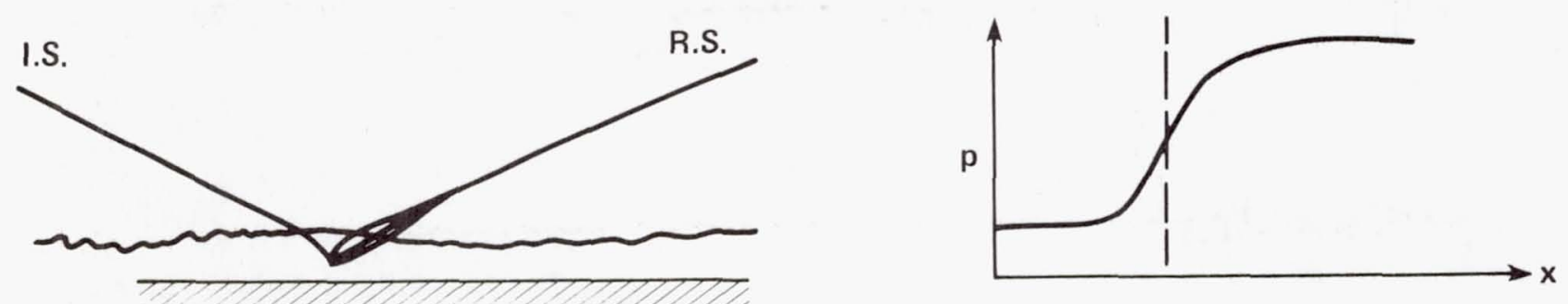

I

\section{STRONG INTERACTION}
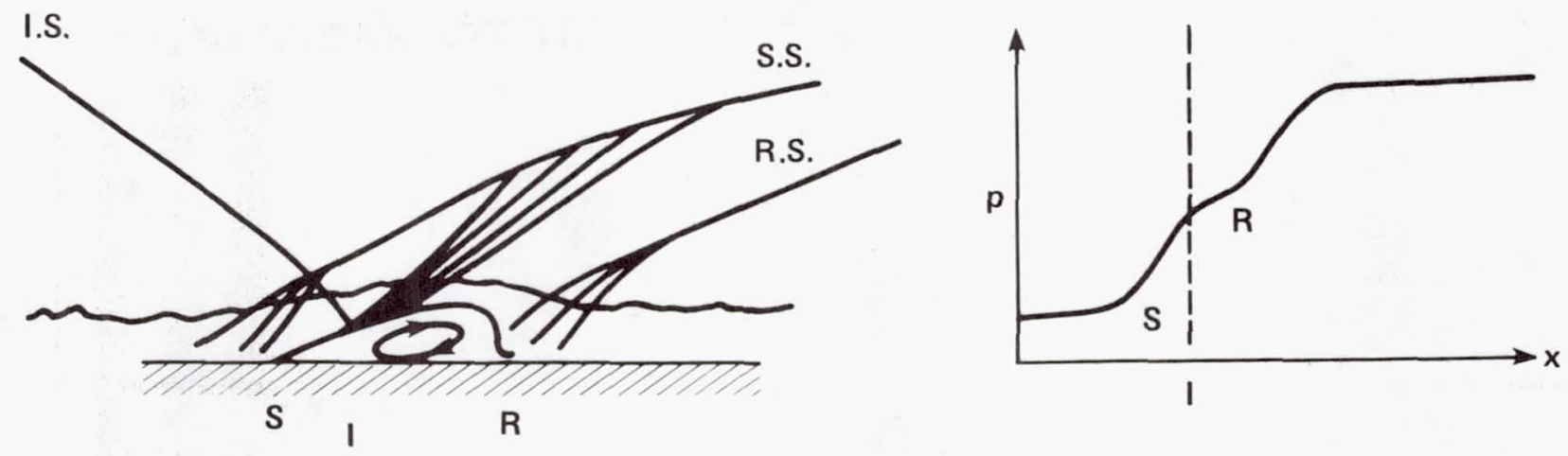

Figure 2.- Physical characteristics of 2-dimensional oblique shock-wave interactions. 

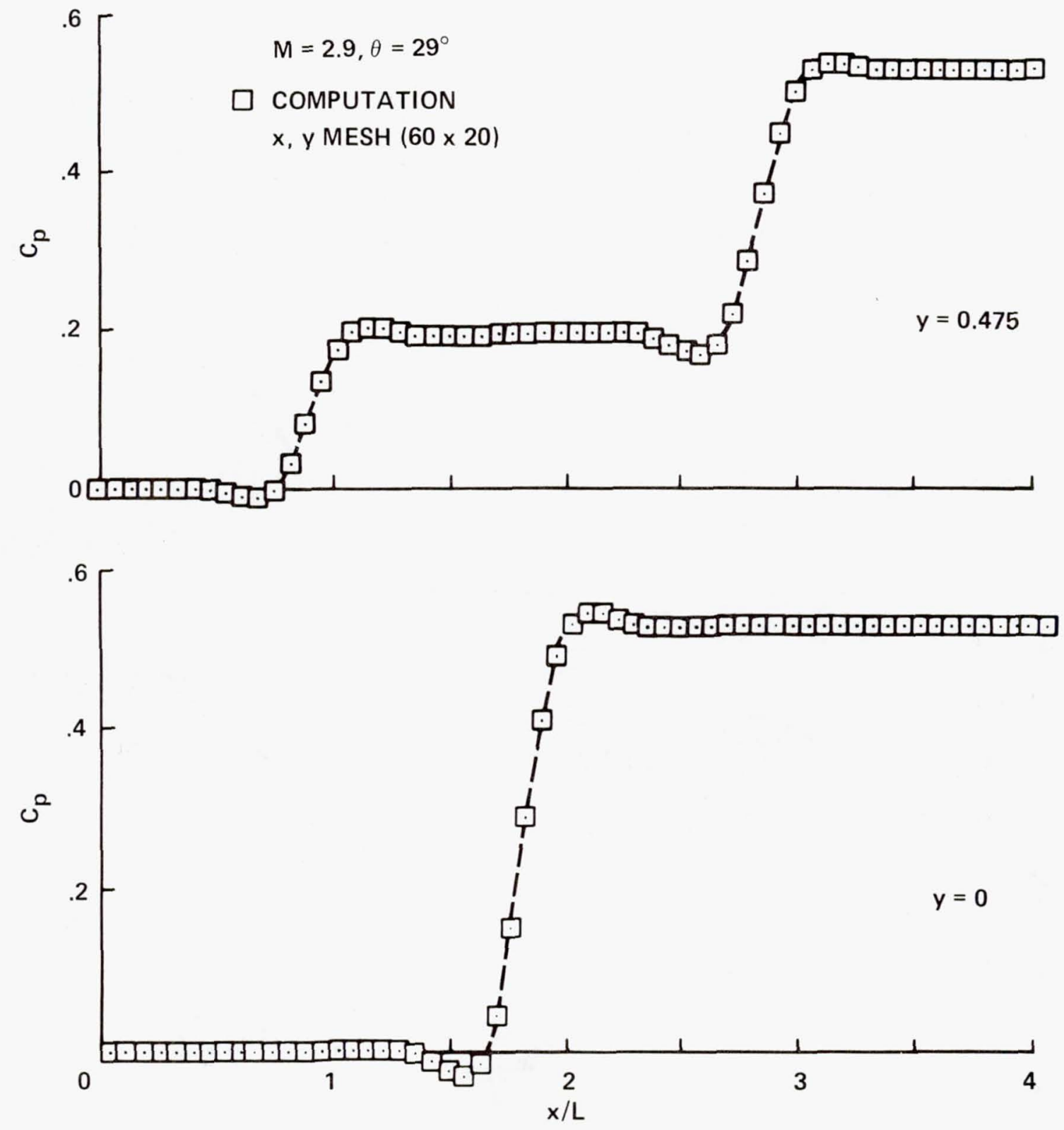

Figure 3.- Modeling of an inviscid oblique shock-wave interaction. 




Figure 4.- Modeling of a strong oblique shock-wave interaction:

(a) Experimental isobars; (b) Computation using a 0-eq. turbulence model; (c) Computation using a turbulence model modified by experimental information. 

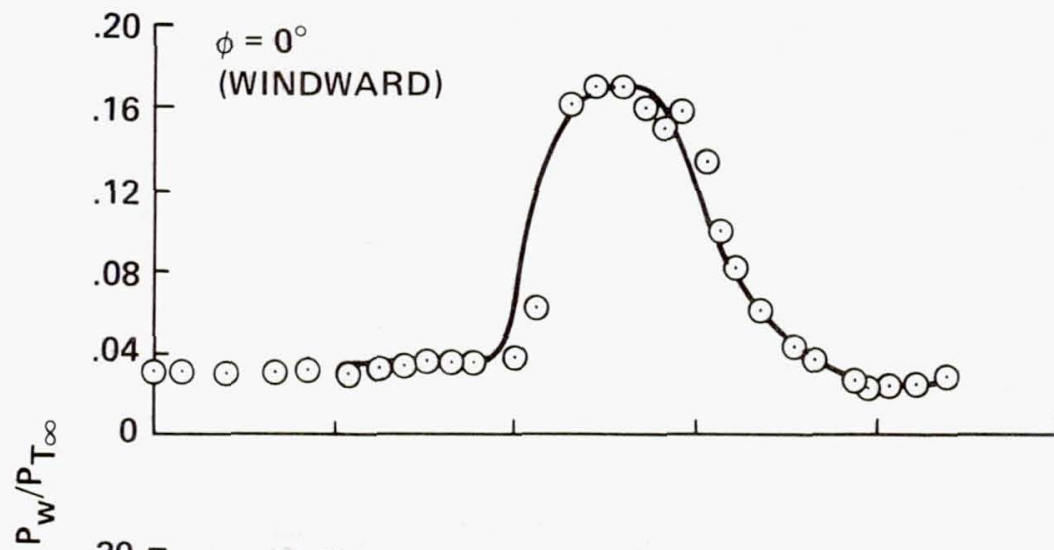

$M_{\infty}=3$

$\operatorname{Re}_{\mathrm{L}}=18 \times 10^{6}$

$\frac{1}{a^{3}}$
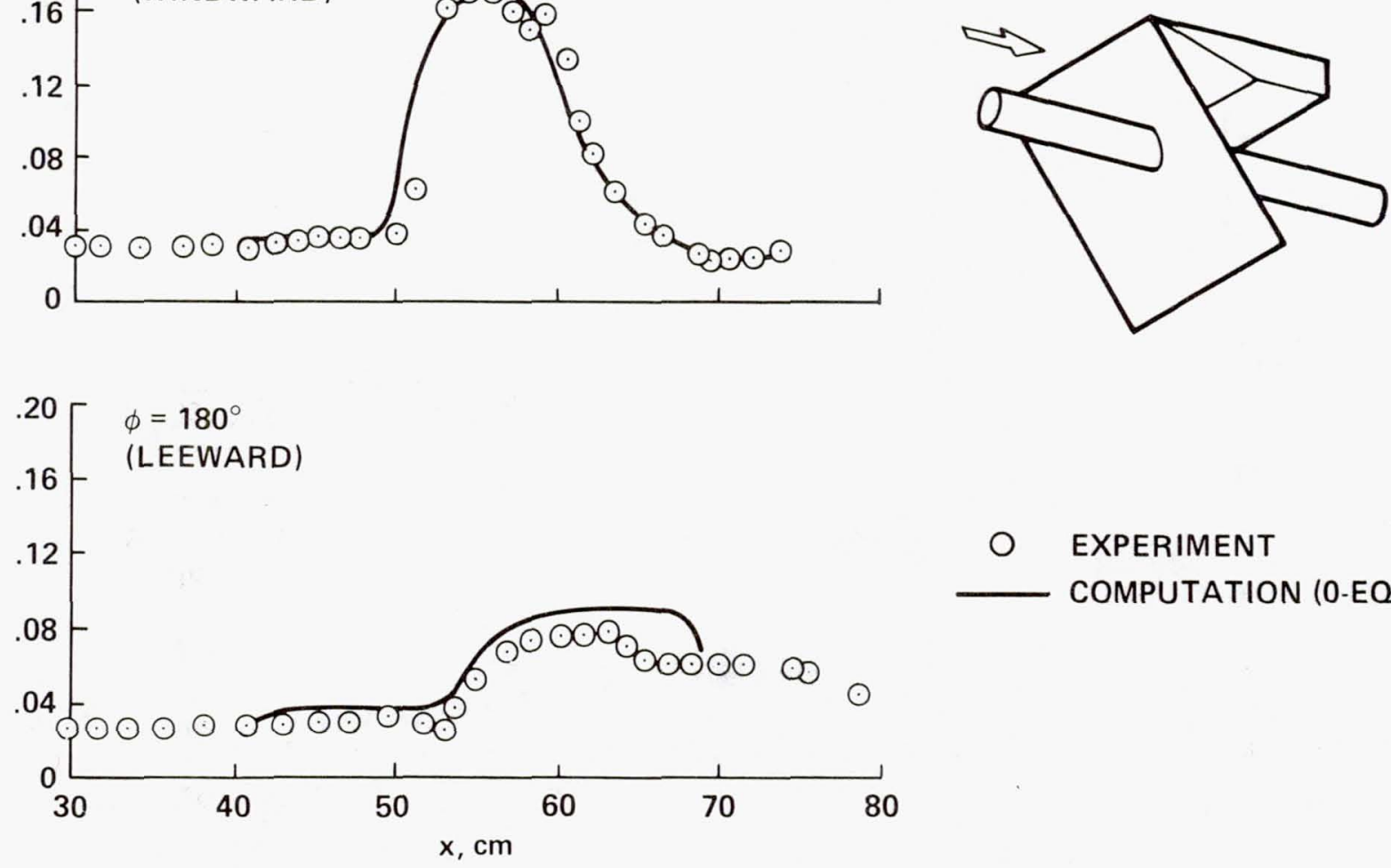

\section{O EXPERIMENT} COMPUTATION (0-EQ.)

Figure 5.- Modeling of a plane strong oblique shock-wave interacting with a flow-aligned cylinder: Surface pressures on windward and leeward planes. 


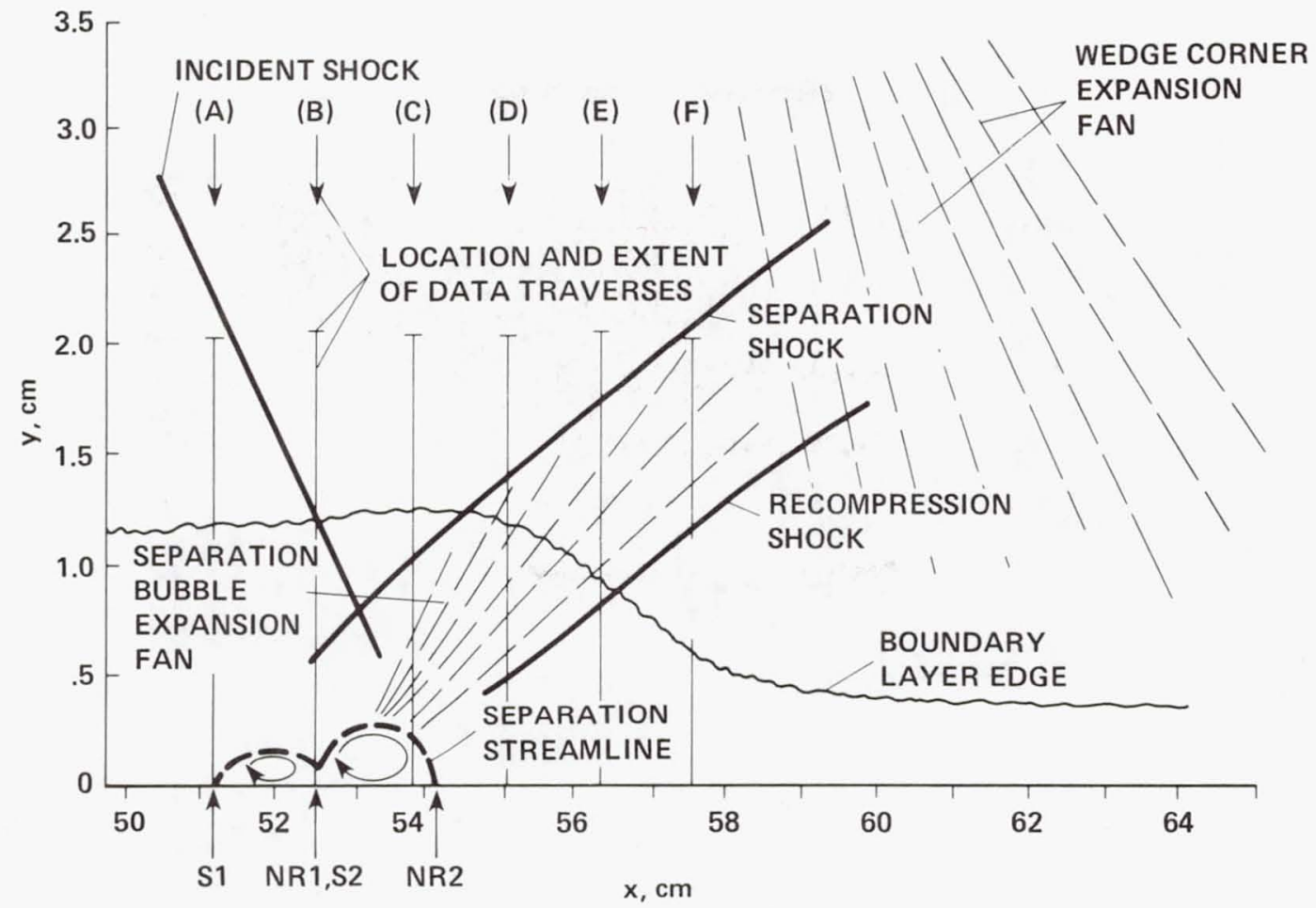

(a) FLOW FIELD INTERPRETATION

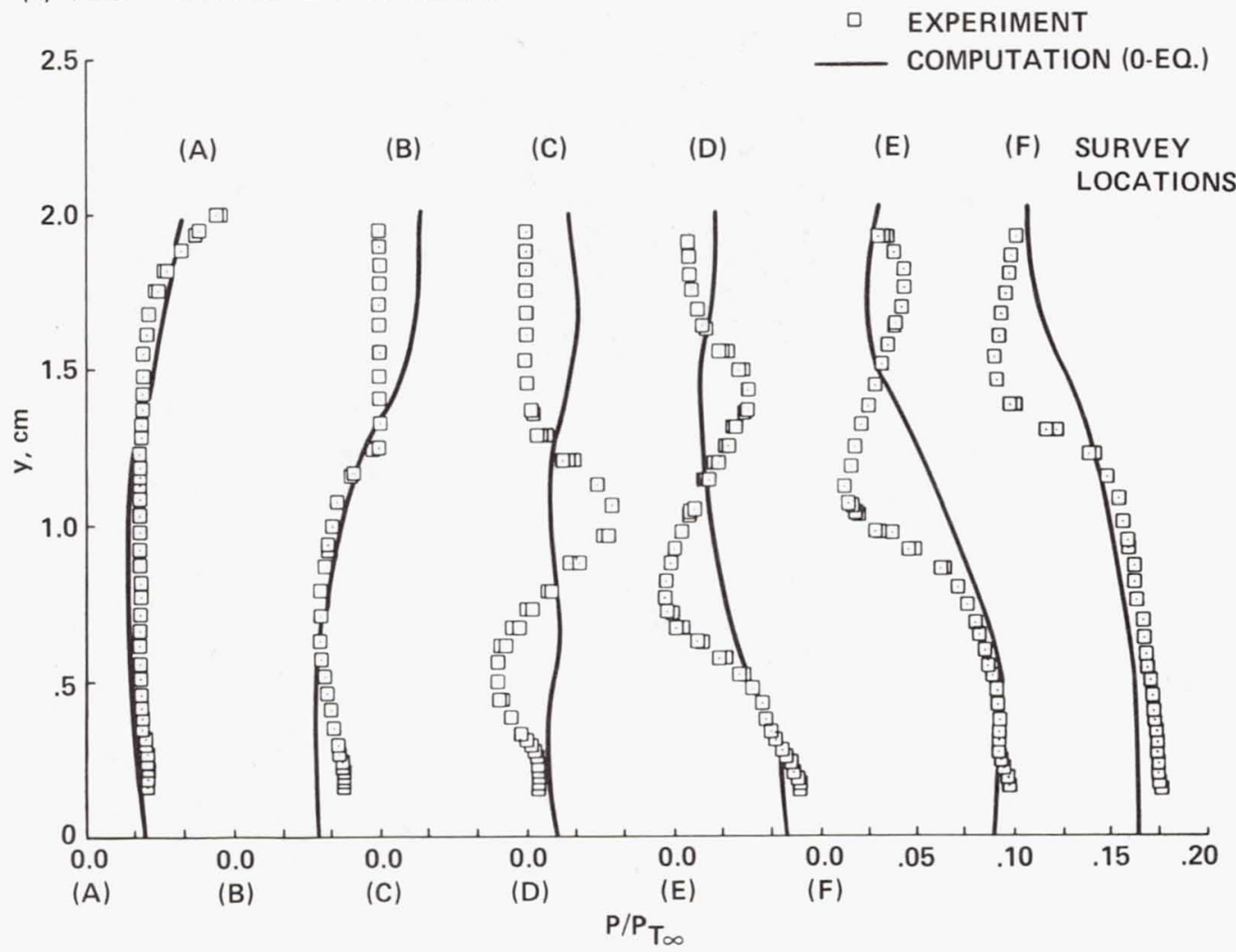

(b) STATIC PRESSURE SURVEY

Figure 6.- Modeling of a plane strong oblique shock-wave interacting with a flow-aligned cylinder: (a) Windward symmetry-plane flow field interpretation from experiment; (b) Comparison of experimental and computational static pressure surveys in the windward symmetry-plane. 


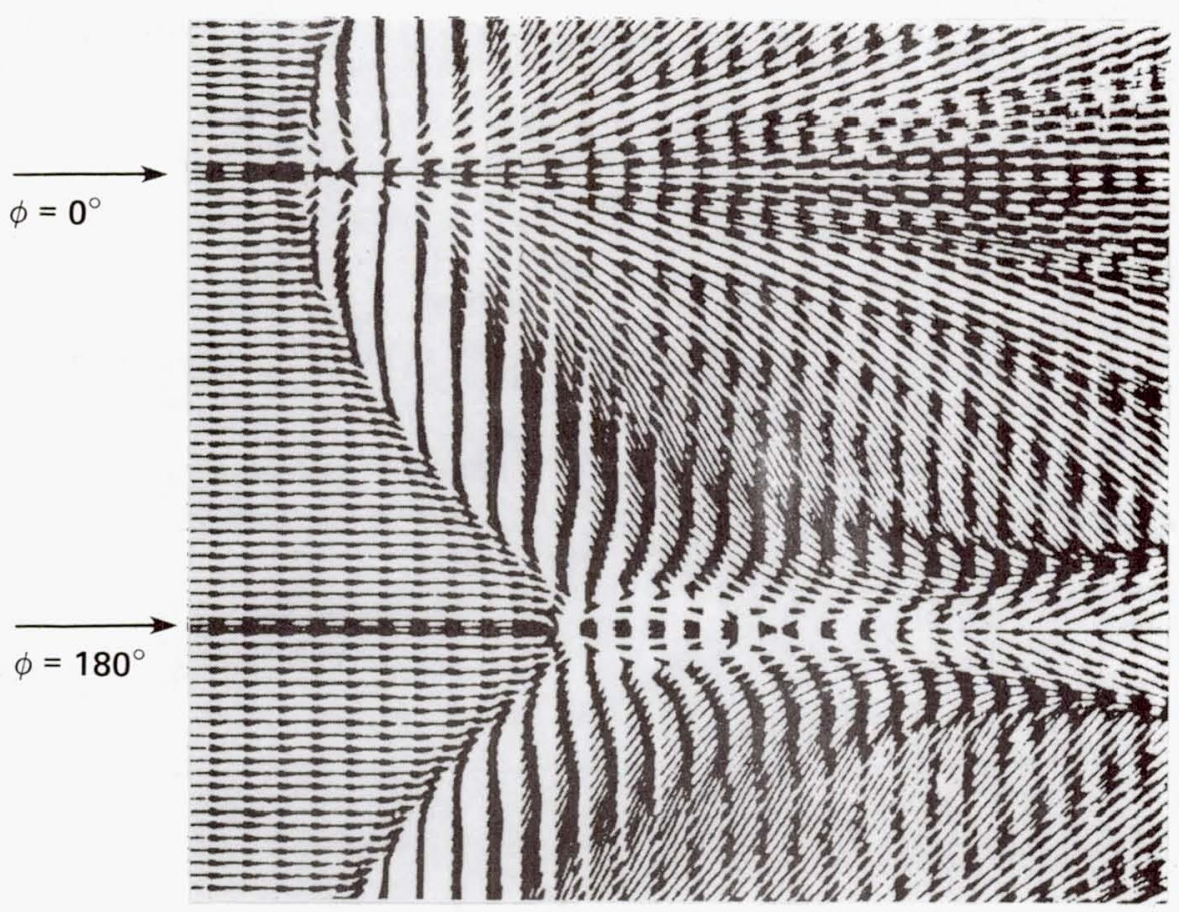

(a) COMPUTATION

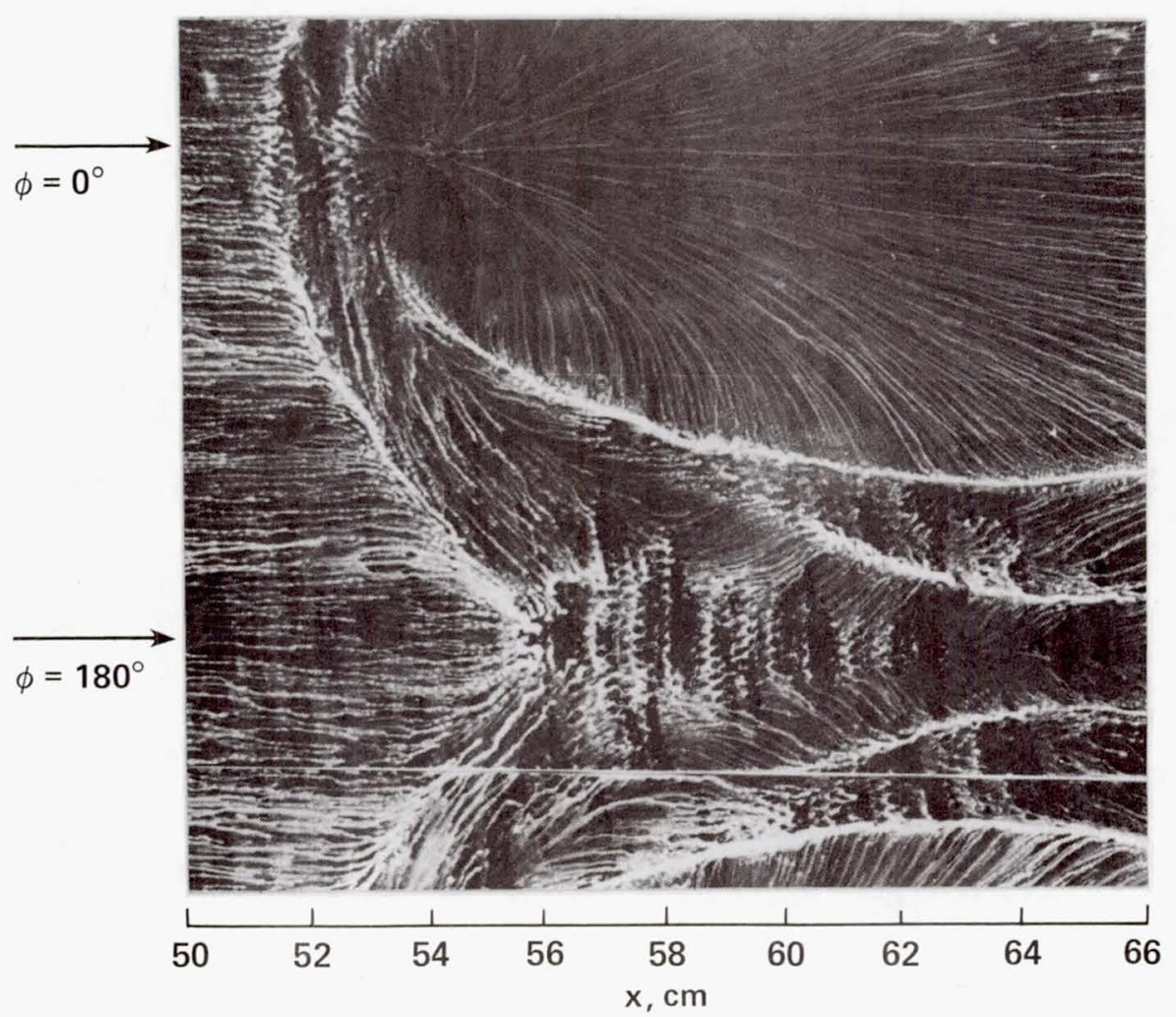

(b) EXPERIMENT

Figure 7.- Modeling of a plane strong oblique shock-wave interacting with a flow-aligned cylinder: Comparison of experimental and computational skin friction lines. 
INVISCID
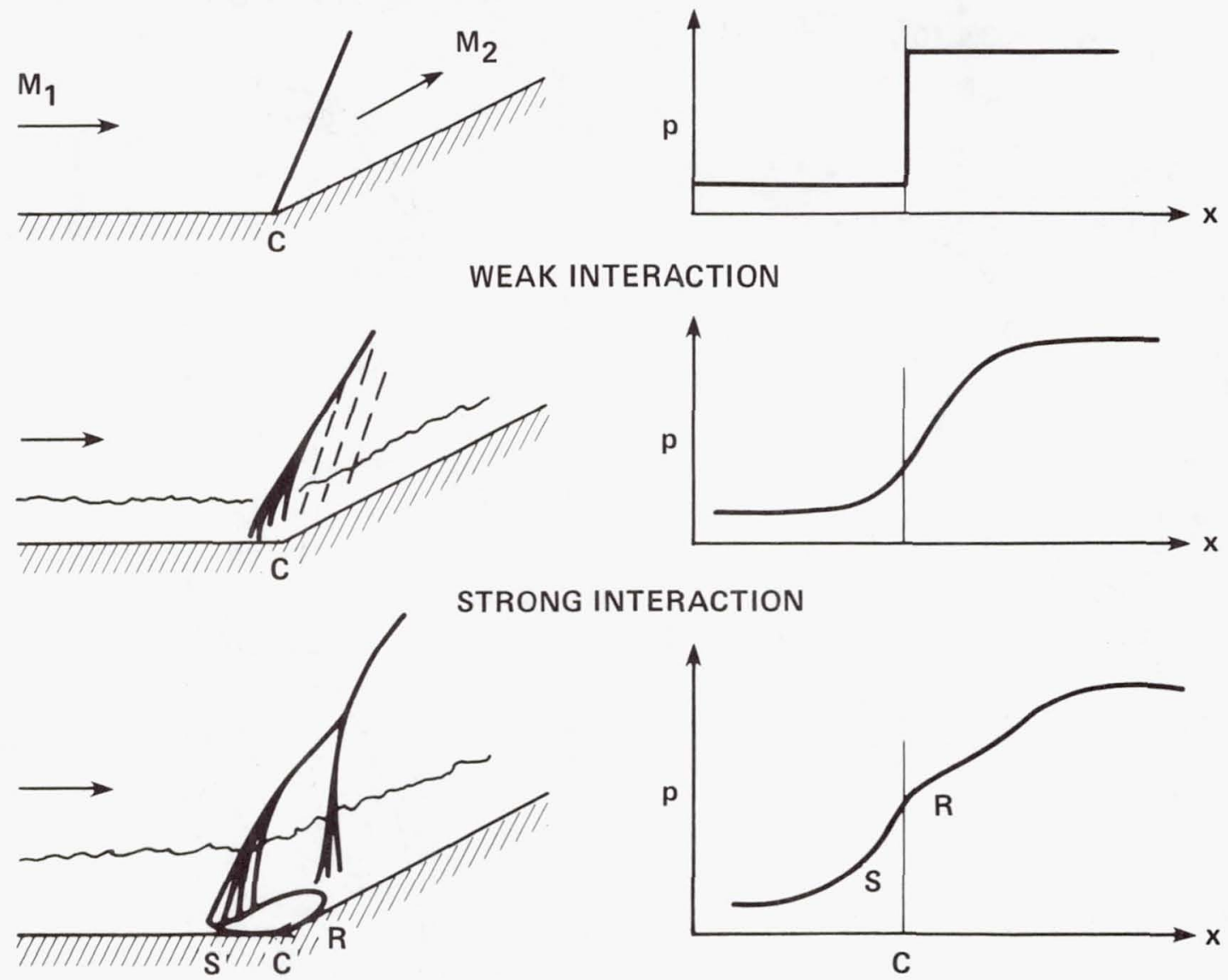

Figure 8.- Physical characteristics of 2-dimensional compression-corner interactions. 



STRONG INTERACTION


Figure 9.- Modeling of a compression-corner interaction using different algorithms and different turbulence models: (a) Pressure distributions; (b) Skin friction distributions. 


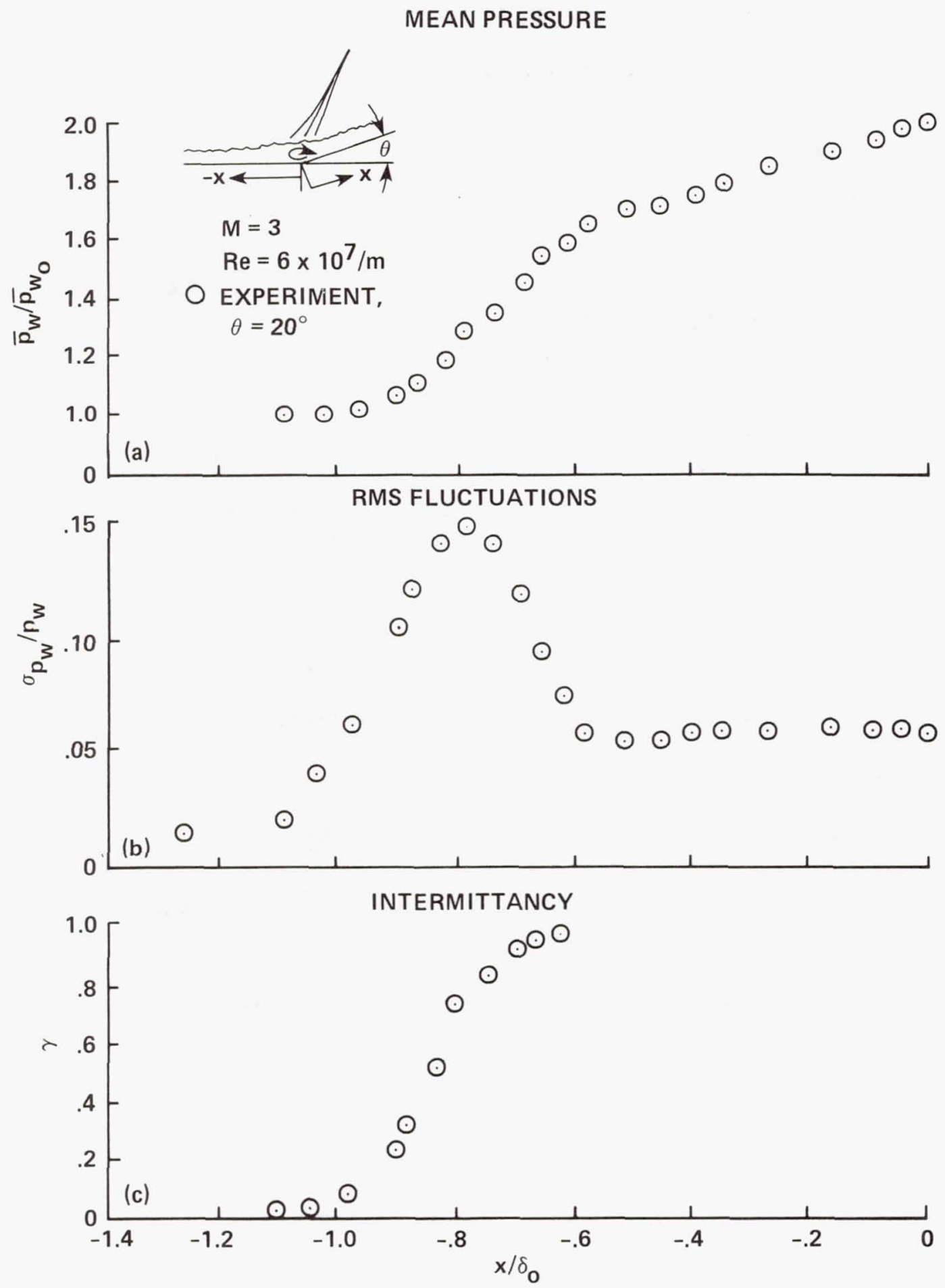

Figure 10.- Effects of unsteadiness on the physical structure of a compression-corner interaction: (a) Mean surface pressure; (b) rms of fluctuating pressure; (c) Intermittency relative to undisturbed flow. 


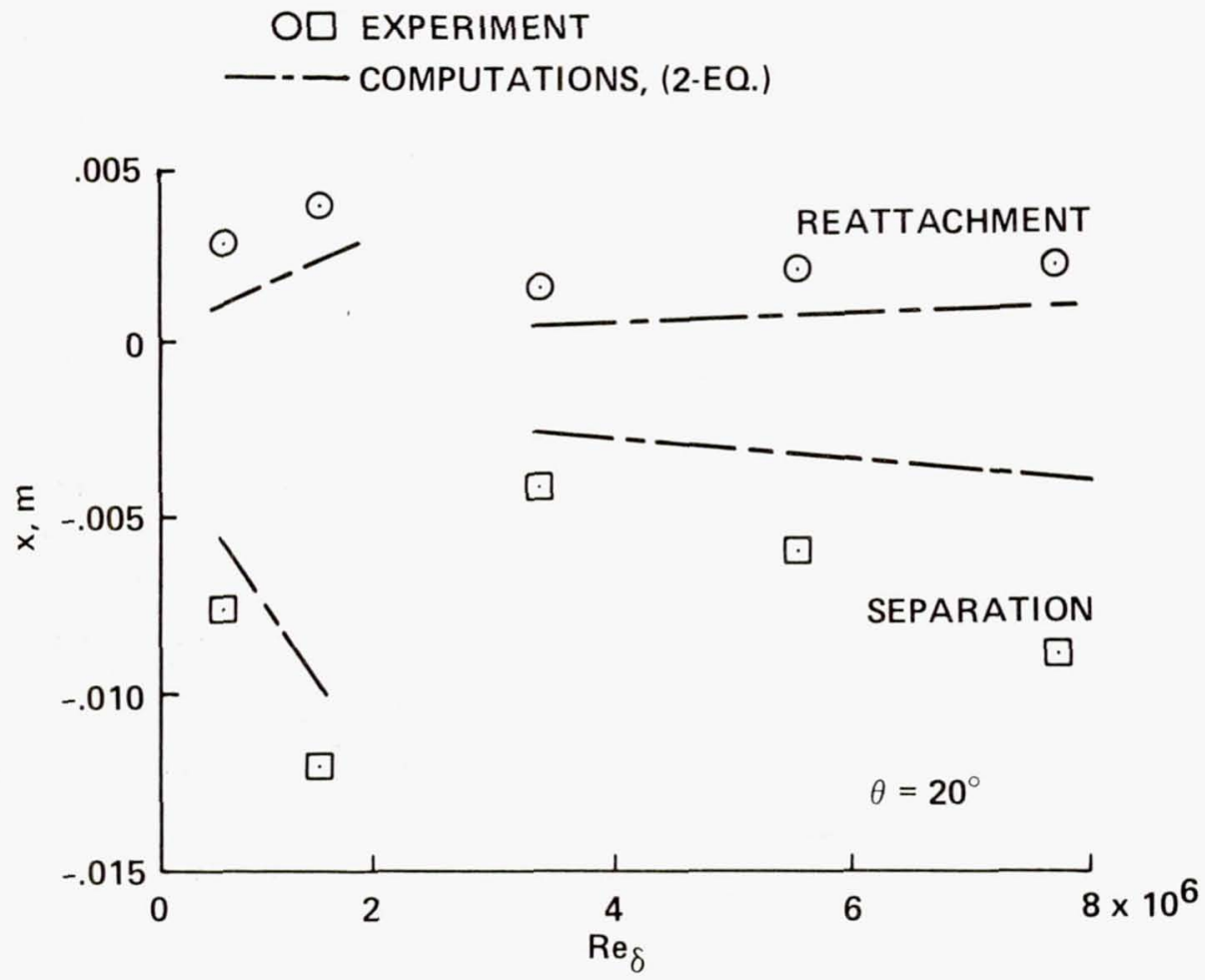

Figure 11.- Modeling of separation and reattachment points for a compression corner. 
(a) SHARP LEADING EDGE

(b) BLUNT LEADING EDGE
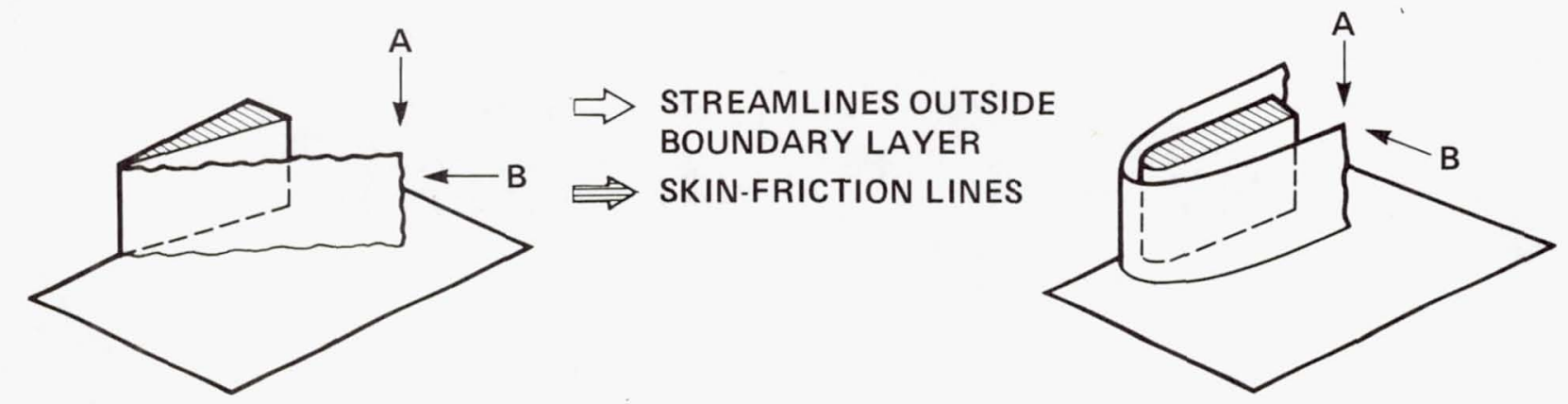



VIEW ALONG A

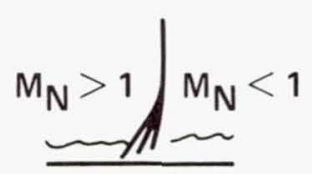

VIEW ALONG B


Figure 12.- Physical characteristics of glancing shock-wave interactions:
(a) Sharp leading edge;
(b) Blunt leading edge. 

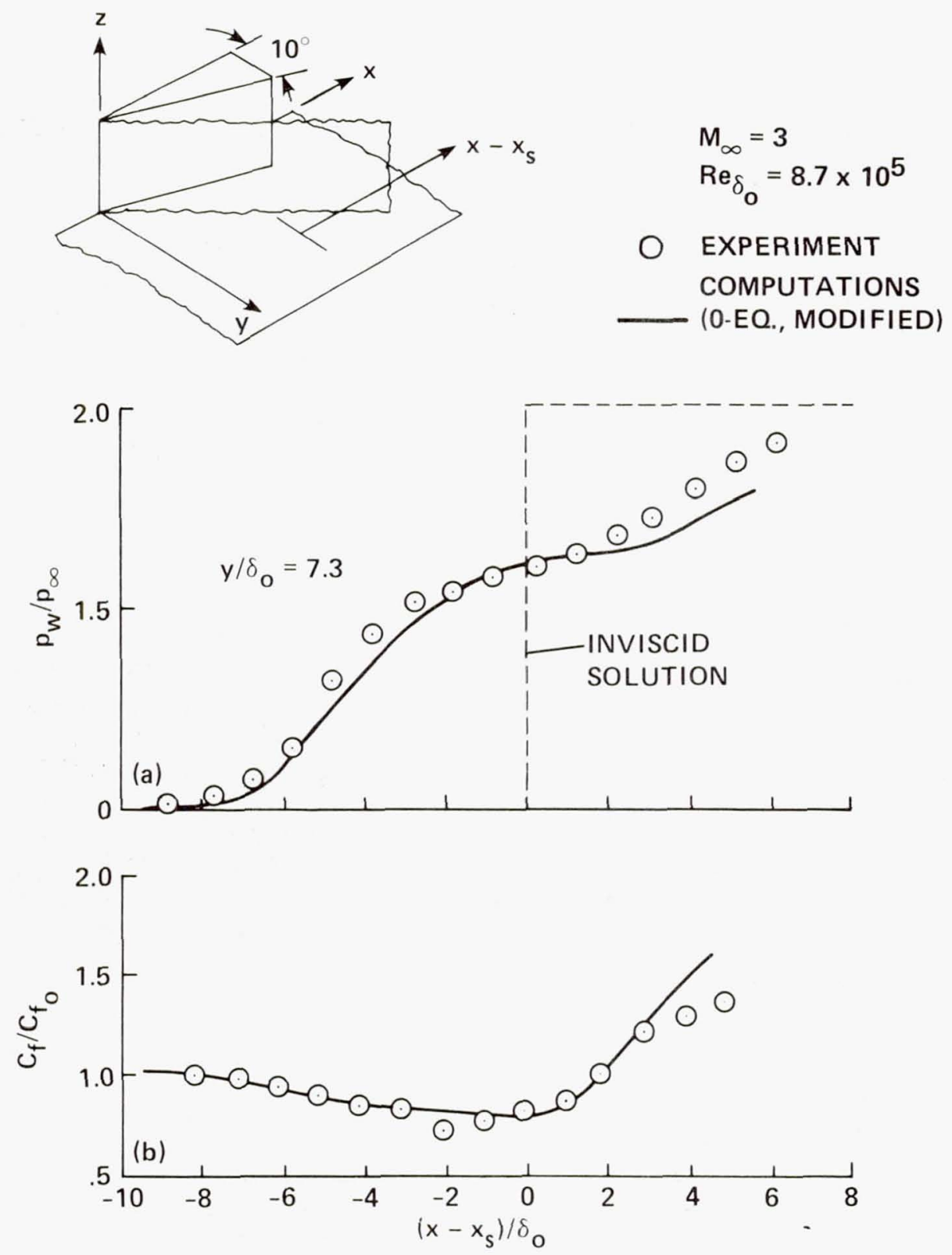

Figure 13.- Modeling of a glancing shock-wave interaction from a sharp leading-edge wedge: (a) Pressures along streamwise direction; (b) Skin friction along streamwise direction. 

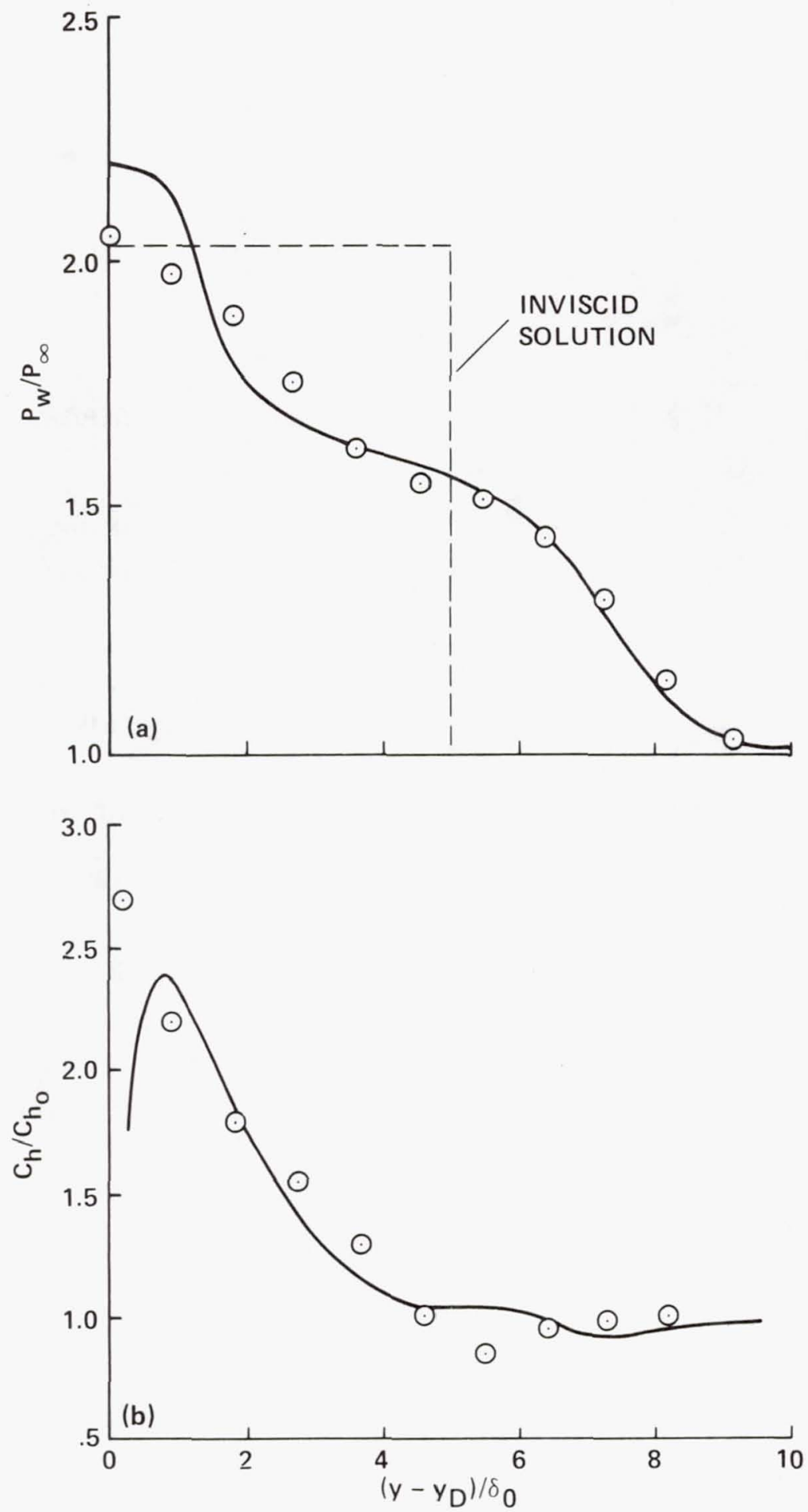

Figure 14.- Modeling of a glancing shock-wave interaction from a sharp leading-edge wedge: (a) Pressures along transverse direction;

(b) Skin friction along transverse direction. 


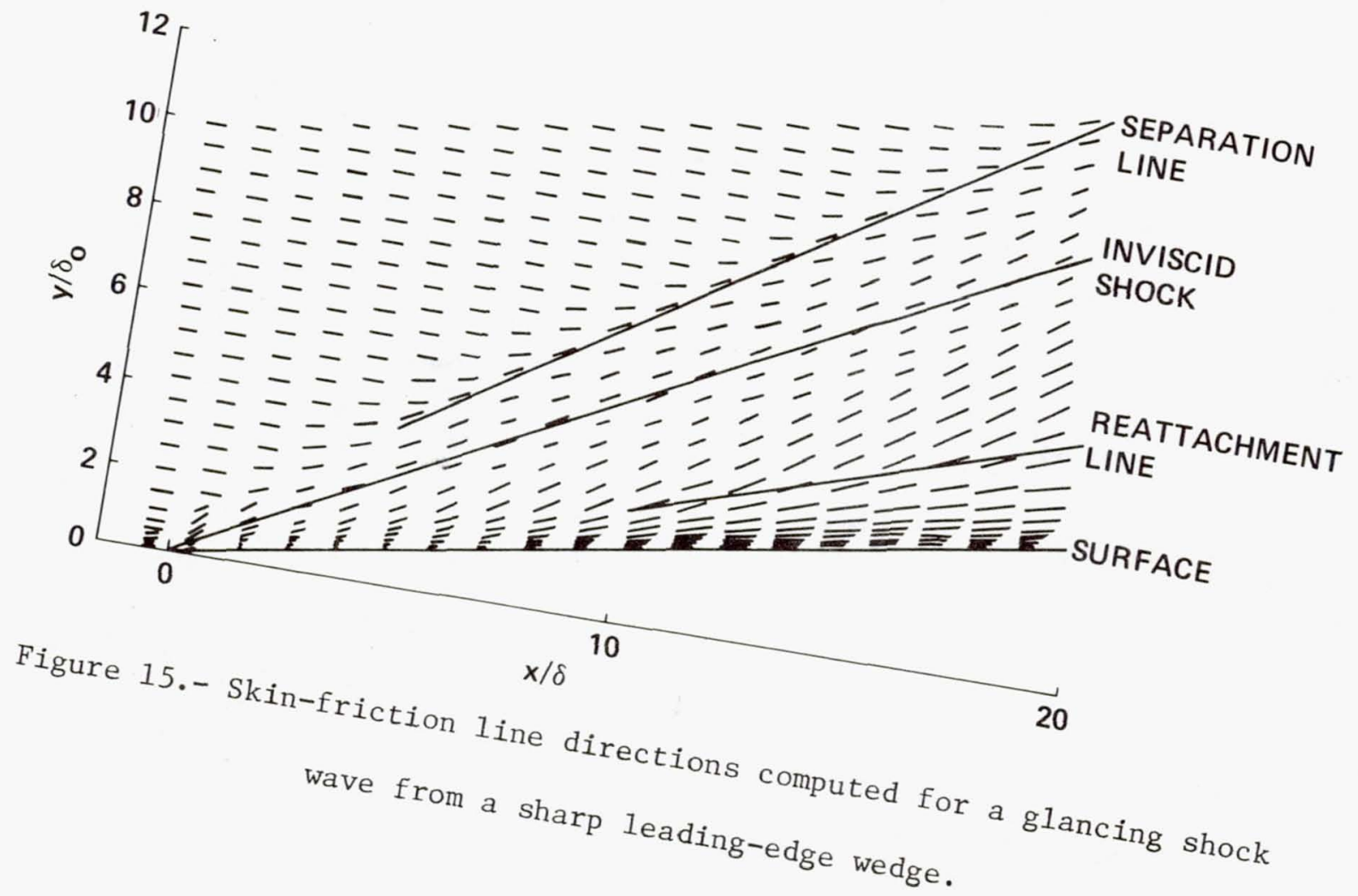



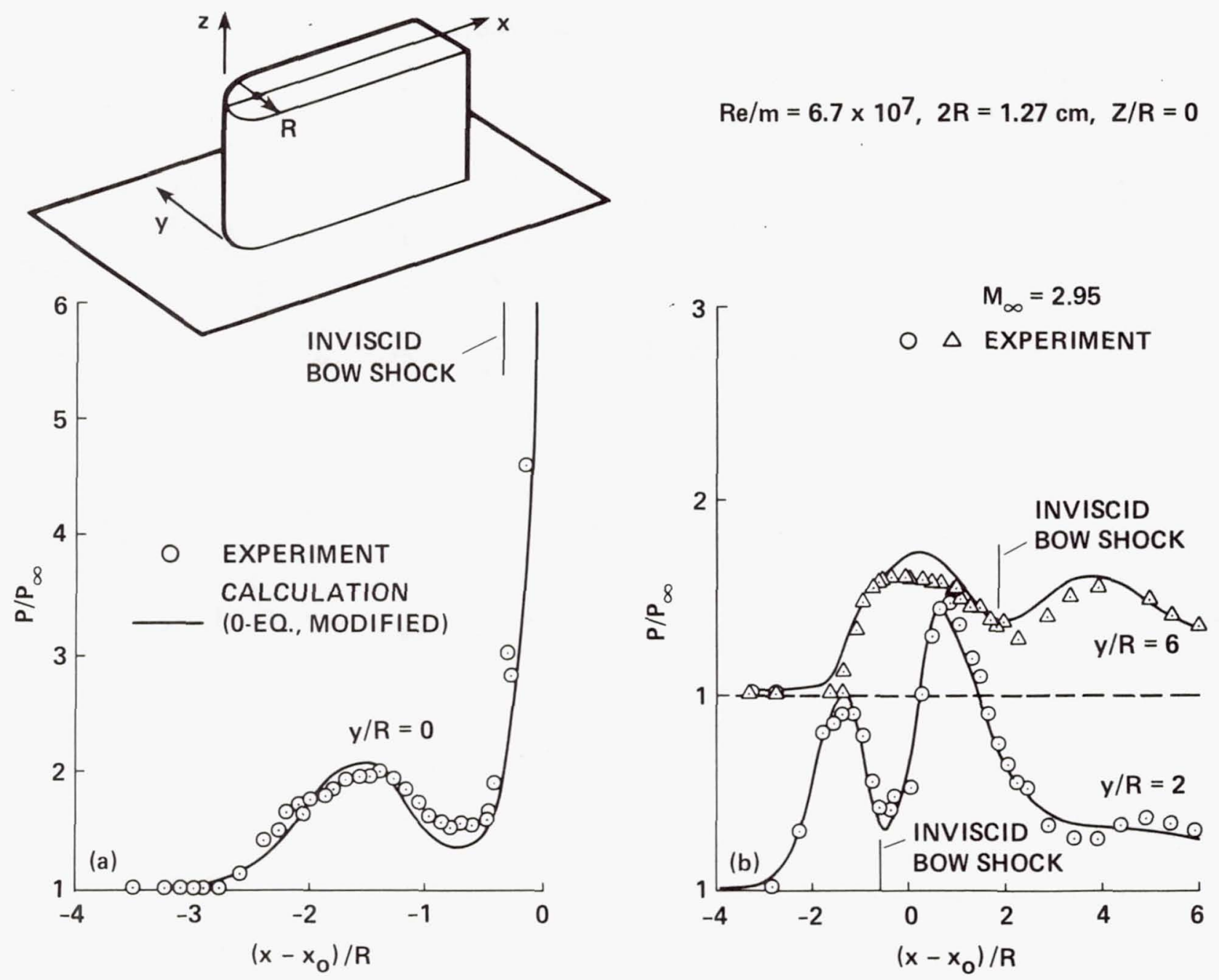

Figure 16.- Modeling of a glancing shock-wave interaction from a bluntplate generator: (a) Pressures on the flat plate in the plane of symmetry; (b) Pressures on the flat plate off the plane of symmetry. 

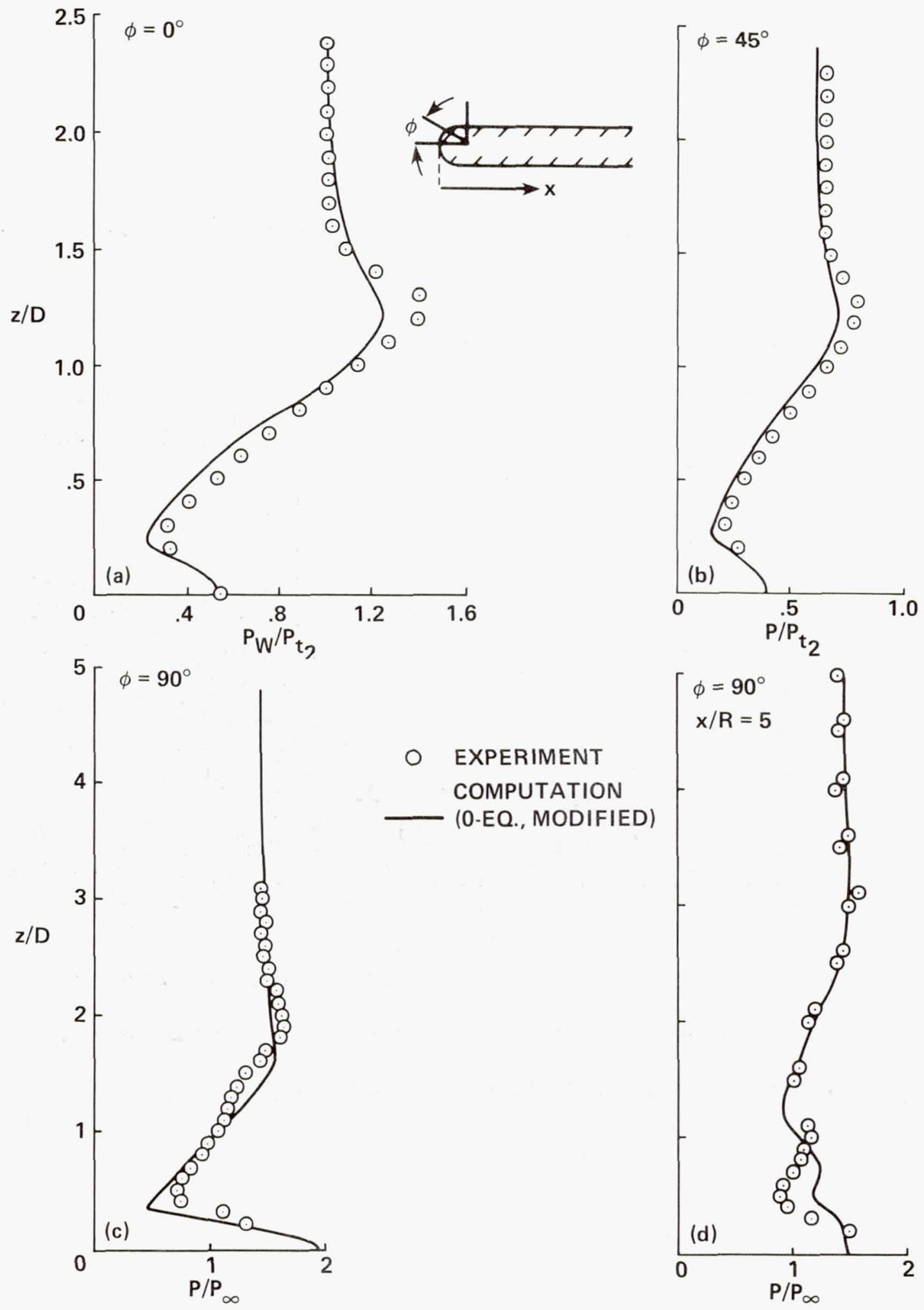

Figure 17.- Modeling of a glancing shock-wave interaction from a bluntplate generator: (a) Pressures on the blunt-plate generator, $\phi=0^{\circ}$; (b) $\phi=45^{\circ}$; (c) $\phi=90^{\circ} ;$ (d) $\phi=90^{\circ}, \mathrm{X} / \mathrm{D}=2.5$. 




$(x) / 2 R$

Figure 18.- Particle paths that depict streamlines in the plane of symmetry ahead of the generator from computations of a glancing shockwave interaction from a blunt-plate generator. 
(a) WEAK SHOCK

SCHLIEREN

$M=1.3$

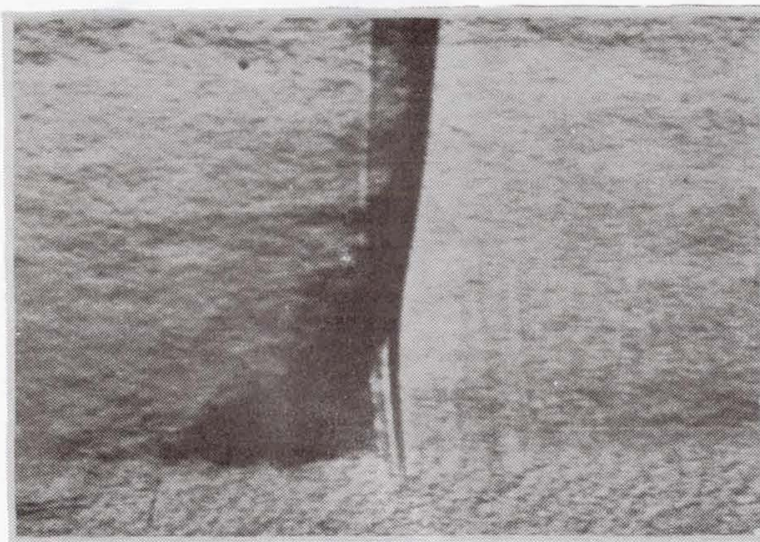

MACH CONTOUR

ă



(b) MODERATE STRONG SHOCK

SCHLIEREN

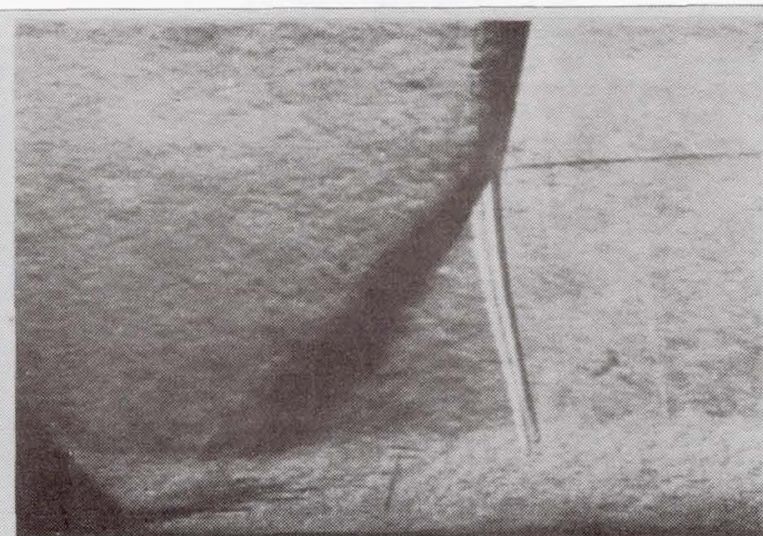

$M=1.4$

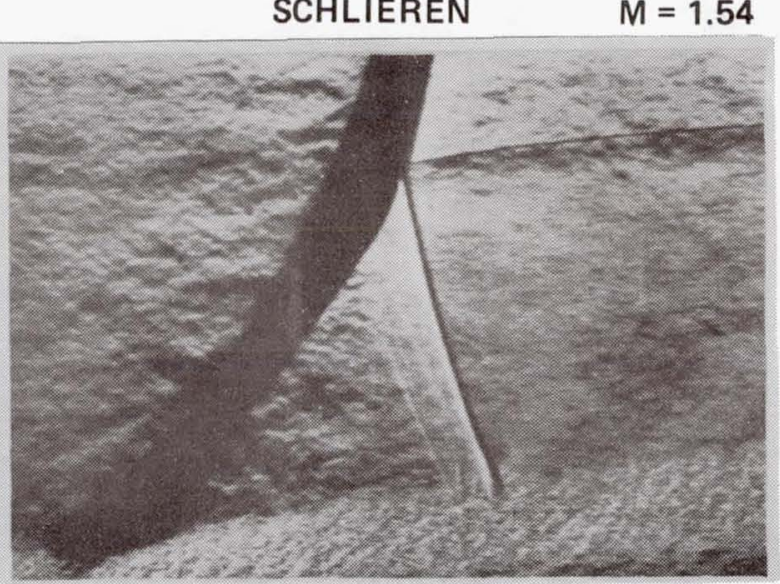

MACH CONTOUR

(LASER VELOCIMETER)

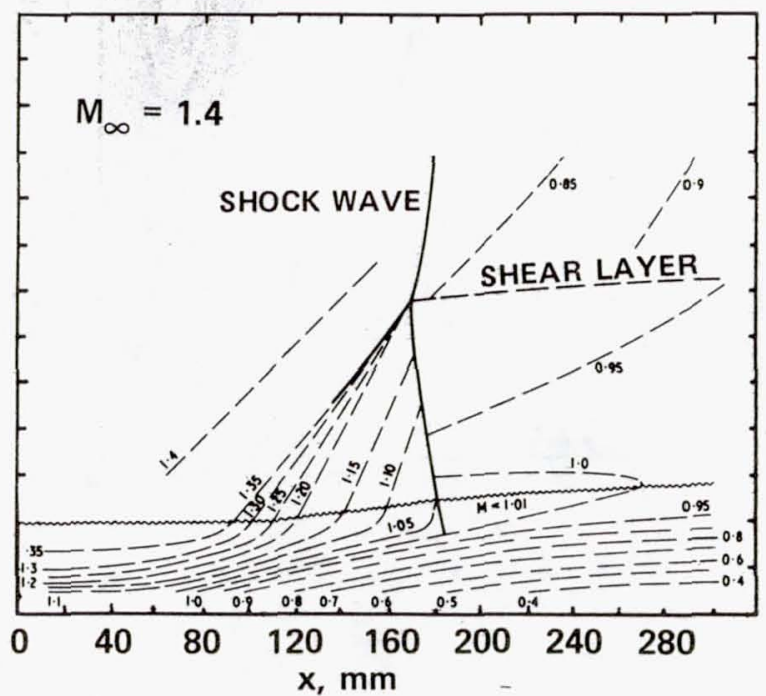

$\mathrm{x}, \mathrm{mm}$
MACH CONTOUR

(LASER VELOCIMETER)

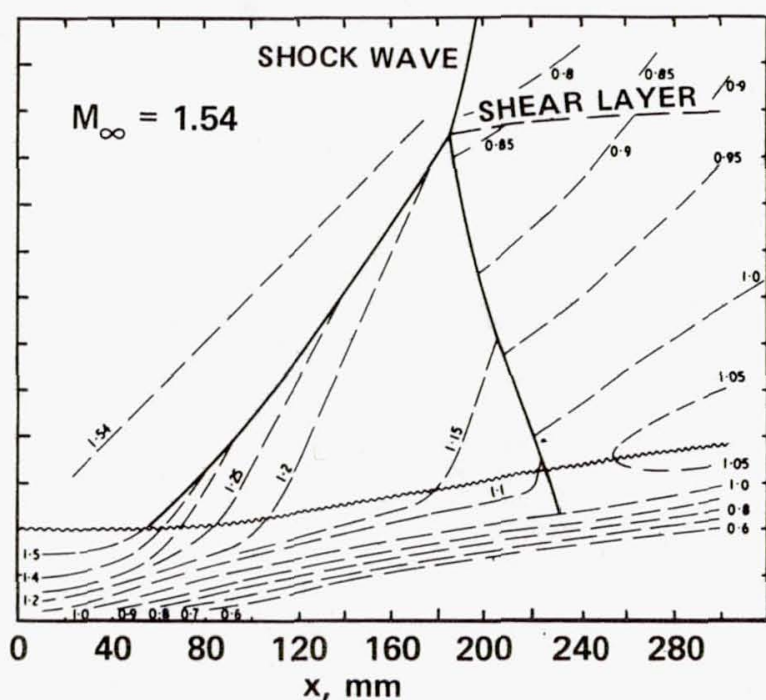

(a) Weak shock; (b) Moderately

Figure 19.- Physical characteristics of normal shock-wave interactions: strong shock; (c) Strong shock. 



Figure 20.- Modeling of a moderately strong normal-shock wave interaction for various Mach and Reynolds numbers: (a) Surface pressures; (b) Displacement thicknesses; (c) Momentum thicknesses. 

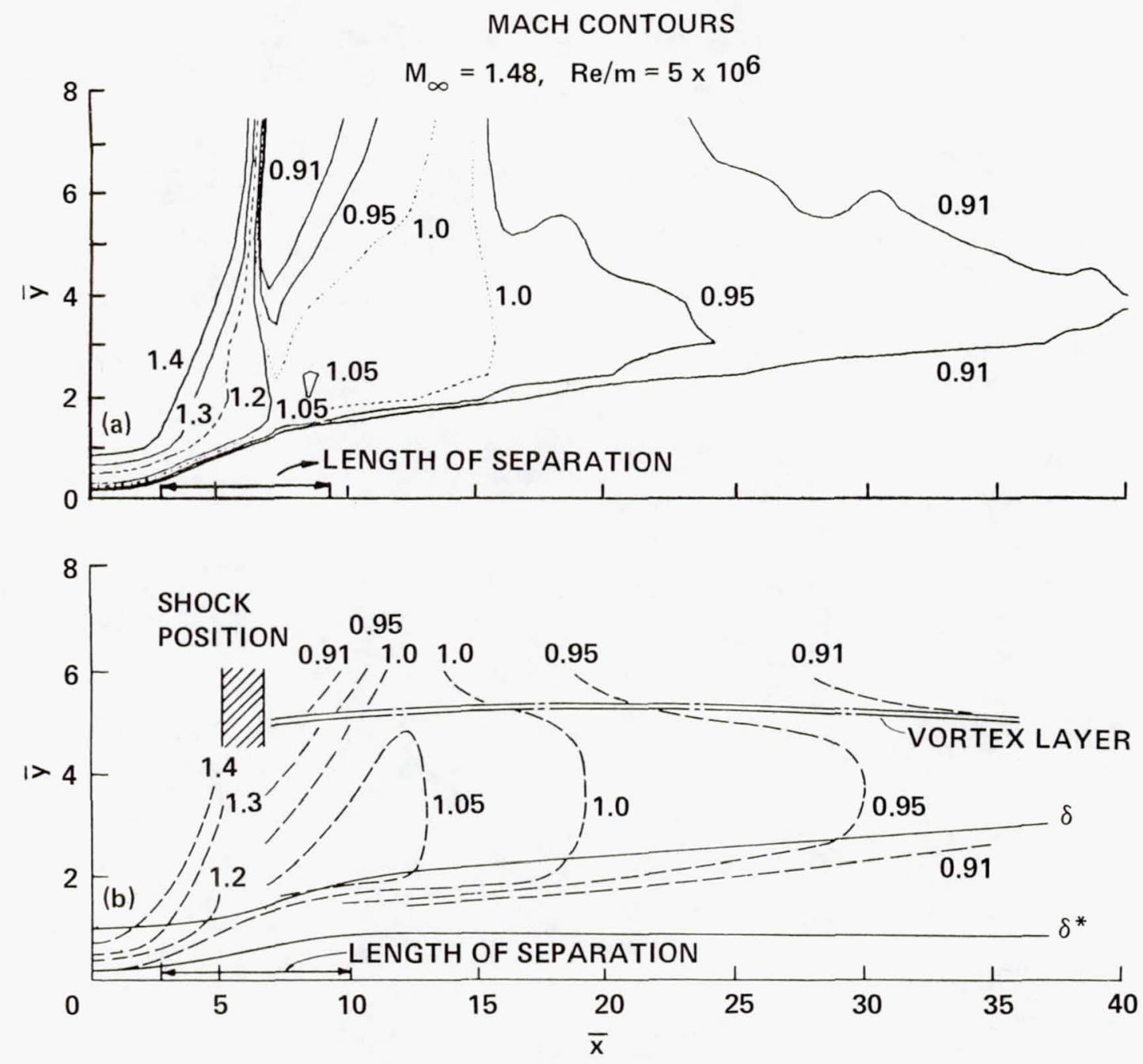

Figure 21.- Modeling of a moderately strong normal shock-wave interaction: (a) Mach contours from the computation; (b) Mach contours from the experiment. 

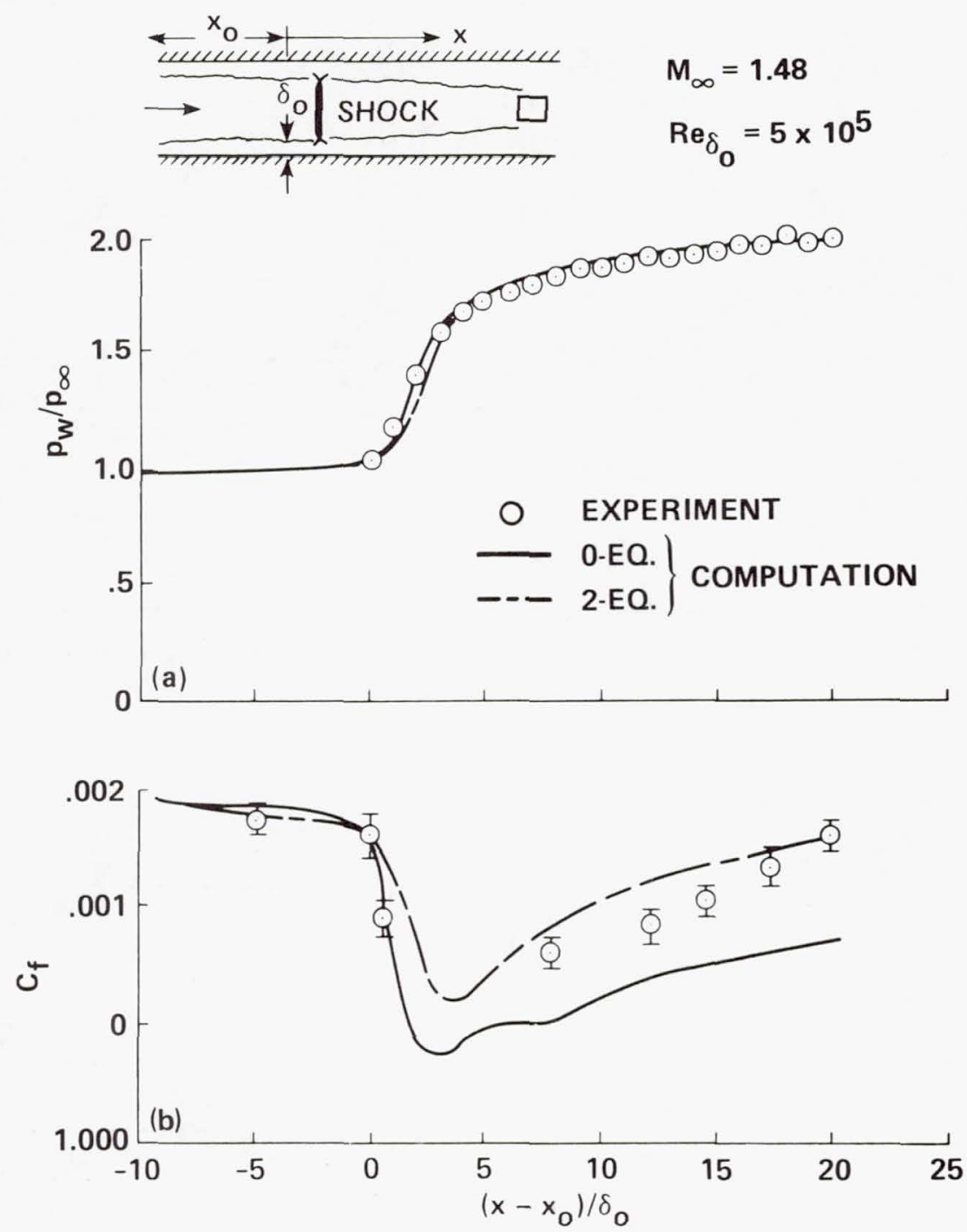

Figure 22.- Effect of turbulence modeling on moderately strong normal shock-wave interactions: (a) Surface pressure; (b) Skin friction. 

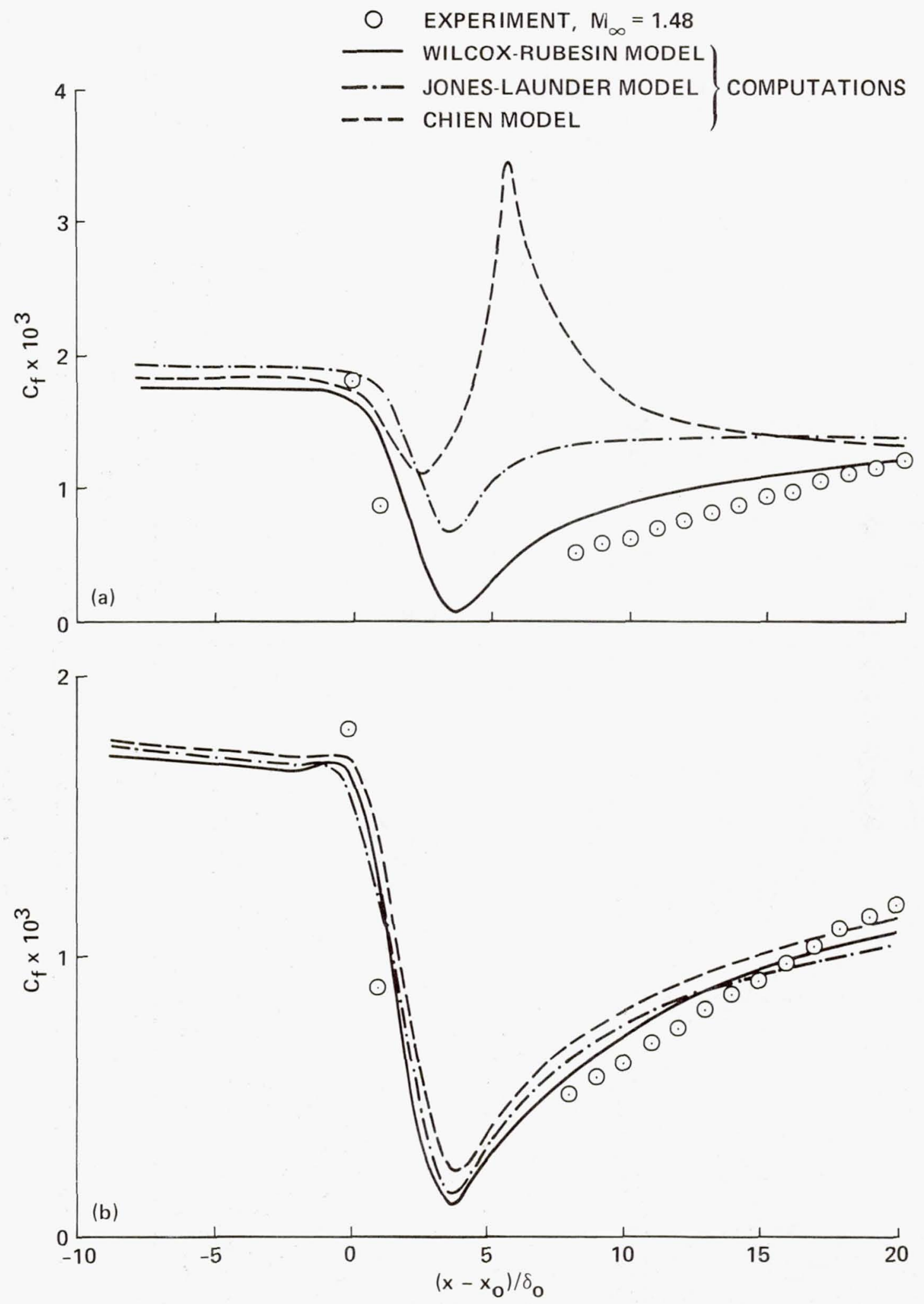

Figure 23.- Effects of low-Reynolds-number-term treatment in 2-eq. models used to predict moderately strong normal shock-wave interactions:

(a) Integration to the wal1; (b) Wall-function treatment. 
EXPERIMENT

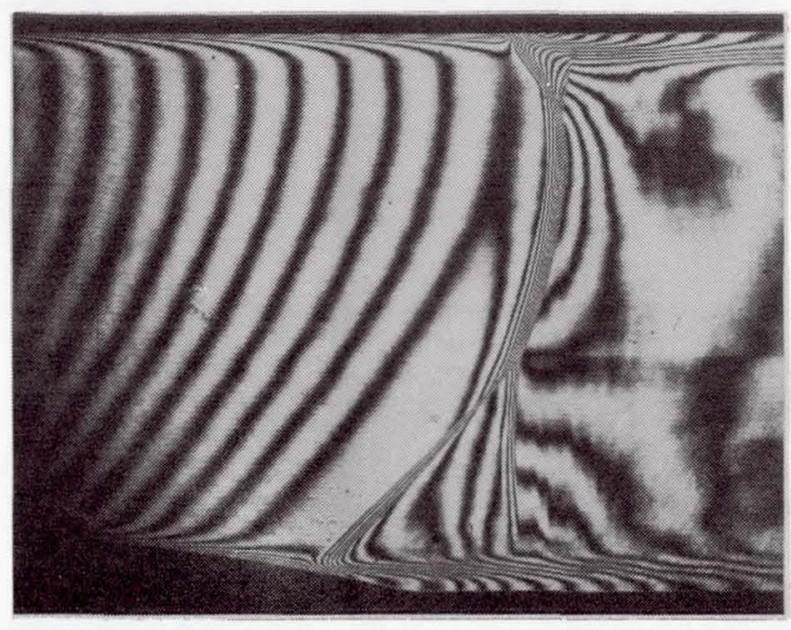

$\stackrel{\infty}{\mapsto}$



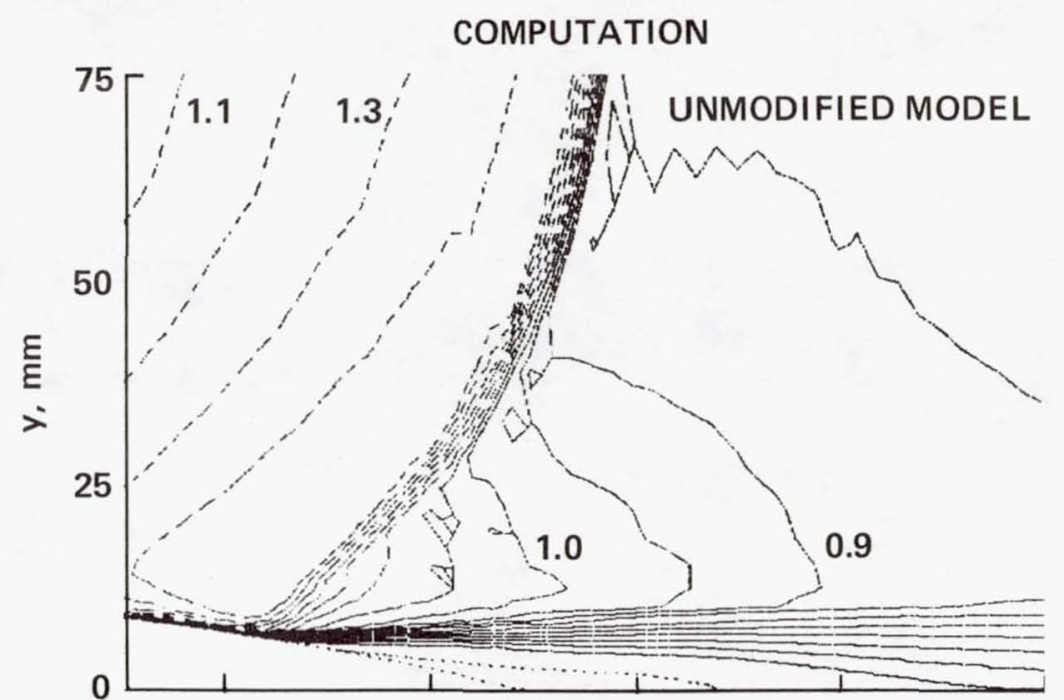

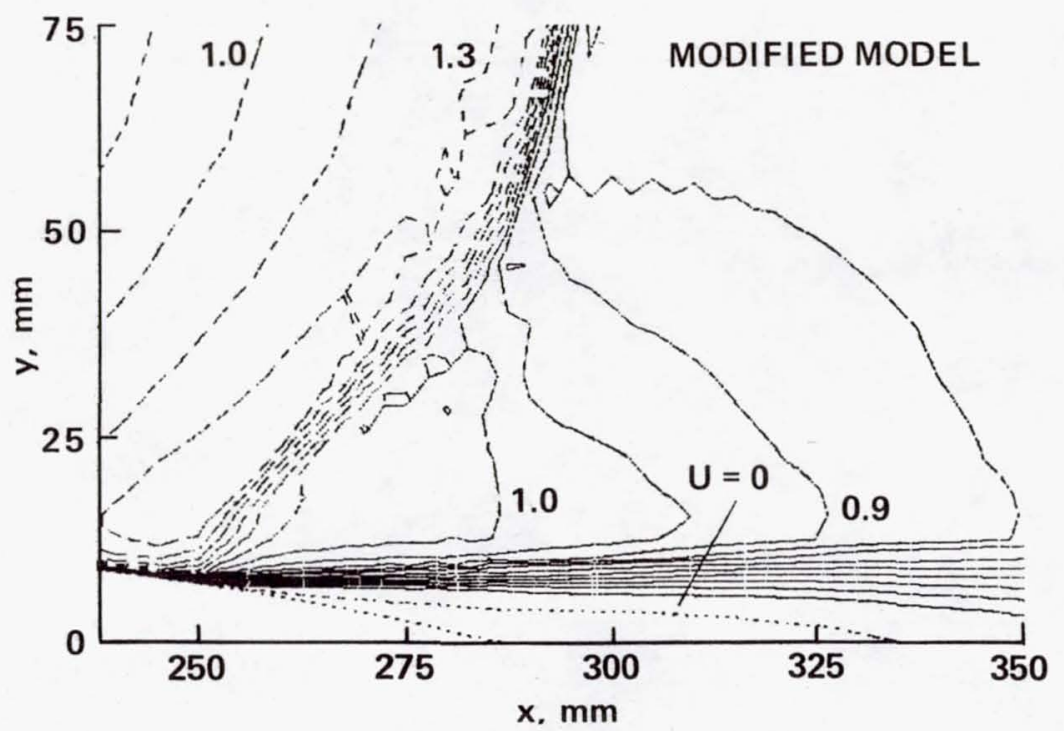

Figure 24.- Modeling of strong normal shock-wave interactions: Comparison of shock structure from experiment and computation. 


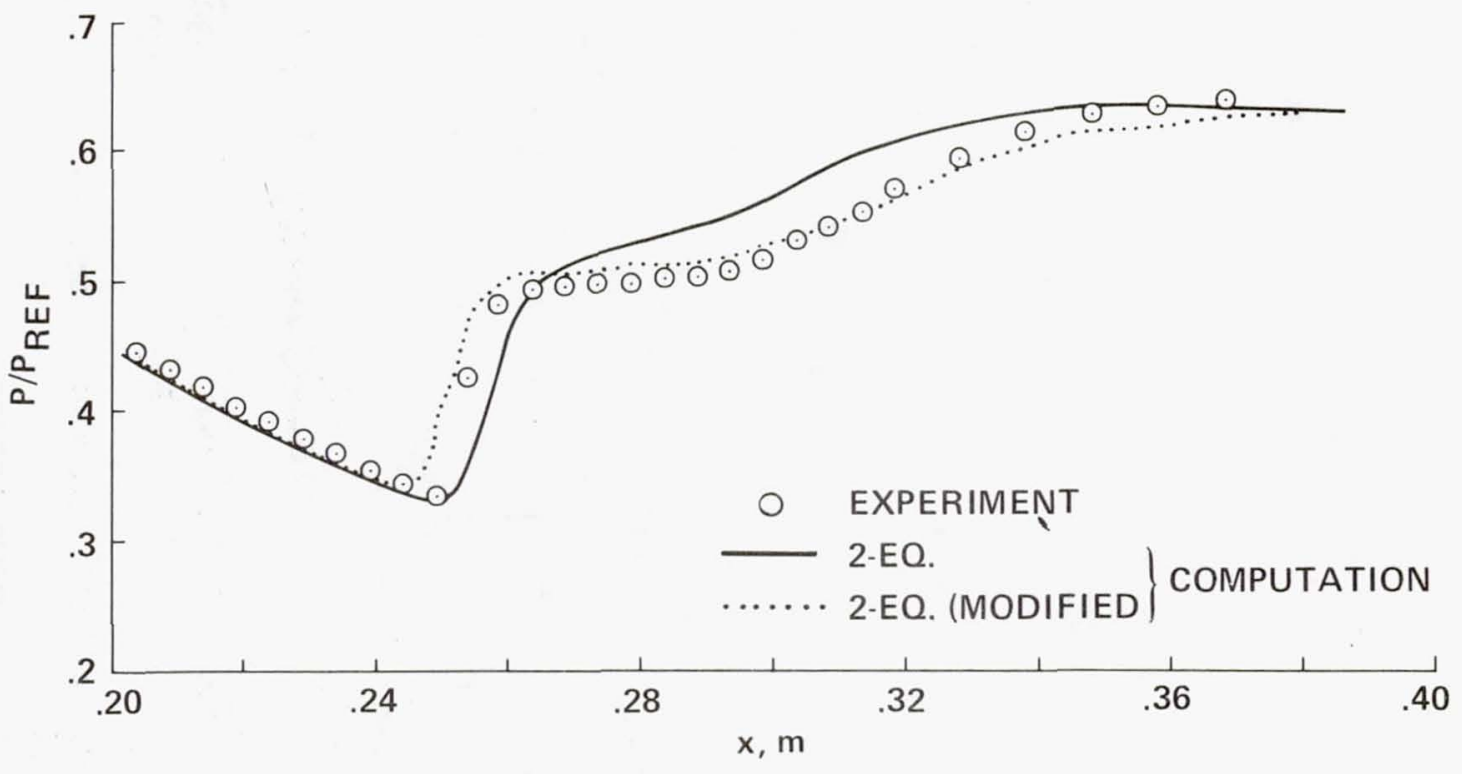

(a) Surface pressures.

Figure 25.- Modeling of strong normal shock-wave interactions. 



(b) Velocity and turbulence profiles.

Figure 25.- Concluded. 

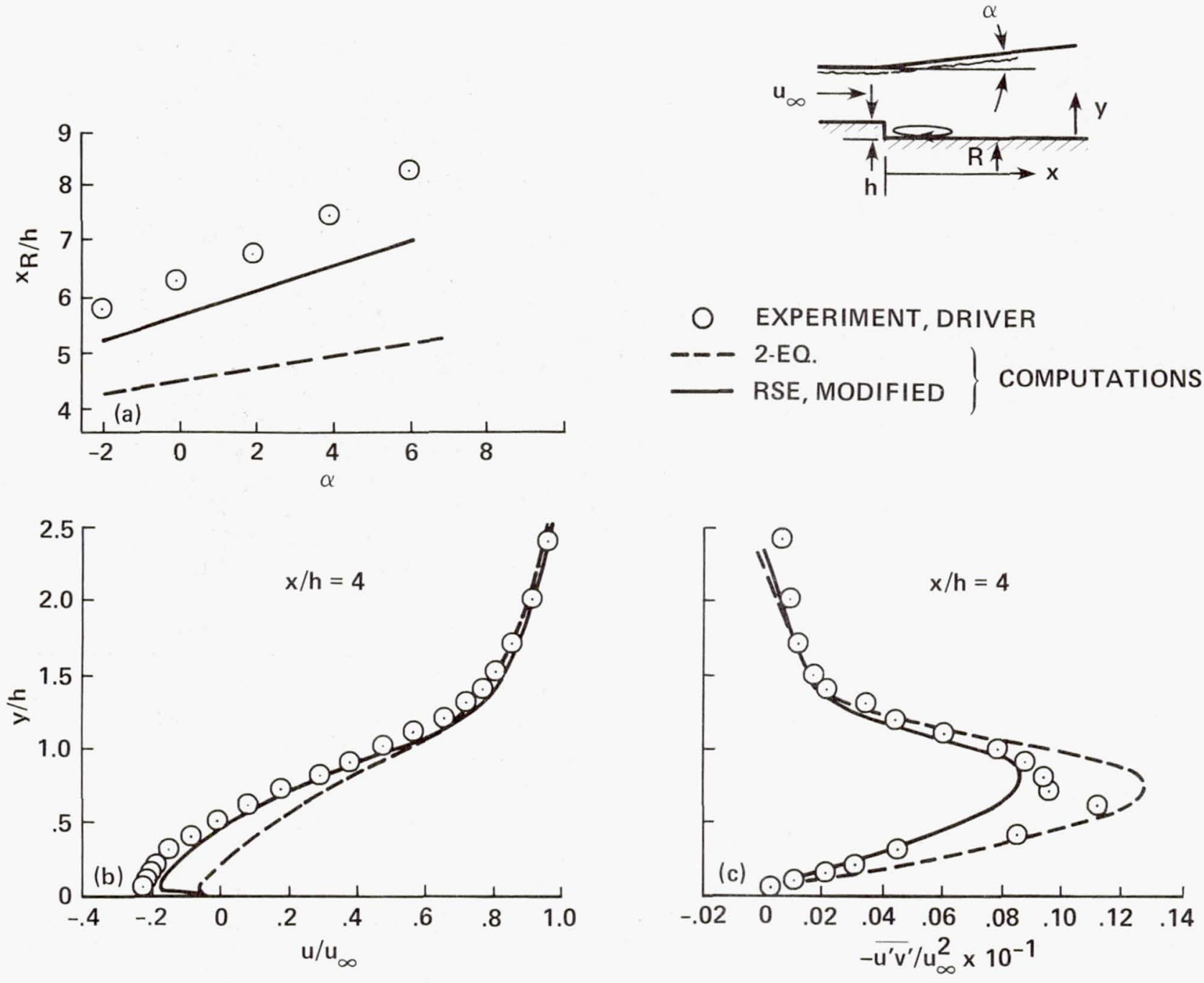

Figure 26.- Step-flow studies undertaken to provide modeling-guidance for large separated flow regions: (a) Reattachment length;

(b) Velocity; (c) Shear stress profiles. 
(a) SPARK SHADOWGRAPH

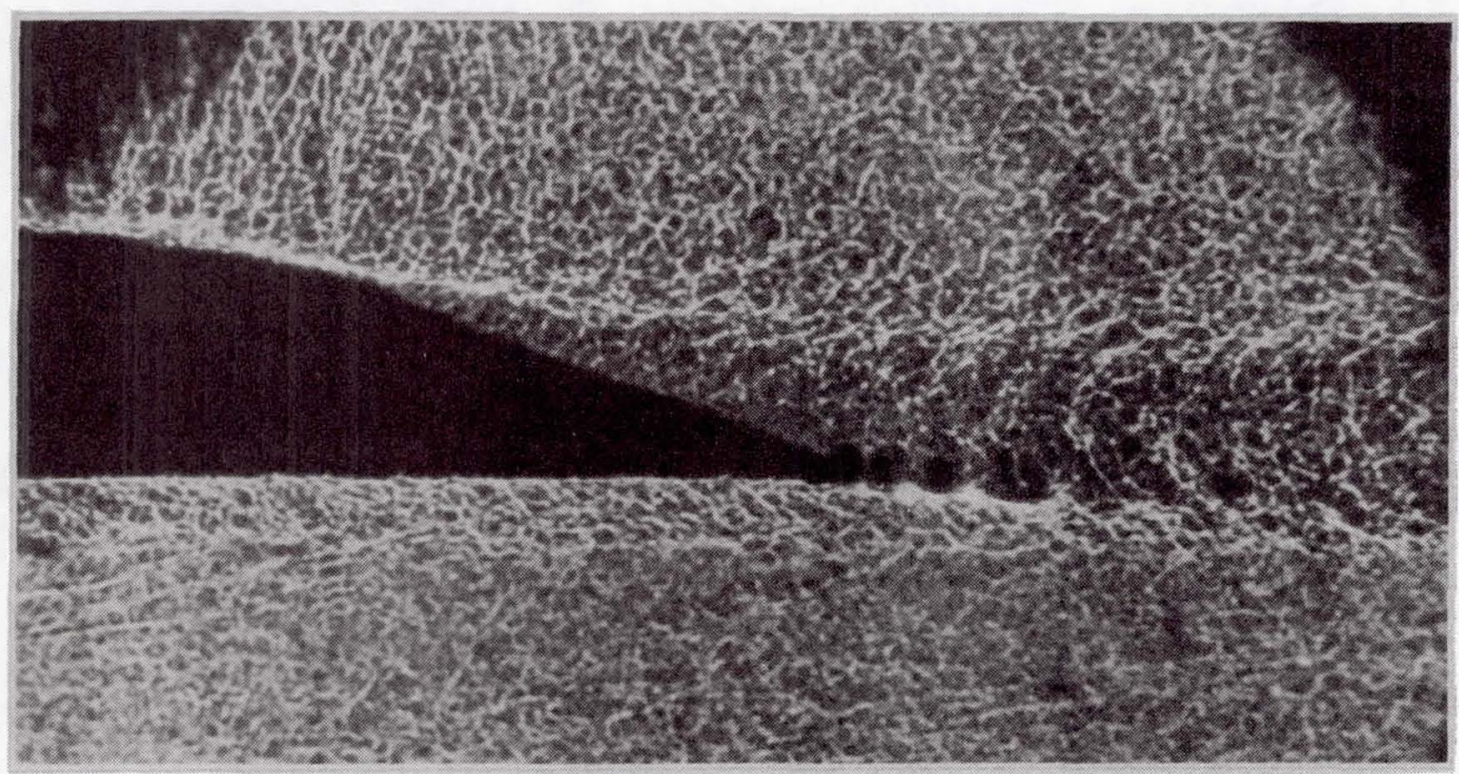

(b) MEAN FLOW FEATURES



Figure 27.- Physical characteristics of a trailing-edge flow with small separation: (a) Spark shadowgraph; (b) Mean flow features from laser velocimeter experiment. 




Figure 28.- Modeling of a trailing-edge flow with small separation: Surface pressures. 

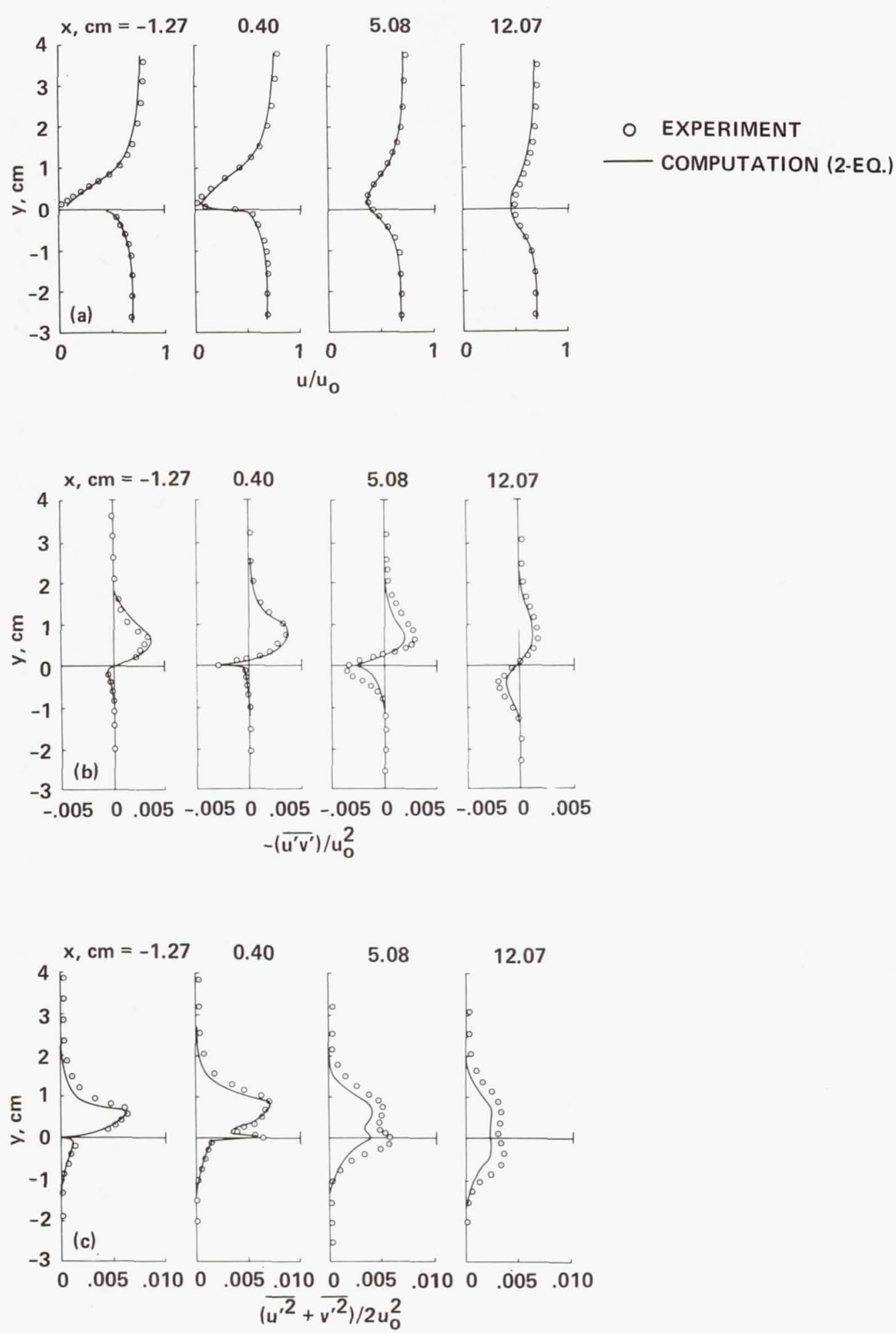

Figure 29.- Modeling of a trailing-edge flow with small separation:

(a) Velocity profiles; (b) Shear-stress profiles; (c) Kinetic energy profiles. 


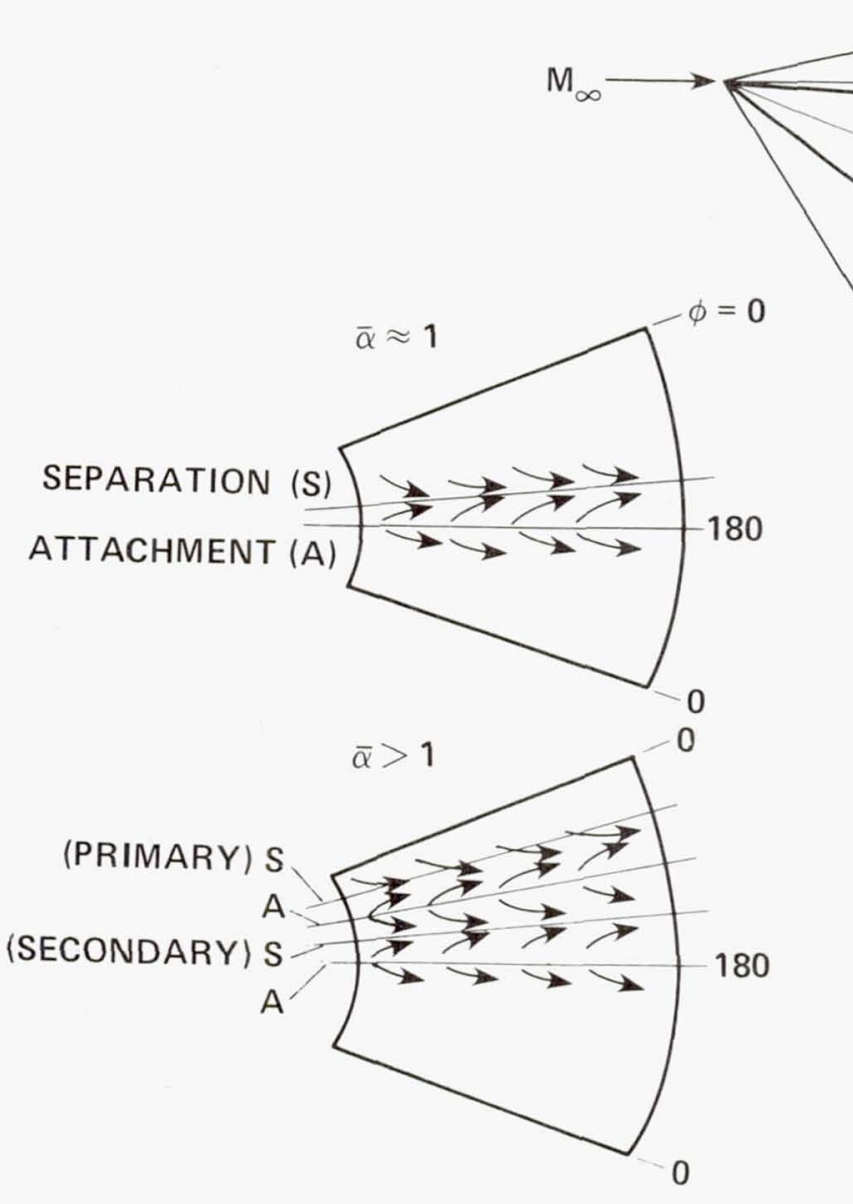

SURFACE SKIN FRICTION LINES


CROSS FLOW PLANE

Figure 30.- Physical characteristics of supersonic flow over sharp cones at high angle of attack. 




Figure 31.- Modeling of supersonic flow over cones at high angle of attack from computations using the parabolized Navier-Stokes equations: (a) Surface pressure; (b) Surface shear-stress angle. 

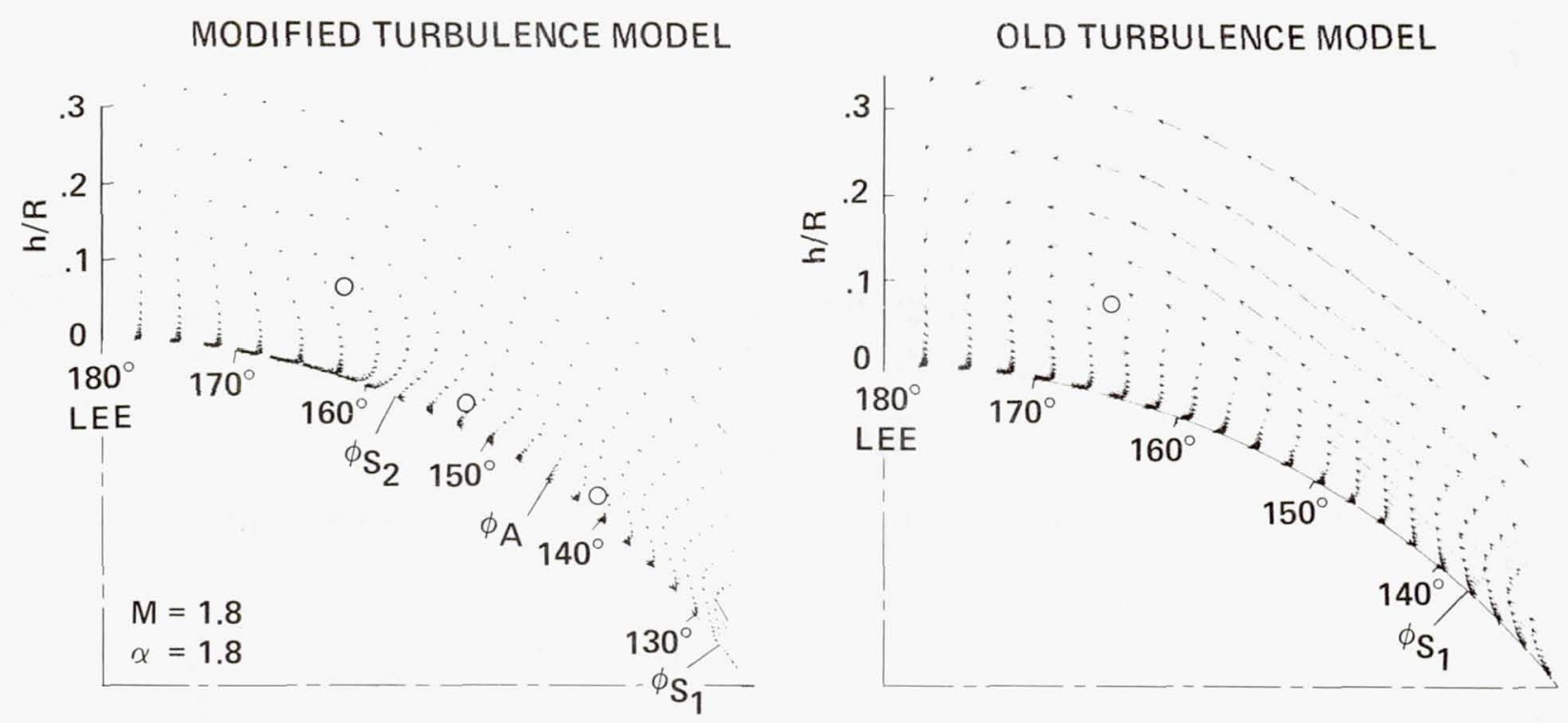

(a) EFFECT OF TURBULENCE MODEL

FINE GRID $\quad \Delta \phi=2.5^{\circ}$

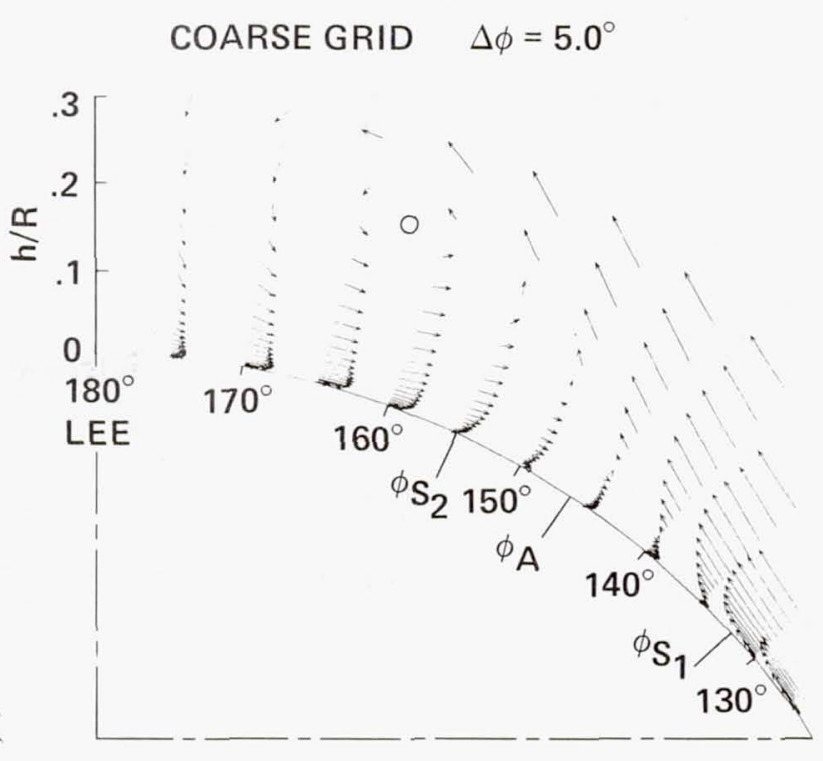

(b) EFFECT OF GRID RESOLUTION

Figure 32.- Modeling of supersonic flow over cones at high angle of attack from computations using the parabolized Navier-Stokes equations: (a) Effect of turbulence model; (b) Effect of azimuthal grid resolution using the modified turbulence model. 
TABLE 1. BENCHMARK FLOWS FOR EVALUATING NAVIER-STOKES COMPUTATIONS: IMPINGING OBLIQUE SHOCK WAVES

\begin{tabular}{|c|c|c|c|c|c|c|}
\hline FLOW & EXPERIMENTS & $M_{\infty}$ & $\operatorname{Re} \times 10^{-6}$ & COMPUTATIONS & $\begin{array}{l}\text { GRID } \\
x, y, \phi\end{array}$ & MODEL ${ }^{a}$ \\
\hline CLOSED SEPARATION & $\begin{array}{l}\text { HOLDEN (1972) } \\
\text { REDDA AND MURPHY (1973) } \\
\text { KUSSOY et al. }(1975)^{\mathrm{b}}\end{array}$ & $\begin{array}{c}8.5 \\
3 \\
7.2\end{array}$ & $\begin{array}{l}22 \\
57 \\
13\end{array}$ & $\begin{array}{l}\text { BALDWIN AND MacCORMACK (1974) } \\
\text { BALDWIN AND ROSE (1975) } \\
\text { BALDWIN AND LOMAX (1978) } \\
\text { VIEGAS AND HORSTMAN (1979) } \\
\text { MARVIN et al. (1975) } \\
\text { COAKLEY et al. (1977) } \\
\text { VIEGAS AND HORSTMAN (1982) }\end{array}$ & $\begin{array}{l}40,32 \\
40,32 \\
40,32 \\
40,35 \\
40,78 \\
29,45 \\
89,50\end{array}$ & $\begin{array}{l}0 ; 2 \\
0 \text { (MOD.) } \\
0 \text { (MOD.) } \\
0 ; 2 \\
0 ; 0 \text { (MOD.) } \\
0 ; 1 ; 2 \\
2\end{array}$ \\
\hline OPEN SEPARATION & KUSSOY et al. $(1980)^{b}$ & 2.2 & 36 & $\begin{array}{l}\text { KUSSOY et al. (1980) } \\
\text { VIEGAS AND HORSTMAN (1982) }\end{array}$ & $\begin{array}{l}47,20,20 \\
47,20,20\end{array}$ & $\begin{array}{l}0 \\
0 ; 2\end{array}$ \\
\hline 3-d & BROSH et al. (1983) & 3 & 18 & BROSH et al. (1983) & $45,34,38$ & 0 (MOD.) \\
\hline
\end{tabular}

aZERO-, ONE-, AND TWO-EQUATION MODELS

bSELECTED FOR AFOSR/HTTM STANFORD CONFERENCE (KLINE et al., 1981) 
TABLE 2. BENCHMARK FLOWS FOR EVALUATING NAVIER-STOKES COMPUTATIONS: COMPRESSION CORNER

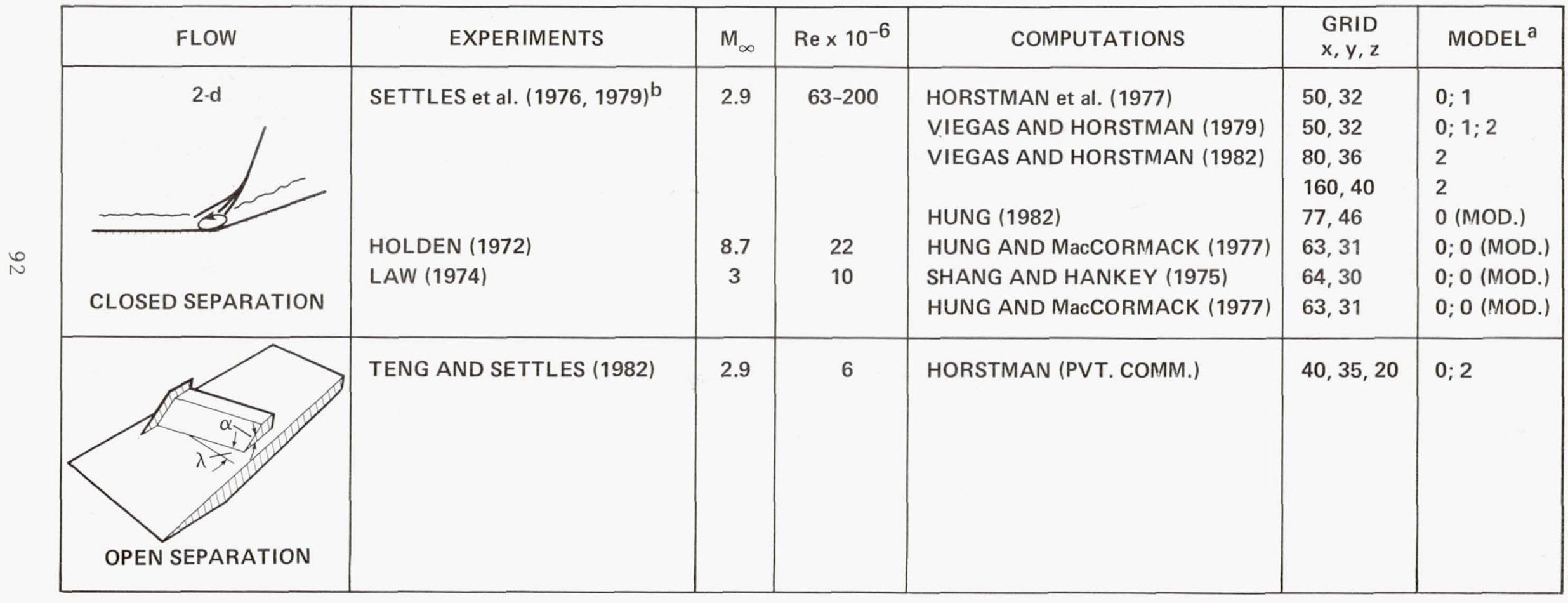

aZERO-, ONE-, AND TWO-EQUATION MODELS

bSELECTED FOR AFOSR/HTTM STANFORD CONFERENCE (KLINE et al., 1981) 
TABLE 3. BENCHMARK FLOWS FOR EVALUATING NAVIER-STOKES COMPUTATIONS: GLANCING SHOCK WAVES



aZERO-, ONE-, AND TWO-EQUATION MODELS




TABLE 4. BENCHMARK FLOWS FOR EVALUATING NAVIER-STOKES COMPUTATIONS: IMPINGING NORMAL SHOCK WAVES

\begin{tabular}{|c|c|c|c|c|c|c|}
\hline FLOW & EXPERIMENTS & $\mathrm{M}_{\infty}$ & $\operatorname{Re} \times 10^{-6}$ & COMPUTATIONS & $\begin{array}{l}\text { GRID } \\
x, y\end{array}$ & MODEL $^{a}$ \\
\hline $\begin{array}{l}\text { CLOSED SEPARATION } \\
\text { STRAIGHT WALLS }\end{array}$ & $\begin{array}{l}\text { SEDDON (1960) } \\
\text { MATEER et al. }(1976,1979)^{b}\end{array}$ & $\begin{array}{c}1.5 \\
1.3-1.5\end{array}$ & $\begin{array}{c}0.6 \\
10-200\end{array}$ & $\begin{array}{l}\text { VIEGAS AND HORSTMAN (1979) } \\
\text { VIEGAS AND RUBESIN (1983) } \\
\text { VIEGAS AND HORSTMAN (1979) } \\
\text { VIEGAS AND HORSTMAN (1982) } \\
\text { McDONALD (1982) }\end{array}$ & $\begin{array}{l}40,35 \\
20,35 \\
40,35 \\
38,40 \\
76,40 \\
31,41\end{array}$ & $\begin{array}{l}0 ; 1 ; 2 \\
2(\mathrm{MOD} .) \\
0 ; 1 ; 2 \\
2 \\
2 \\
2\end{array}$ \\
\hline $\begin{array}{l}\text { 2-d } \\
M>1 \\
\text { CLOSED SEPARATION } \\
\text { CURVED/DIVERGED } \\
\text { WALL(S) }\end{array}$ & $\begin{array}{l}\text { OM et al. (1982) } \\
\text { DELERY (1983) } \\
\text { SALMON et al. (1981) }\end{array}$ & $\begin{array}{l}1.3-1.5 \\
1.3-1.5 \\
1.3-1.4\end{array}$ & $\begin{array}{c}0.5-1 \\
2-4 \\
4\end{array}$ & $\begin{array}{l}\text { OM et al. (1982) } \\
\text { CAMBIER et al. (1981) } \\
\text { HORSTMAN (PVT. COMM.) } \\
\text { LIOU et al. (1981) }\end{array}$ & $\begin{array}{r}170,40 \\
61,21 \\
80,50\end{array}$ & $\begin{array}{l}2 \\
0 \\
0 ; 2 \\
2\end{array}$ \\
\hline
\end{tabular}

aZERO-, ONE-, AND TWO-EQUATION MODELS

bSELECTED FOR AFOSR/HTTM STANFORD CONFERENCE (KLINE et al., 1981) 
TABLE 5. BENCHMARK FLOWS FOR EVALUATING NAVIER-STOKES COMPUTATIONS: TRAILING-EDGE FLOWS

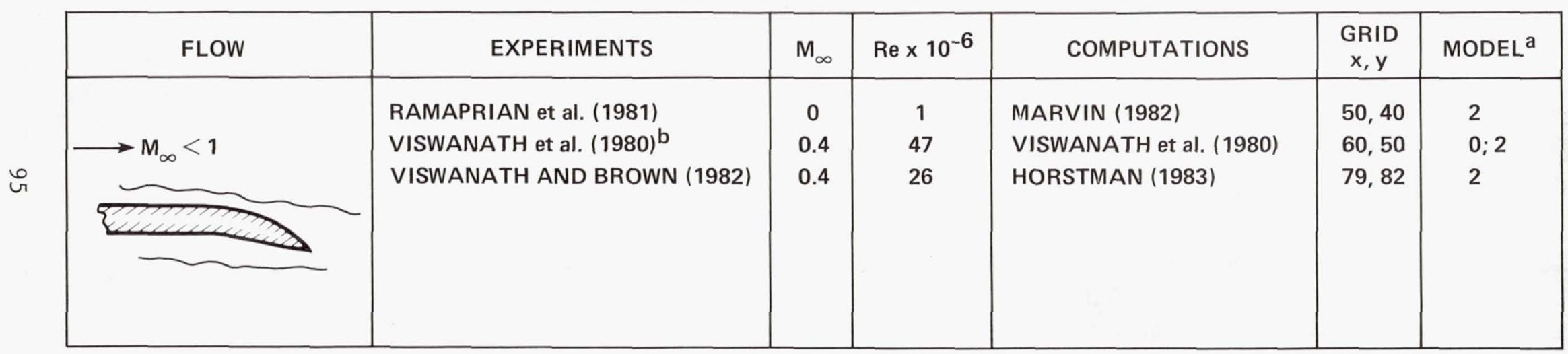

aZERO-, ONE-, AND TWO-EQUATION MODELS

${ }^{b}$ SELECTED FOR AFOSR/HTTM STANFORD CONFERENCE (KLINE et al., 1981) 
TABLE 6. BENCHMARK FLOWS FOR EVALUATING NAVIER-STOKES COMPUTATIONS:

SUPERSONIC - HIGH ANGLE OF ATTACK

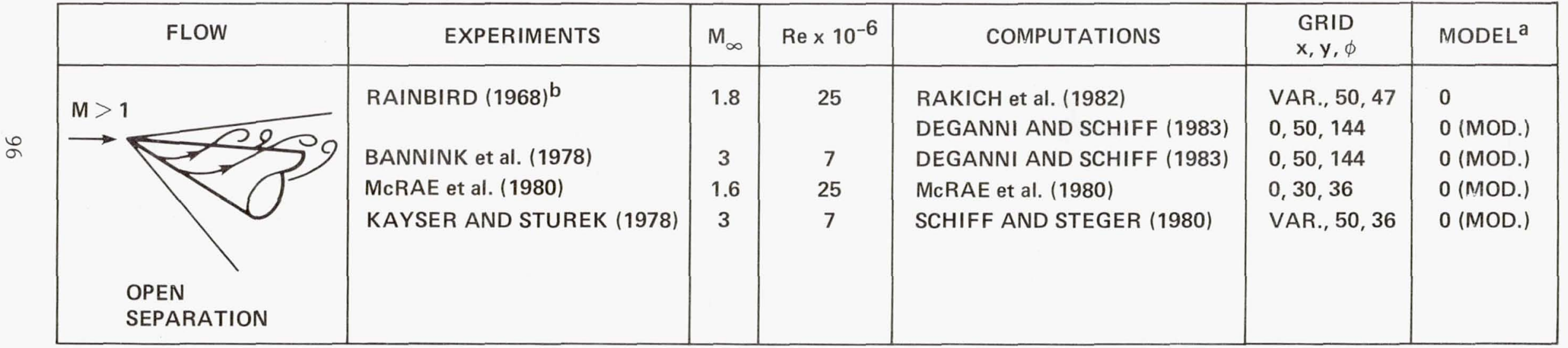

aZERO-, ONE-, AND TWO-EQUATION MODELS

bSELECTED FOR AFOSR/HTTM STANFORD CONFERENCE (KLINE et al., 1981) 


\begin{tabular}{|c|c|c|c|}
\hline $\begin{array}{l}\text { 1. Report No. } \\
\text { NASA TM-84392 }\end{array}$ & 2. Government Accession No. & \multicolumn{2}{|c|}{ 3. Recipient's Catalog No. } \\
\hline \multicolumn{2}{|l|}{ 4. Title and Subtitle } & \multicolumn{2}{|c|}{$\begin{array}{l}\text { 5. Report Date } \\
\text { August } 1983\end{array}$} \\
\hline \multicolumn{2}{|c|}{$\begin{array}{l}\text { MODELING OF TURBULENT SEPARATED FLOWS FOR } \\
\text { AERODYNAMIC APPLICATIONS }\end{array}$} & \multicolumn{2}{|c|}{ 6. Performing Organization Code } \\
\hline $\begin{array}{l}\text { 7. Author(s) } \\
\text { Joseph G. Marvin }\end{array}$ & & \multicolumn{2}{|c|}{$\begin{array}{l}\text { 8. Performing Organization Report No. } \\
\text { A-9438 }\end{array}$} \\
\hline \multirow{2}{*}{\multicolumn{2}{|c|}{$\begin{array}{l}\text { 9. Performing Organization Name and Address } \\
\text { NASA Ames Research Center } \\
\text { Moffett Field, Calif. } 94035\end{array}$}} & \multicolumn{2}{|l|}{$\begin{array}{l}\text { 10. Work Unit No. } \\
\text { T-4219 }\end{array}$} \\
\hline & & \multicolumn{2}{|c|}{ 11. Contract or Grant No. } \\
\hline \multirow{2}{*}{\multicolumn{2}{|c|}{$\begin{array}{l}\text { 12. Sponsoring Agency Name and Address } \\
\text { Nationa1 Aeronautics and Space Administration } \\
\text { Washington, D.C. } 20546\end{array}$}} & \multicolumn{2}{|c|}{$\begin{array}{l}\text { 13. Type of Report and Period Covered } \\
\text { Technical Memorandum }\end{array}$} \\
\hline & & \multicolumn{2}{|c|}{$\begin{array}{l}\text { 14. Sponsoring Agency Code } \\
505-36-31\end{array}$} \\
\hline \multicolumn{4}{|c|}{$\begin{array}{l}\text { Point of Contact: Joseph J. Marvin, Ames Research } \\
\text { Fie1d, CA 94035. (415) 965-5390 or FTS 448-5390. }\end{array}$} \\
\hline \multicolumn{4}{|c|}{$\begin{array}{l}\text { 16. Abstract } \\
\text { A review is given of the advances made over the past decade in modeling } \\
\text { steady, high speed, compressible separated flows through numerical simula- } \\
\text { tions resulting from solutions of the mass-averaged Navier-Stokes equations. } \\
\text { Emphasis is placed on bench-mark flows that represent simplified (but } \\
\text { realistic) aerodynamic phenomena. These include impinging shock waves, com- } \\
\text { pression corners, glancing shock waves, trailing edge regions, and super- } \\
\text { sonic high angle-of-attack flows. A critical assessment of modeling capa- } \\
\text { bilities is provided by comparing the numerical simulations with experiment. } \\
\text { The importance of combining experiment, numerical algorithm, grid, and } \\
\text { turbulence model to effectively develop this potentially powerful simulation } \\
\text { technique is stressed. }\end{array}$} \\
\hline $\begin{array}{l}\text { 17. Key Words (Suggested by Auth } \\
\text { Viscous flows } \\
\text { Compressible turb } \\
\text { Computational flu }\end{array}$ & $\begin{array}{l}\text { 18. Distribu } \\
\text { Un } 1 i \text {. }\end{array}$ & ct Category & \\
\hline $\begin{array}{l}\text { 19. Security Classif. (of this report) } \\
\text { Unclassified }\end{array}$ & $\begin{array}{l}\text { 20. Security Classif. (of this page) } \\
\text { Unclassified }\end{array}$ & $\begin{array}{l}\text { 21. No. of Pages } \\
99\end{array}$ & $\begin{array}{l}\text { 22. Price* } \\
\text { A0 } 5\end{array}$ \\
\hline
\end{tabular}

•For sale by the National Technical Information Service, Springfield, Virginia 22161 